\title{
WestVirginiaUniversity
}

THE RESEARCH REPOSITORY @ WVU

Graduate Theses, Dissertations, and Problem Reports

2009

\section{Effect of compaction effort on SuperPave base course materials}

Cornelius Adamah

West Virginia University

Follow this and additional works at: https://researchrepository.wvu.edu/etd

\section{Recommended Citation}

Adamah, Cornelius, "Effect of compaction effort on SuperPave base course materials" (2009). Graduate Theses, Dissertations, and Problem Reports. 2061.

https://researchrepository.wvu.edu/etd/2061

This Thesis is protected by copyright and/or related rights. It has been brought to you by the The Research Repository @ WVU with permission from the rights-holder(s). You are free to use this Thesis in any way that is permitted by the copyright and related rights legislation that applies to your use. For other uses you must obtain permission from the rights-holder(s) directly, unless additional rights are indicated by a Creative Commons license in the record and/ or on the work itself. This Thesis has been accepted for inclusion in WVU Graduate Theses, Dissertations, and Problem Reports collection by an authorized administrator of The Research Repository @ WVU. For more information, please contact researchrepository@mail.wvu.edu. 
Effect of Compaction Effort on SuperPave Base Course Materials

\section{Cornelius Adamah}

Thesis submitted to the College of Engineering and Mineral Resources at West Virginia University in partial fulfillment of the requirements for the degree of

Master of Science

In

Civil Engineering

Dr. John P. Zaniewski, Chair

Dr. Gary Winn

Dr. Indrajit Ray

Mr. Andrew Morgan

Department of Civil and Environmental Engineering

Morgantown, West Virginia

2009

Keywords: SuperPave, asphalt mix design, compaction effort, laboratory rutting 


\section{ABSTRACT \\ Effect of Compaction Effort on SuperPave Base Course Materials}

\section{Cornelius Adamah}

SuperPave mixes have performed well with in West Virginia, especially with respects to permanent deformation. Recent studies raise concerns with premature fatigue cracking and difficulty in compaction during construction. Two base course mixes were tested by lowering compaction effort from 100 gyrations to 80 gyrations for the $19 \mathrm{~mm}$ mix and to 65 gyrations for the $37.5 \mathrm{~mm}$ mix and evaluating rutting potential with Asphalt Pavement Analyzer and Indirect Tension test. Only gyration level and binder percent were changed. Lower compaction effort resulted in an increased binder content. The $19 \mathrm{~mm}$ mixes showed an increased rutting potential. However, investigation of the data demonstrated position of the sample in the APA machine confounded the results of the test. No statistically significant rutting potential was found with the lowered compaction effort or increased binder content for the $37.5 \mathrm{~mm}$ mix. 


\section{Table of Contents}

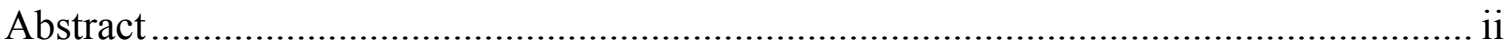

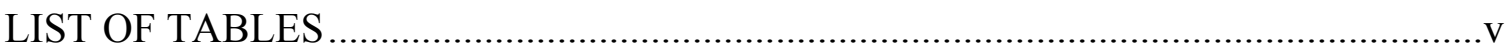

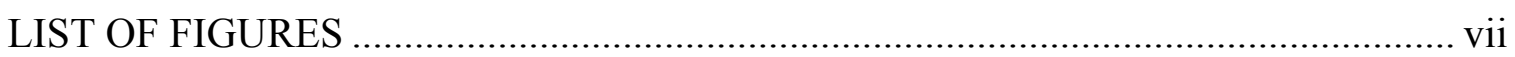

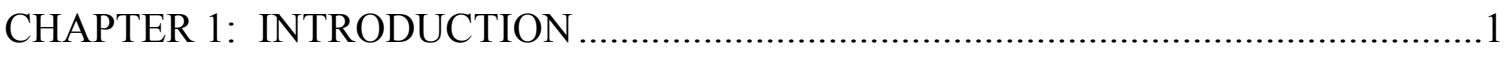

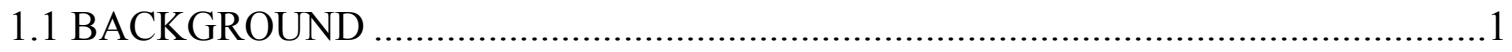

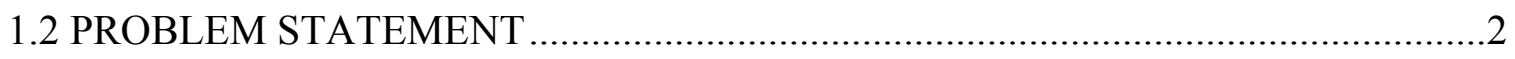

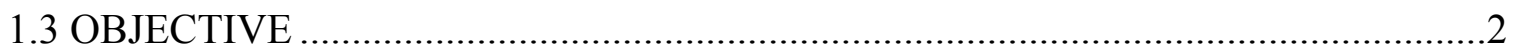

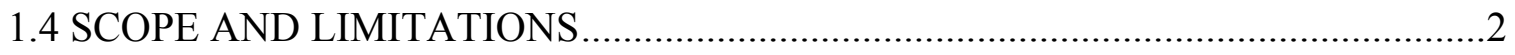

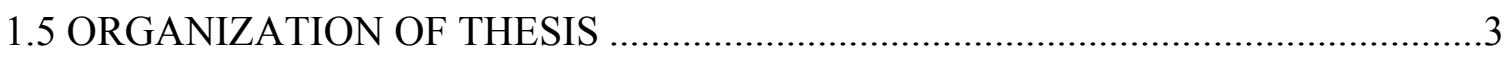

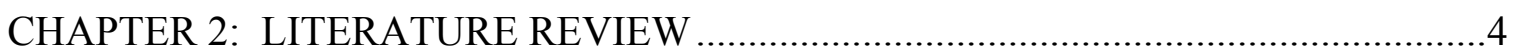

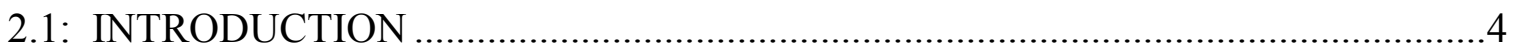

2.2. SUPERPAVE MIX DESIGN METHOD .............................................................

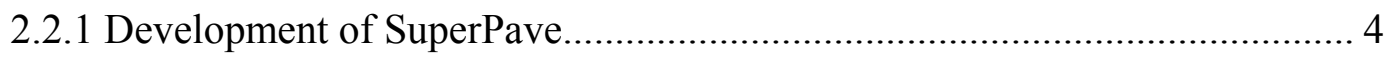

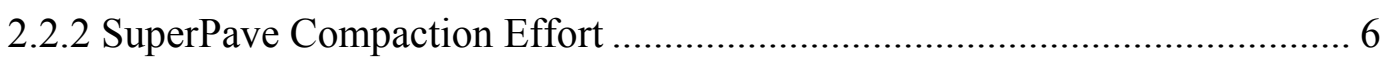

2.2.3 Current SuperPave Compaction Effort ....................................................... 8

2.2.4 AASHTO SuperPave Requirements ........................................................ 9

2.3 STATE RESEARCH ON COMPACTION EFFORT ………………………..........12

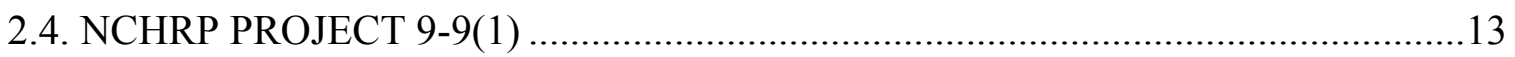

2.5: METHOS FOR EVALUATING RUTTING PERFORMANCE ................................16

2.5.1: Asphalt Pavement Analyzer (APA) ........................................................... 18

2.5.2: Temperature Effect Model..................................................................... 20

2.5.3: Indirect Tensile Test ……………………………................................. 21

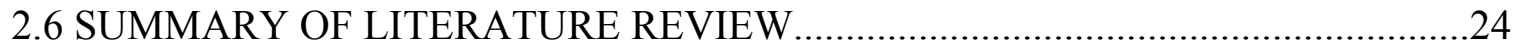


CHAPTER3: RESEARCH METHODOLOGY .25

3.1 INTRODUCTION .25

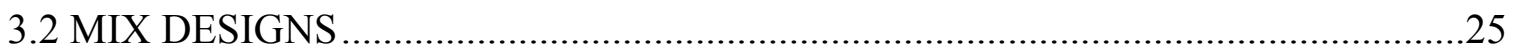

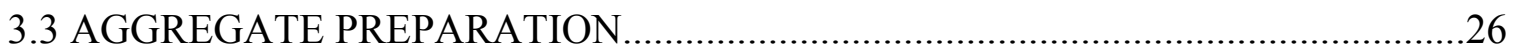

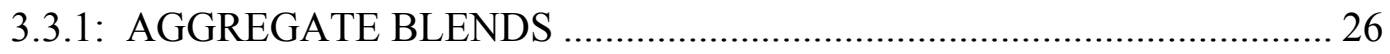

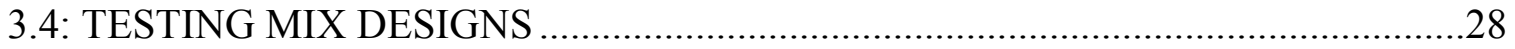

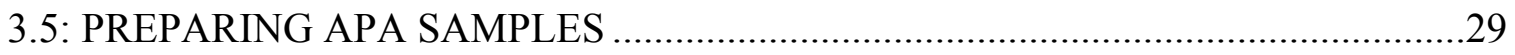

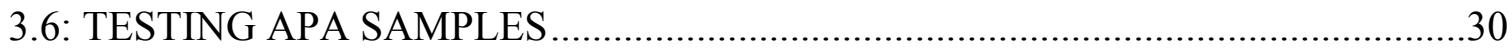

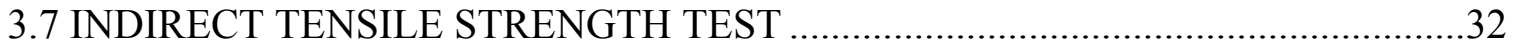

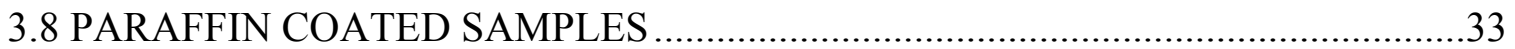

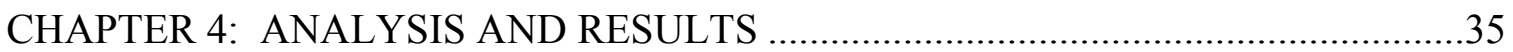

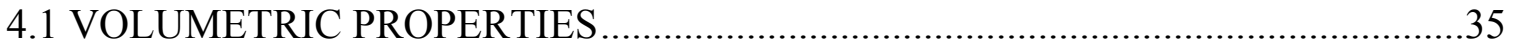

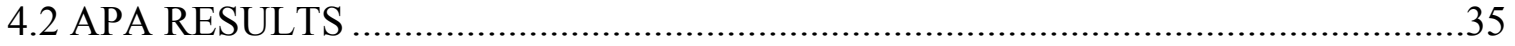

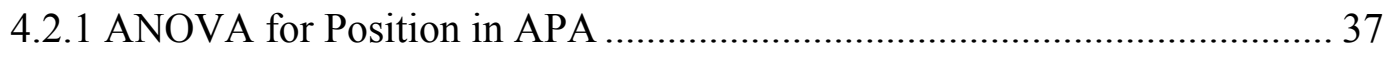

4.2.2 ANOVA for Experimental Factors ............................................................ 42

4.3 INDIRECT TENSILE TEST (IDT) RESULTS ....................................................4

4.3.1 Comparing IDT with APA ......................................................................... 47

CHAPTER 5: CONCLUSIONS AND RECOMMENDATIONS _..................................49

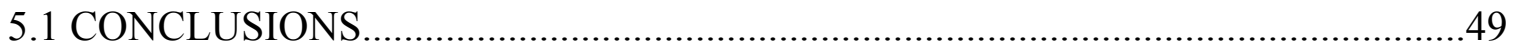

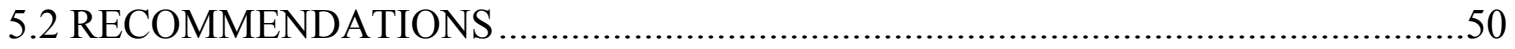

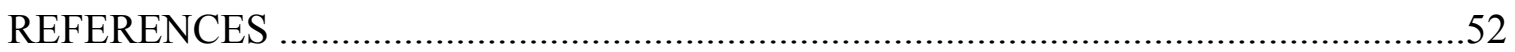

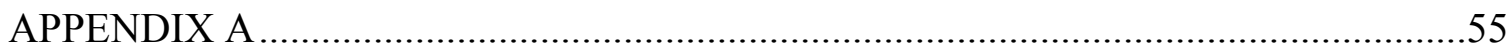

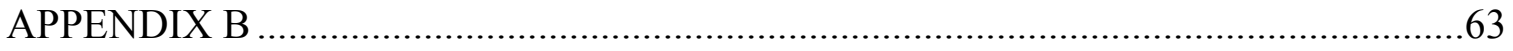




\section{LIST OF TABLES}

Table 2.1 Compaction levels for four temperature and seven traffic classifications...........8

Table 2.2 Consolidated SGC Compaction Table with Four Levels of Traffic ...................9

Table 2.3 SuperPave Criteria on $\% \mathrm{G}_{\mathrm{mm}}$, VMA, VFA and Dust-to-Binder Ratio..............11

Table 2.4 SuperPave Consensus Aggregate Properties ...............................................11

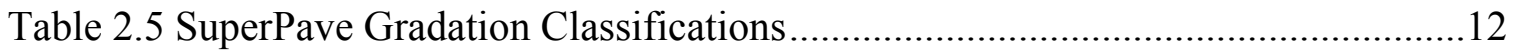

Table 2.6 Recommended $\mathrm{N}_{\text {design }}$ Levels from NCHRP Project 9-9(1) ............................16

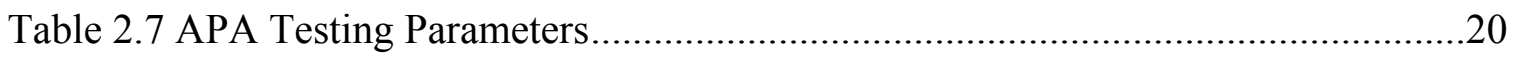

Table 3.1 Blend Properties for $19 \mathrm{~mm}$ and $37.5 \mathrm{~mm}$ Mixes .......................................25



Table 3.3 AASHTO T-166 and AASHTO T 275-91 $\mathrm{G}_{\mathrm{mb}}$ for $37.5 \mathrm{~mm}$ mix .....................34

Table 4.1 Volumetric Properties and West Virginia Criteria ........................................35

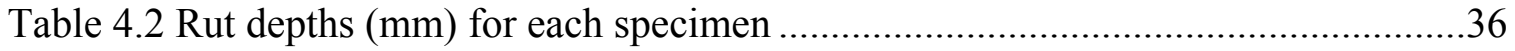

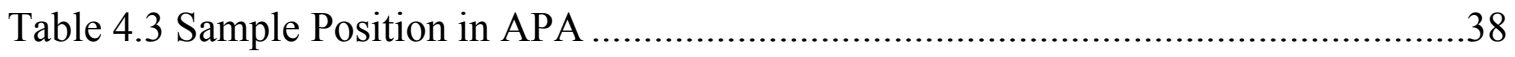

Table 4.4 ANOVA Results for Sample Position in APA .............................................38

Table 4.5 Modified Data Set for Position in APA ..................................................... 40

Table 4.6 ANOVA for test Position with modified data set .......................................41

Table 4.7 Factor Levels for Rut Depth Analysis ...................................................43

Table 4.8 ANOVA for Experimental Factors, original data set ....................................43

Table 4.9 ANOVA for Experimental Factors with modified data set .............................44

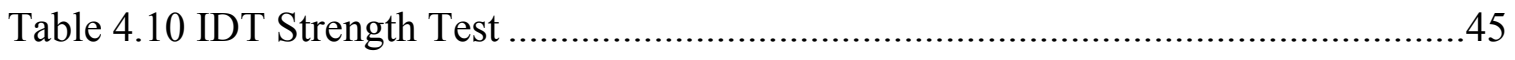

Table 4.11 IDT Strength for Design Binder Contents ..............................................47

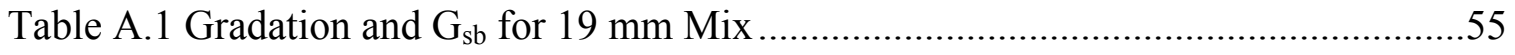

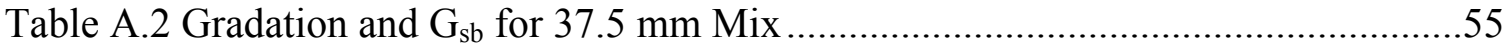


Table A.3 Specific Gravity for $19 \mathrm{~mm}$ and $37.5 \mathrm{~mm}$ Blends ....................................56

Table A.4 Volumetric Parameters for $19 \mathrm{~mm}$ and $37.5 \mathrm{~mm}$ Verification Mix.................56

Table A.5 Optimum Binder Content for 19 mm 80 Gyrations Mix ...............................57

Table A.6 Optimum Binder Content for 37.5 mm 65 Gyrations Mix ............................57

Table B.1 Weight-out Table for 19 mm Mix with RAP ..............................................74

Table B.2 Weight-out Table for 37.5 mm Mix with RAP ..........................................75 


\section{LIST OF FIGURES}

Figure 2.1 Overview of SuperPave mix Design Method.................................................

Figure 2.2 SuperPave Gyratory Compactor..................................................................

Figure 2.3 Cumulative frequency distribution of as-constructed, in-place density ...........14

Figure 2.4 Cumulative frequency plot for in-place density by sampling period ...............15

Figure 2.5 Georgia Loaded Wheel Tester..................................................................17

Figure 2.6 Asphalt Pavement Analyzer .........................................................................19

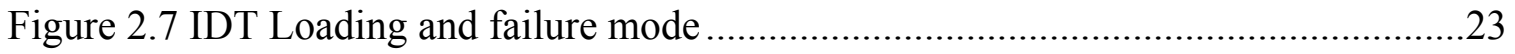

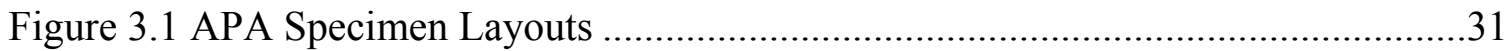

Figure 3.2 IDT Strength Test Setup with Marshall Stabilometer .......................................32

Figure 3.3 Interconnected air voids of Coarse and Fine Graded mixes.............................33

Figure 4.1 Duncan Multiple Range Test for APA Positions .................................................39

Figure 4.2 Modified Duncan Multiple Range Test for APA Positions...............................42

Figure 4.3 IDT Strength vs Binder Percent for $19 \mathrm{~mm}$ Mixes..........................................46

Figure 4.4 IDT Strength vs Binder Percent for 37.5 mm Mixes........................................46

Figure 4.5 IDT Strength vs APA Rut Depth for $19 \mathrm{~mm}$ Mix ............................................48

Figure 4.6 IDT Strength vs APA Rut Depth for $37.5 \mathrm{~mm}$ Mix ..........................................48

Figure A.1 VTM vs Binder Percent for 19 mm 80 Gyrations Mix.....................................58

Figure A.2 VMA vs Percent Binder for 19 mm 80 Gyrations Mix ...................................58

Figure A.3 VFA vs Percent Binder for 19 mm 80 Gyrations Mix ..................................59

Figure A.4 D/B vs Percent Binder for 19 mm 80 Gyrations Mix.....................................59

Figure A.5 $\% \mathrm{G}_{\mathrm{mm}}$ vs Percent Binder for $19 \mathrm{~mm} 80$ Gyrations Mix ................................60

Figure A.6 VTM vs Binder Percent for 37.5 mm 65 Gyrations Mix.................................60

Figure A.7 VMA vs Percent Binder for 37.5 mm 65 Gyrations Mix ................................61 
Figure A.8 VFA vs Percent Binder for 37.5 mm 65 Gyrations Mix ............................61

Figure A.9 D/B vs Percent Binder for 37.5 mm 65 Gyrations Mix................................62

Figure A.10 \% $\mathrm{G}_{\mathrm{mm}}$ vs Percent Binder for 37.5 mm 65 Gyrations Mix ..........................62

Figure B.1 Data for SAS Program evaluating Rutting Potential ..................................63

Figure B.2 Factor Levels for SAS Program Evaluating Rutting Potential ......................64

Figure B.3 ANOVA Results for Base Course Rutting Potential ..................................65

Figure B.4 Duncan Multiple Range Test for Rutting Potential .....................................66

Figure B.5 Data for SAS Program evaluating Rutting Potential vs APA Position...........67

Figure B.6 Factor Levels for SAS Program evaluating Rutting Potential vs APA Position68

Figure B.7 ANOVA Results for Rutting Potential vs APA Position..............................69

Figure B.8 ANOVA Results for Base Course Rutting Potential (Modified Data) ............70

Figure B.9 Duncan Multiple Range Test for Rutting Potential (Modified Data) ..............71

Figure B.10 ANOVA Test for Rutting Potential vs APA Position (Modified Data) ........72

Figure B.12 Duncan Multiple Range Test for Rutting Potential (Modified Data) ............72

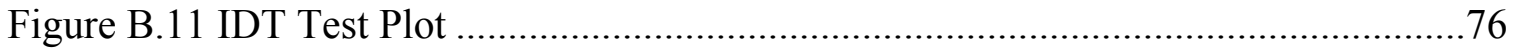

Figure B.12 IDT Strength vs Percent Binder for 19 mm Mix with Regression ................77

Figure B.13 IDT Strength vs Percent Binder for 37.5 mm Mix with Regression .............77

Figure B.14 APA Data Recording Sheet for Initial Readings .....................................78

Figure B.15 APA Data Recording Sheet for Final Readings.......................................79 


\section{CHAPTER 1: INTRODUCTION}

\subsection{BACKGROUND}

Hot mix asphalt (HMA) is the most widely used pavement surface in the United States. Approximately $96 \%$ of the 2.3 million miles of roadways in the United States have HMA surfaces (Roberts, et al, 1996). HMA consists of coarse and fine aggregates, asphalt, air, and occasionally some additives to improve the engineering properties. The proportions of these materials are determined by a mix design process. The SuperPave mix design method, developed during the Strategic Highway Research Program, has been adopted by all state highway agencies in the U.S (Kuennen, 2003).

The design binder content of SuperPave mixes is determined based on the volumetric properties of samples prepared at different asphalt contents. The SuperPave Gyratory Compactor (SGC) is used to prepare the HMA samples. This compactor was selected because it can produce specimens with densities similar to field-compacted HMA (Cominsky, 1994). The density achieved for a given combination of aggregates and asphalt is a function of the compaction effort applied by the SGC. Compaction effort is a composite term that embraces the vertical force, the tilt angle, and the number of gyrations applied to the sample. While conceptually it would be possible to alter the compaction effort by altering any of these three parameters, the standard practice is to keep the vertical force and tilt angle constant and alter the number of gyrations to achieve a desired compaction effort.

The compaction effort used initially for the SuperPave method was established through evaluation of mixes, which preformed well (Roberts et al, 2002). Initially, 28 levels of compaction effort were specified to accommodate seven traffic levels and four climatic conditions (Cominsky, 1994). However, since the inception of the implementation phase of SuperPave, there have been multiple research projects at both the national and state level that have examined the compaction effort, or number of gyrations, used for determining the design binder content (Brown and Buchanan, 1999). Most recently, the National Center for Asphalt Technology (NCAT) has completed the National Highway Research Program (NCHRP) Project 9-9(1), SuperPave Mix Design: Verifying Gyration Levels in the $N_{\text {design }}$ Table; it concluded that the number of gyrations 
used for determining the design binder content should be reduced compared to the current compaction requirements specified in AASHTO Test Method R35.

\subsection{PROBLEM STATEMENT}

The West Virginia Division of Highways (WVDOH) has been constructing pavements with HMAC designed with the SuperPave method of pavement design for several years. In general, these pavements have performed very well and none have been observed to display problems with rutting (Zaniewski and Patino, 2005). The WVDOH commonly adopts nationally developed methods without modification. If the recommendations of NCHRP Project 9-9(1) are adopted at the national level, then the WVDOH will need to make a decision to either continue with the existing SuperPave compaction effort, which has worked well, or adapt the revised compaction effort. Since the revised compaction effort should reduce in mixes with a higher asphalt content, for a given blend of aggregates, mixes designed using the revised compaction effort should improve the performance of the mixes with respect to fatigue and thermal cracking, but this may come at the expense of increased rutting potential.

\subsection{OBJECTIVE}

The objective of this research was to determine if mixes designed using the compaction effort recommended by NCHRP 9-9(1) (Prowell and Brown, 2007) have adequate performance with respect to rutting susceptibility as evaluated with the Asphalt Pavement Analyzer, APA, and Indirect Tension test(IDT).

\subsection{SCOPE AND LIMITATIONS}

The WVDOH predominantly uses four SuperPave mix types; 9.5 and $12.5 \mathrm{~mm}$ mixes for surface or wearing courses, and 19 and $37.5 \mathrm{~mm}$ mixes for base courses. The characteristics of the wearing courses were evaluated previously (Hornbeck, 2008). Thus, this study evaluated the effects of lowering compaction effort has on 19 and $37.5 \mathrm{~mm}$ mixes.

Mix design data were obtained from a contractor for both $19 \mathrm{~mm}$ and $37.5 \mathrm{~mm}$ mixes. Samples of the aggregate and binder used in these mixes were obtained by the contractor. The percent binder of these mixes was selected using the current 
requirements for compaction effort. The compaction effort from the recommendations of Prowell and Brown (2007) were used to determine a new optimum binder content. Samples of both the original and redesigned mix were then tested using the Asphalt Pavement Analyzer and Indirect Tensile Test. No attempt was made to optimize the blend of the aggregates for the new compaction effort. This task was left to another research effort.

\subsection{ORGANIZATION OF THESIS}

This thesis contains five chapters. The first chapter is the introduction to the research. Chapter 2 is the literature review with changes in the $\mathrm{N}_{\text {design }}$ table, state research on compaction effort, and a summary of the NCHRP Report \#573. Chapter 3 contains the research methodology used for this research. Chapter 4 contains the analysis and results. Conclusions and recommendations are presented in Chapter 5. Laboratory data shown in Appendix A and Appendix B represents the statistical analysis. 


\section{CHAPTER 2: LITERATURE REVIEW}

\section{1: INTRODUCTION}

Since the 1940s and 1950s, the Hveem and Marshall Mix design methods have been used for road construction. For many years, these mix design methods performed well but with increased traffic volumes, tire pressure, and heavier loads, it was determined in the early 1980s that an improved method of mix design was needed (Roberts et al, 2002). A method was needed that could be used to rationally design mixtures for various traffic volumes, axle loads and the environment. From October 1987 through March 1993, the Strategic Highway Research Program (SHRP) conducted a federally funded, $\$ 50$ million research effort to help develop new ways to specify, design, and test asphalt materials. The research was to help provide a system of checks and balances to ensure that Hot Mix Asphalt (HMA) is durable and rut resistant. It was believed that this research would provide tests and models that would result in better asphalt pavement performance.

SHRP primarily focused on binder specifications, aggregate property specifications, design gradation ranges, a laboratory compaction procedure, specifications for volumetric properties, and an evaluation of moisture sensitivity (Roberts, et al, 2002). Due to the relatively condensed time period available for the development of SuperPave, it was anticipated that ongoing effort would be needed to refine the SuperPave method. One of SHRP's key study areas, and the subject of this research, was the compaction effort used for preparing samples for the volumetric analysis. With all other factors being equal, the design binder content determined in mix design method is a function of this compaction effort.

\subsection{SUPERPAVE MIX DESIGN METHOD}

\subsubsection{Development of SuperPave}

Figure 2.1 is an overview of the SuperPave mix design method. Once suitable binder and aggregates are selected, a volumetric procedure is used to evaluate the suitability of a design aggregate structure (DAS). The design binder content (DBC), is 
Figure 2.1 Overview of SuperPave mix Design Method

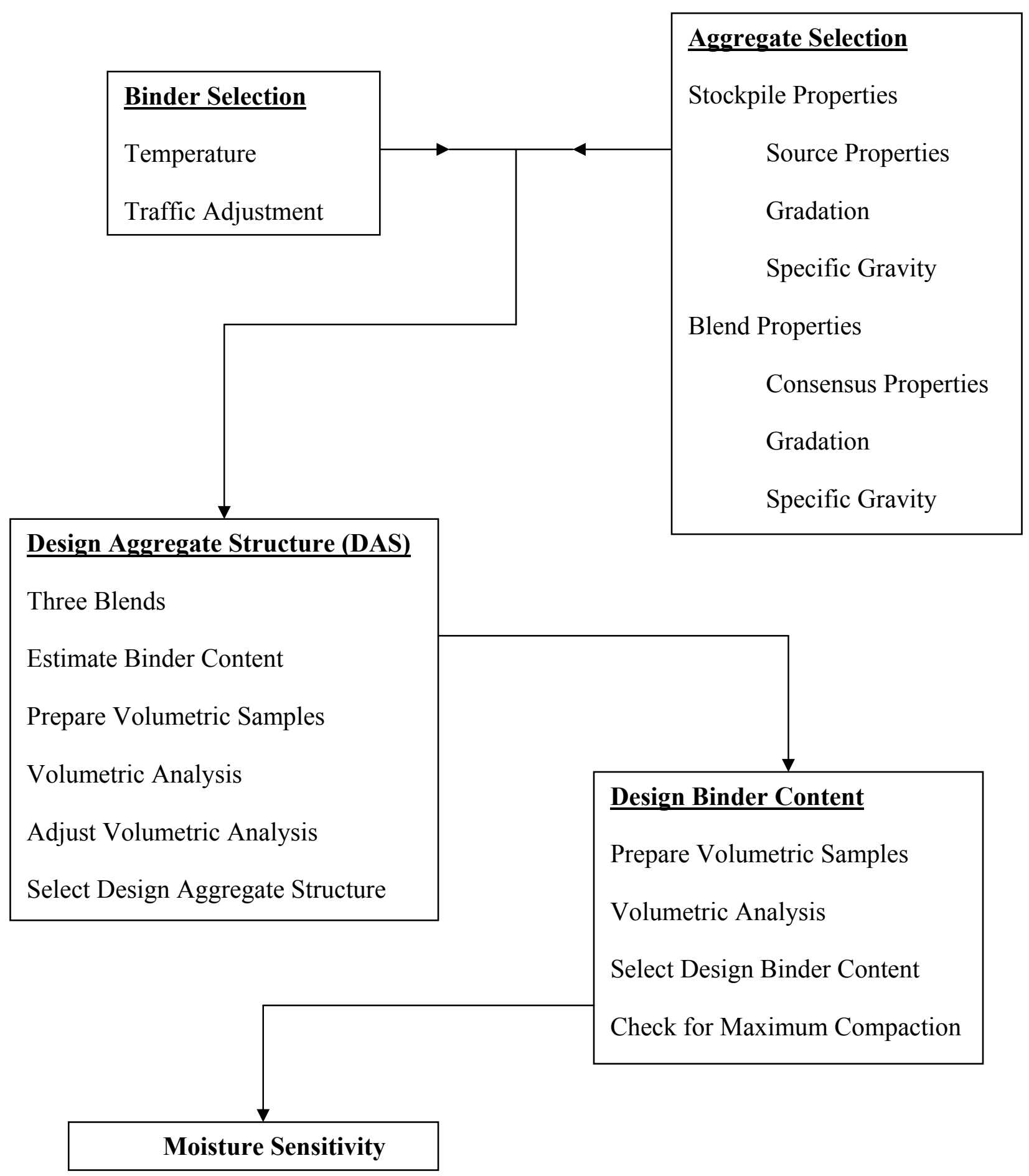


then determined for the selected DAS, again using volumetric analysis. Finally the moisture sensitivity is evaluated for a mix prepared using the DAS and the DBC.

The keys to selection of both the DAS and the DBC are volumetric properties of the mix. Volumetric properties are a function of the specific gravity of the binder, the aggregate blend, and the maximum theoretical specific gravity and bulk specific gravity of the mix. The bulk specific gravity of the mix is directly a function of the energy used to compact the mix.

\subsubsection{SuperPave Compaction Effort}

Due to the importance of the compaction procedure on the properties of SuperPave mixes a great deal effort was placed on the selection of the compaction equipment and the operational parameters used to control the compaction effort. The SHRP researchers concluded that samples prepared using a gyratory shear method produced samples with suitable characteristics and good repeatability. Machines designed specifically to meet the compaction requirements specified by the SHRP researchers became known as SuperPave gyratory compactors (SGC).

The principles of the SGC are shown in Figure 2.2. There are three parameters which control the compaction effort placed on a sample; the vertical force or pressure, the tilt angle, and the number of revolutions applied to the sample. The SHRP researchers recommended fixing the vertical pressure at $600 \mathrm{kPa}$ and the tilt angle to $1.25^{\circ}$ measured external to the sample mold (Brown et al, 2001). The tilt angle was subsequently refined to $1.16^{\circ}$ measured internally (Prowell et al, 2003). The easiest parameter to vary in order to change the compaction effort is the number of gyrations or revolutions applied to the sample.

One of the specifications required for a SGC is the ability of the machine to measure the height of the sample with each gyration. The SHRP researchers identified that the height information could be used to indicate the compatibility characteristics of a mix that could be related to the characteristics of the mix in the field. They identified three instances with respect to field characteristics related to the compaction characteristics of a mix. 
Figure 2.2 SuperPave Gyratory Compactor

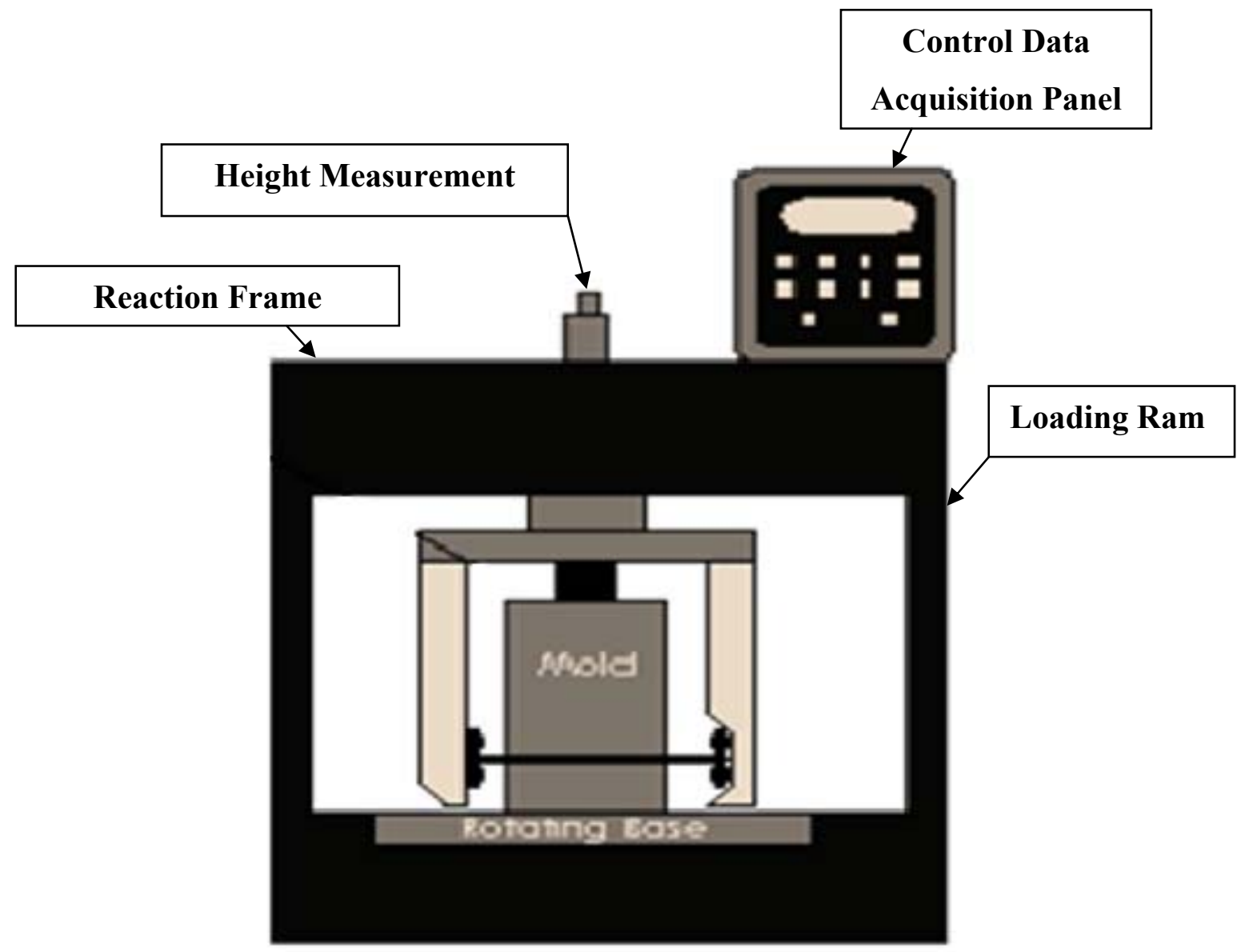

1) During construction, a mix needs a minimum amount of internal resistance to allow the mix to densify without being displaced by the rollers.

2) At the end of construction, or shortly thereafter, the mix should have an air void content similar to the air void content used in the mix design process.

3) After a "long" time period the mix should retain a minimum air void content to reduce the likelihood of rutting and bleeding problems.

The SHRP researchers coined the terminology $\mathrm{N}_{\text {initial }}, \mathrm{N}_{\text {design }}$, and $\mathrm{N}_{\text {maximum }}$ to coincide with the three field characteristics respectively.

Initially, mixes were always compacted using $\mathrm{N}_{\text {maximum }}$ gyrations and volumetric properties were estimated for $\mathrm{N}_{\text {initial }}$ and $\mathrm{N}_{\text {design. }}$. However, this process lacked precision 
for determining the volumetric properties at $\mathrm{N}_{\text {design. }}$. Since the volumetric properties are critical at $\mathrm{N}_{\text {design, }}$, the compaction process was altered to use $\mathrm{N}_{\text {design }}$ or the compaction effort for preparing the samples used for determining DAS and DBC.

Once the methodology and concept for the compaction process were established, it was necessary to associate a specific compaction effort with different design environments. Conceptually, the design of rut resistant mixes should consider both the anticipated traffic levels on the pavement and the expected maximum pavement temperature. In general, mixes with low asphalt contents are more rut resistant than mixes with higher asphalt contents. With respect to mix design, this concept translates into using higher compaction efforts for mixes subjected to high traffic volumes and elevated temperatures. Using this logic, the SHRP researchers defined compaction levels for four temperature ranges and seven traffic classifications as shown in Table 2.1.

Table 2.1 Compaction levels for four temperature and seven traffic classifications

\begin{tabular}{|c|c|c|c|c|c|c|c|c|c|c|c|c|c|}
\hline \multirow{2}{*}{$\begin{array}{c}\text { Design } \\
\text { ESALs }\end{array}$} & \multicolumn{9}{|c|}{ AVERAGE DESIGN HIGH AIR TEMPERATURE } \\
(millions) & $\mathrm{Ni}$ & $\mathrm{Nd}$ & $\mathrm{Nm}$ & $\mathrm{Ni}$ & $\mathrm{Nd}$ & $\mathrm{Nm}$ & $\mathrm{Ni}$ & $\mathrm{Nd}$ & $\mathrm{Nm}$ & $\mathrm{Ni}$ & $\mathrm{Nd}$ & $\mathrm{Nm}$ \\
\hline$<0.3$ & 7 & 68 & 104 & 7 & 74 & 114 & 7 & 78 & 121 & 7 & 82 & 127 \\
\hline$<1$ & 7 & 76 & 117 & 7 & 83 & 129 & 7 & 88 & 138 & 8 & 93 & 146 \\
\hline$<3$ & 7 & 86 & 134 & 8 & 95 & 150 & 8 & 100 & 158 & 8 & 105 & 167 \\
\hline$<10$ & 8 & 96 & 152 & 8 & 106 & 169 & 8 & 113 & 181 & 9 & 119 & 192 \\
\hline$<30$ & 8 & 109 & 174 & 9 & 121 & 195 & 9 & 128 & 208 & 9 & 135 & 220 \\
\hline$<100$ & 9 & 126 & 204 & 9 & 139 & 228 & 9 & 146 & 240 & 10 & 153 & 253 \\
\hline$<100$ & 9 & 143 & 233 & 10 & 158 & 262 & 10 & 165 & 275 & 10 & 172 & 288 \\
\hline
\end{tabular}

\subsubsection{Current SuperPave Compaction Effort}

Experience demonstrated the number of combinations of traffic and temperature were excessive and the compaction effort was excessive. Following the SHRP research program an Expert Task Group (ETG), was established to evaluate the results and recommendation of the research. The SuperPave ETG identified several assumptions and limitations of the SHRP research on compaction during mix design (ETG 1995 meeting as documented by Brown and Mallick, 1998). The NCHRP awarded Project 9-9 to the National Center for Asphalt Technology, NCAT, to evaluate the compaction effort used 
for mix design. As the result of Project 9-9, the AASHTO SuperPave mix design procedure was revised to use the compaction levels shown in Table 2.2.

Table 2.2 Consolidated SGC Compaction Table with Four Levels of Traffic

\begin{tabular}{|c|c|c|c|}
\hline \multirow{2}{*}{$\begin{array}{c}\text { Design } \\
\text { ESALs } \\
\text { (millions) }\end{array}$} & \multicolumn{3}{|c|}{ Compaction Parameter } \\
\cline { 2 - 4 } & Ninitial & Ndesign & Nmaximum \\
\hline$<0.3$ & 6 & 50 & 75 \\
\hline 0.3 to $<3$ & 7 & 75 & 115 \\
\hline 3 to $<30$ & 8 & 100 & 160 \\
\hline$\geq 30$ & 9 & 125 & 205 \\
\hline
\end{tabular}

The requirements in Table 2.2 are considerably lower than the recommendations in Table 2.1. The maximum $\mathrm{N}_{\text {design }}$ in Table 2.1 is 172 gyrations whereas in Table 2.2 the maximum is 125 gyrations. The West Virginia DOH requires the compaction effort defined in Table 2.2, with the following note:

Note: For design traffic levels of $\geq 3$ million ESALs, specifications or contract documents may require the Job Mix Formula (JMF) gyratory compaction criteria for mixtures located $\geq 4$ inches $(100 \mathrm{~mm})$ below the pavement surface be lowered by one ESAL level. Also, if a different binder grade is required in mixtures located $\geq 4$ inches $(100 \mathrm{~mm})$ below the pavement surface, this information will be provided in the specifications or in the contract documents. If less than $25 \%$ of the mixture layer is within 4 inches $(100 \mathrm{~mm})$ of the surface, the layer shall be considered to be below 4 inches $(100 \mathrm{~mm})$ for design purposes.

\subsubsection{AASHTO SuperPave Requirements}

The SuperPave volumetric mix design procedure (AASHTO MP2 and M323) was developed from the SHRP. When the method was first developed by the SHRP researchers, it was known as AASHTO PP28, based on the intention of having three levels of design. Level one design consisted of materials selection and volumetric proportioning and was designated for low-traffic roads having less than 1 million ESALs. Levels two and three were designed for increasingly heavier traffic with level three pavements being defined by SHRP as those experiencing over 10 million ESALs. Level two pavements were designed for loads between 1 to 10 million ESALs and level three was for roads with more than 10 million ESALs. The concept of design levels was never 
implemented. All SuperPave mixes are designed using the volumetric requirements originally developed for level one (Roads \& Bridges, 1996).

The detailed Specification for SuperPave Volumetric Design can be found in AASTO M323-04 and the description of the mix design procedure can be found in AASTO R35-04 (AASHTO, 2004(a)). AASHTO SuperPave mix design must meet all the following requirements:

a) The asphalt mixture must have a target air voids at $4 \%$ when compacted to $\mathrm{N}_{\text {design }}$ gyrations.

b) The Voids in Mineral Aggregate (VMA) of the compacted mixture at $\mathrm{N}_{\text {design }}$ gyrations must meet the minimum VMA requirements shown in Table 2.3.

c) Voids Filled with Asphalt (VFA) of the compacted mixture at $\mathrm{N}_{\text {design }}$ gyrations must fall within the range shown in Table 2.4.

d) Ratio of the weight of the mineral filler to the weight of the effective binder, dust-to-binder ratio, must be in the range of 0.6 and 1.2. Agencies can elect to use a dust to binder ratio of 0.8 to 1.6 for coarse graded mixes.

e) The $\% \mathrm{G}_{\mathrm{mm}}$ of the asphalt mixture compacted to $\mathrm{N}_{\text {initial }}$ must not exceed the limits as shown in Table 2.3.

f) The $\% \mathrm{G}_{\mathrm{mm}}$ of the mixture compacted to $\mathrm{N}_{\text {maximum }}$ must not exceed $98 \%$.

The asphalt binder should be a PG grade meeting the requirements of AASHTO MP1a-04. 
Table 2.3 SuperPave Criteria on $\% \mathrm{G}_{\mathrm{mm}}$, VMA, VFA and Dust-to-Binder Ratio

\begin{tabular}{|c|c|c|c|c|c|c|c|c|c|c|}
\hline \multirow{3}{*}{$\begin{array}{l}\text { Design } \\
\text { Trafiic } \\
\text { (million } \\
\text { ESALs) }\end{array}$} & \multirow{3}{*}{$\begin{array}{l}\text { VFA } \\
(\%)\end{array}$} & \multicolumn{3}{|c|}{ Required \%Gmm } & \multirow{2}{*}{\multicolumn{5}{|c|}{$\begin{array}{c}\text { Required minimum VMA (\%) } \\
\text { Nominal Max. Agg. Size, mm }\end{array}$}} & \multirow{3}{*}{$\begin{array}{l}\text { Dust-to- } \\
\text { Binder } \\
\text { Ratio }\end{array}$} \\
\hline & & \multirow{2}{*}{$\mathbf{N}_{\text {initial }}$} & \multirow{2}{*}{$\mathbf{N}_{\text {design }}$} & \multirow{2}{*}{$\mathbf{N}_{\max }$} & & & & & & \\
\hline & & & & & 37.5 & 25.0 & 19.0 & 12.5 & 9.5 & \\
\hline$<0.3$ & $70-80$ & $\leq 91.5$ & \multirow{5}{*}{96.0} & \multirow{5}{*}{$\leq 98.0$} & \multirow{5}{*}{11.0} & \multirow{5}{*}{12.0} & \multirow{5}{*}{13.0} & \multirow{5}{*}{14.0} & \multirow{5}{*}{15.0} & \multirow{5}{*}{$0.6-1.2$} \\
\hline 0.3 to $<3$ & $65-78$ & $\leq 90.5$ & & & & & & & & \\
\hline 3 to $<10$ & \multirow{3}{*}{$65-75$} & \multirow{3}{*}{$\leq 89.0$} & & & & & & & & \\
\hline 10 to $<30$ & & & & & & & & & & \\
\hline$\geq 30$ & & & & & & & & & & \\
\hline
\end{tabular}

The binder grade selected for a project is determined based on the expected pavement temperature range at the project location. The binder upper temperature grade is increased one level for either heavy truck traffic volume or for slow moving traffic. If both heavy truck traffic and slow speeds are expected the binder grade is increased by two levels for the upper temperature. Source properties such as L.A abrasion, soundness, and deleterious materials requirements must be met according to local highway agency specifications. The consensus aggregate properties are shown in Table 2.4 and the gradation classifications are shown in Table 2.5.

Table 2.4 SuperPave Consensus Aggregate Properties

\begin{tabular}{|c|c|c|c|c|c|c|}
\hline \multirow[t]{2}{*}{$\begin{array}{l}\text { Design } \\
\text { Traffic } \\
\text { (million } \\
\text { ESALs) }\end{array}$} & \multicolumn{2}{|c|}{$\begin{array}{l}\text { Coarse Aggregate } \\
\text { Angularity, Minimum } \\
\text { (\% with one fractured } \\
\text { face } \% \text { with two } \\
\text { fractured faces) }\end{array}$} & \multicolumn{2}{|c|}{$\begin{array}{c}\text { Uncompacted Void } \\
\text { Content of Fine } \\
\text { Aggregate, Minimum } \\
(\%)\end{array}$} & \multirow[t]{2}{*}{$\begin{array}{l}\text { Sand } \\
\text { Equivalent, } \\
\text { Minimum } \\
(\%)\end{array}$} & \multirow[t]{2}{*}{$\begin{array}{c}\text { Flat and } \\
\text { Elongated, } \\
\text { Maximum } \\
(\%)\end{array}$} \\
\hline & $\begin{array}{l}\text { Thickness } \\
\leq 100 \mathrm{~mm}\end{array}$ & $\begin{array}{l}\text { Thickness } \\
>100 \mathrm{~mm}\end{array}$ & $\begin{array}{l}\text { Thickness } \\
\leq 100 \mathrm{~mm}\end{array}$ & $\begin{array}{l}\text { Thickness } \\
>100 \mathrm{~mm}\end{array}$ & & \\
\hline$<0.3$ & $55 /-$ & - & - & - & 40 & - \\
\hline $\begin{array}{c}0.3 \text { to }< \\
3\end{array}$ & $75 /-$ & $50 /-$ & 40 & 40 & 40 & \multirow{4}{*}{10} \\
\hline $\begin{array}{c}3 \text { to }< \\
10\end{array}$ & $85 / 80$ & $60 /-$ & 45 & 40 & 45 & \\
\hline $\begin{array}{c}10 \text { to }< \\
30\end{array}$ & $95 / 90$ & $80 / 75$ & 45 & 40 & 45 & \\
\hline$\geq 30$ & $100 / 100$ & $100 / 100$ & 45 & 45 & 50 & \\
\hline
\end{tabular}


Table 2.5 SuperPave Gradation Classifications

\begin{tabular}{|c|c|c|c|c|c|c|}
\hline \multicolumn{7}{|c|}{ SuperPave Gradation Requirements } \\
\hline \multirow{2}{*}{$\begin{array}{c}\text { Standard } \\
\text { Sieve } \\
(\mathrm{mm})\end{array}$} & \multicolumn{6}{|c|}{$\begin{array}{c}\text { Percent Passing Criteria (Control Points) } \\
\text { Nominal Maximum Sieve Size }\end{array}$} \\
\hline & 4.75 & $9.5 \mathrm{~mm}$ & $12.5 \mathrm{~mm}$ & $19 \mathrm{~mm}$ & $25 \mathrm{~mm}$ & $37.5 \mathrm{~mm}$ \\
\hline 50 & & & & & & 100 \\
\hline 37.5 & & & & & 100 & $90-100$ \\
\hline 25 & & & & 100 & $90-100$ & 90.0 max. \\
\hline 19 & & & 100 & $90-100$ & $90.0 \max$. & \\
\hline 12.5 & 100 & 100 & $90-100$ & $90.0 \max$. & & \\
\hline 9.5 & $95-100$ & $90-100$ & 90.0 max. & & & 47 \\
\hline 4.75 & $90-100$ & $90.0 \max$. & & 47 & 40 & \\
\hline \multirow{2}{*}{2.36} & & $32-67$ & $28-58$ & \multirow{2}{*}{$23-49$} & \multirow{2}{*}{$19-45$} & \multirow{2}{*}{$15-41$} \\
\hline & & 47 & 39 & & & \\
\hline 1.18 & $30-60$ & & & & & \\
\hline 0.075 & $6-12$ & $2.0-10.0$ & $2.0-10.0$ & $2.0-8.0$ & $1.0-7.0$ & $0.0-6.0$ \\
\hline & $\begin{array}{l}\text { adatio } \\
\text { ssifiec }\end{array}$ & $\begin{array}{l}\text { hich fall } \\
\text { coarse gr }\end{array}$ & $\begin{array}{l}\text { low the p } \\
\text { ations }\end{array}$ & mary col & 1 sieve al & \\
\hline
\end{tabular}

\subsection{STATE RESEARCH ON COMPACTION EFFORT}

The Colorado Department of Transportation (CDOT) conducted a research to collect and validate data regarding the number of $\mathrm{N}_{\text {design }}$ gyrations used to select the optimum asphalt and recommend a new set of values for the number of gyrations.

Research objectives were focused on the determination of laboratory compactive effort to ensure that the proper binder content was being used in mix designs (Harmelink and Aschenbrener, 2002).

The research examined the densification of 25 evaluation selections selected from 22 projects selected to represent the range of environmental conditions and traffic levels in the state. Mixes were designed with the Texas gyratory compactor, but it was verified that the mixes met the SuperPave mix criteria. The researcher found that, in general, pavement density increased for three years following construction then the pavements did not densify any further. The air voids three years after construction were higher than derived leading the researchers to conclude that the mixes were too stiff. The researchers conclude that the problem was associated with the asphalt content being too low and recommended either lowering the number of gyrations used for mix design or adjusting 
the target air voids during mix design. The researchers did not provide specific values for the changes in their parameters.

Brown (2005) summarized the experience of several states with respect to the asphalt content versus compaction level of SuperPave mixes. Based on the work of Harmelink and Aschenbrener (2002), Colorado mixes are designed at four percent air voids, but the state may allow the production target air void to be three to allow for a higher asphalt content to three percent to increase binder content. The Maryland Asphalt Association encourages local agencies to use $\mathrm{N}_{\text {design }}$ of 50 gyrations as a means to have higher binder contents. Virginia DOT uses a single compaction effort of 65 gyrations for all traffic levels but increases the upper temperature binder grade to provide mix stiffness.

The most common approach to increasing asphalt content is to reduce the compaction effort Brown (2005) quotes Huber, associate director of research at Heritage Research Group.. Huber asserts this is flawed logic and the control limits for the voids in the mineral aggregates should be analyzed. If VMA is not changed, the aggregates can be altered such that the lower compactive effort does not necessarily increase the binder content used in mixes.

\subsection{NCHRP PROJECT 9-9(1)}

As documented by Brown and Mallick (1998), the data set used to develop Table 2.2 was very limited.

As documented by Brown (2005) states were taking the initiative to alter the AASHTO compaction specifications. The NCHRP funded Project 9-9(1) to verify the compaction effort on a nationwide basis (Prowell and Brown, 2007). Projects with a performance history of four years were evaluated across 16 states. More than 4,000 SGC compacted samples and over 5,600 cores were examined during the study.

Figure 2.3 is a cumulative distribution curve for the projects (Prowell and Brown, 2007). It was found that 55 percent of the projects had an initial density following construction of less than 92 percent of $\mathrm{G}_{\mathrm{mm}}$. This low level of density, which corresponds to 8 percent air voids, indicates the pavements are permeable (Roberts, et al, 
Figure 2.3 Cumulative frequency distribution of as-constructed, in-place density

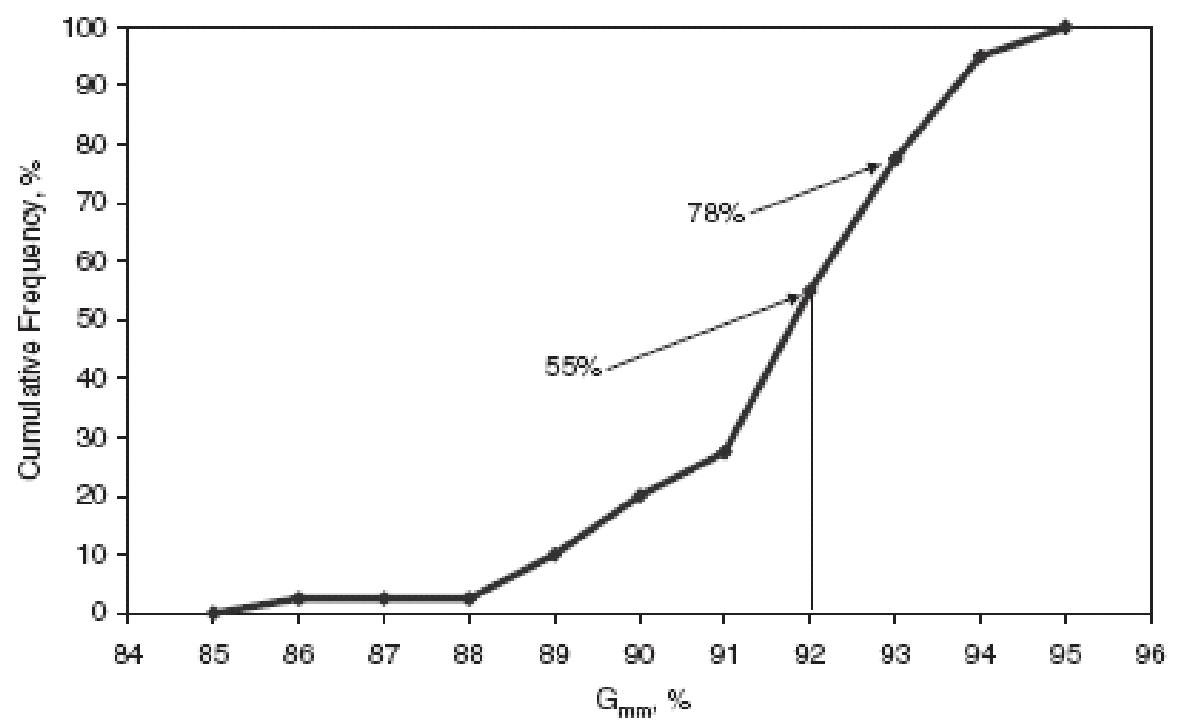

1996) and also air void contents in excess of 8 percent have interconnected passages which permit rapid water damage and oxidation of the asphalt.

While there are several factors which can contribute to low field densities, a low mix design asphalt content would certainly contribute to the problem.

The densification of the asphalt following construction was examined producing the cumulative distribution curve shown in Figure 2.4 (Prowell and Brown, 2007). The majority of the asphalt concrete densification occurred during the first three months following construction. The rate of densification decreases with time and after two years little additional densification occurs.

As would be expected on a project of this magnitude, many factors affecting compaction were evaluated including region of country, binder grade, construction season, etc. Although the researchers encountered a great deal of variability in the samples, they did recommend altering the SuperPave gyration requirements to the values in Table 2.6. 
Figure 2.4 Cumulative frequency plot for in-place density by sampling period

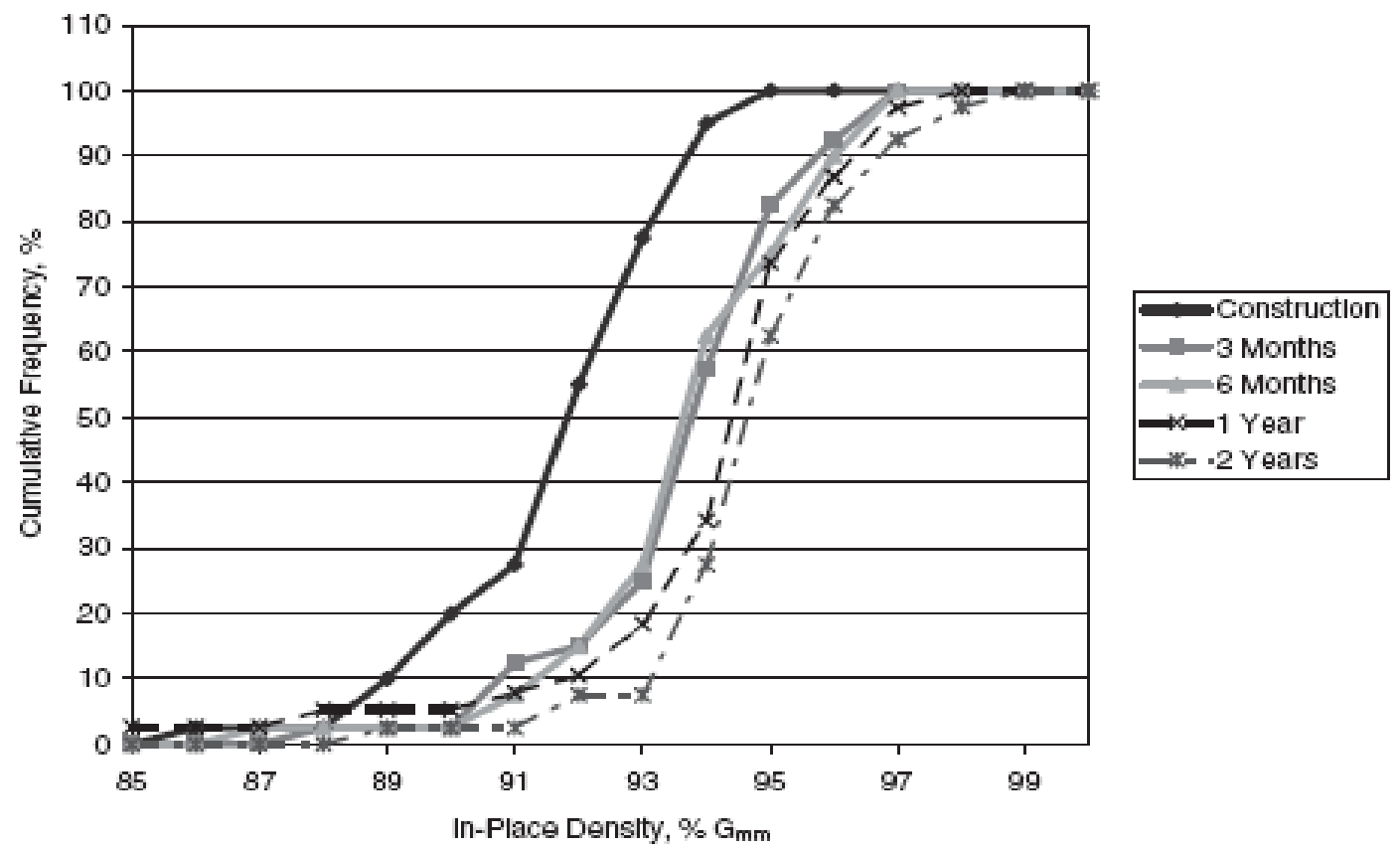

The researchers recommend elimination of the $\mathrm{N}_{\text {initial }}$ and $\mathrm{N}_{\text {maximum }}$ requirements as these were not reliable indicators of field performance. The researchers included compaction requirements for 2-year design traffic, but retained the 20 year design traffic levels from the current SuperPave mix design method. The recommended gyrations for SuperPave mixes in the top $100 \mathrm{~mm}$, constructed with PG $76-\mathrm{xx}$ binders, are lower than the current requirements. For designs with a "stiff" binder, $\geq$ PG $76-\mathrm{xx}$, or for mixes more than $100 \mathrm{~mm}$ from the surface, the researchers recommended a further reduction in the compaction effort. 
Table 2.6 Recommended $\mathrm{N}_{\text {design }}$ Levels from NCHRP Project 9-9(1)

\begin{tabular}{|c|c|c|c|}
\hline 20-Year Design Traffic, & 2-Year Design Traffic, \\
ESALs & $\begin{array}{c}\mathrm{N}_{\text {design }} \text { for } \\
\text { binders } \\
<\text { PG 76- } \\
\text { XX }\end{array}$ & $\begin{array}{c}\mathrm{N}_{\text {design }} \text { for } \\
\text { binders } \\
\geq \text { PG 76 - } \\
\text { XX or } \\
\text { mixes } \\
\text { placed } \\
100 \mathrm{~mm} \\
\text { from } \\
\text { surface }\end{array}$ \\
\hline$<300,000$ & $<30,000$ & 50 & NA \\
\hline 300,000 to $3,000,000$ & 30,000 to 230,000 & 65 & 50 \\
\hline $3,000,000$ to $10,000,000$ & 230,000 to 925,000 & 80 & 65 \\
\hline $10,000,000$ to $30,000,000$ & 925,000 to $2,500,000$ & 80 & 65 \\
\hline$>30,000,000$ & $>2,500,000$ & 100 & 80 \\
\hline
\end{tabular}

\section{5: METHOS FOR EVALUATING RUTTING PERFORMANCE}

The current SuperPave mix design criteria partially address rutting performance of HMA mixes through gradations control points and consensus aggregate specifications. With aggregate being the main load carrying component of the mix, the aggregate properties are highly critical in providing the resistance to permanent deformation at higher temperatures. There are currently no mechanical testing procedures that pertain to rutting. Performance related tests are used to develop different models which are also used to predict the rutting potential. The performance test includes diametrical tests, uniaxial tests, triaxial tests, shear tests, empirical tests, and simulative tests. Simulative tests are conducted by using a wheel tracking device that measures quality or performance by applying repeated loads across the surface of the specimen. These wheel tracking devices can also be used to predict fatigue and moisture susceptibility which can be correlated to actual pavement conditions.

The most common form of the wheel device used for testing rutting mixes in the laboratory has been the Georgia loaded wheel tester (GLWT) (Kandhal and Cooley, 2002). The Georgia loaded wheel tester was developed through a research study between the Georgia Department of Transportation (DOT) and the Georgia Institute of Technology (Lai, 1986). This device can be used to test either cylindrical or beam 
asphalt concrete specimens. Beam dimensions are generally $125 \mathrm{~mm}$ wide, $300 \mathrm{~mm}$ long, and $75 \mathrm{~mm}$ high (5 in x 12 in $\times 3$ in). Cylindrical specimens are prepared to 150 $\mathrm{mm}$ in diameter and $75 \mathrm{~mm}$ tall. Both specimens are compacted to either 4 or 7 percent air voids but some success has been accomplished by using a targeted air void as low as 2 percent (Collins, et al, 1996). The test consists of applying a 445-N (100-lb) load onto a pneumatic linear hose pressurized to $690 \mathrm{kPa}$ (100 psi). The load is applied through an aluminum wheel onto the linear hose, which resides on the sample. Test specimens are tracked back and forth under the applied stationary loading for a total of 8,000 loading cycles (one cycle is defined as the backward and forward movement over samples by the wheel device.

Figure 2.5 Georgia Loaded Wheel Tester

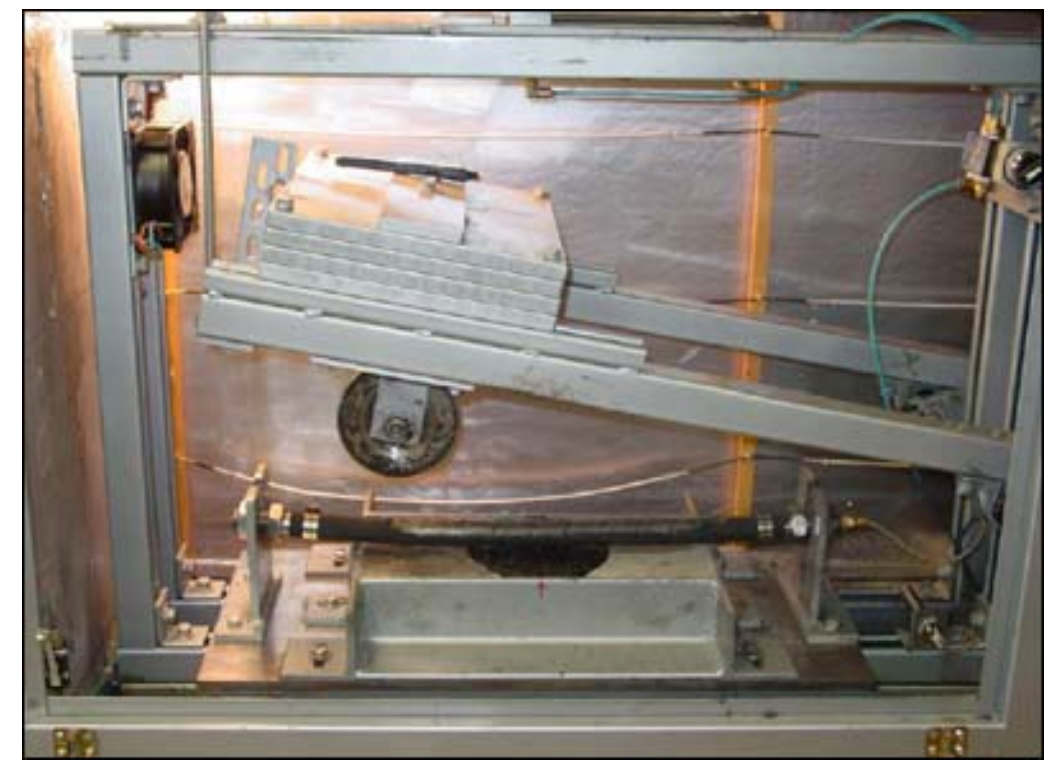

Test temperatures are within the typical ranges from $35^{\circ} \mathrm{C}$ to $60^{\circ} \mathrm{C}\left(95^{\circ} \mathrm{F}\right.$ to $\left.140^{\circ} \mathrm{F}\right)$. The original work performed by Lai was tested at $35^{\circ} \mathrm{C}\left(95^{\circ} \mathrm{F}\right)(\mathrm{Lai}, 1986)$. The rut depth is obtained at the conclusion of the 8,000 cycle and it's calculated by determining the difference in the measurement of the surface prior to testing and after testing. This is achieved by using some type of micrometer (Kandhal and Cooley, 2002).

The GLWT has been used extensively by many researchers and state agencies to evaluate permanent deformation in HMA mixes. The Florida DOT used the GLWT to 
rank the rut susceptibility of three different kinds of mixes which resulted in a good relationship between the rankings and the field rut depths (Mohammad, 2006). The demand for research in permanent deformation is very high because it is the earliest premature failure (Brown, et al, 2001). Determining the rutting susceptibility of a mix by analyzing the compaction curves of the SuperPave Gyratory Compactor as stated in previous studies is not a feasible approach due to the different high temperatures and binder grades (Coree and VanDerHorst, 1999).

\subsection{1: Asphalt Pavement Analyzer (APA)}

The Asphalt Pavement Analyzer is a multifunctional loaded wheel tester used for evaluating permanent deformation. It is a modified version of the Georgia loaded wheel tester. A major advantage or improvement the APA has over the Georgia loaded wheel tester is that samples can be submerged and tested in water. Samples can be either beam specimens or cylindrical specimens. The beam specimens can be either fabricated in the laboratory or sawed from an asphalt concrete core obtained from the field. Laboratory beam specimens are compacted by the rolling compaction method, or the vibratory compaction method. Beam specimens are $125 \pm 0.5 \mathrm{~mm}$ in width, $300 \mathrm{~mm} \pm 0.5 \mathrm{~mm}$ in length and $75 \mathrm{~mm} \pm 0.5 \mathrm{~mm}$ in height. Cylindrical specimens are $150 \mathrm{~mm} \pm 0.5 \mathrm{~mm}$ in diameter and $75 \mathrm{~mm} \pm 0.5 \mathrm{~mm}$ in height. They can be either cored from an asphalt pavement in the field or compacted in the laboratory by the gyration compaction method or the vibratory compaction method. The testing temperature ranges from $40.6^{\circ} \mathrm{C}$ to $64^{\circ} \mathrm{C}\left(105^{\circ} \mathrm{F}\right.$ to $\left.147^{\circ} \mathrm{F}\right)$ and wheel force and hose pressure still remains at $100 \mathrm{lbs}$ and 100 psi respectively. Other studies have also been conducted at slightly above the average seven day pavement temperature (Kandhal and Mallick, 1999) which has been successful by using a wheel load of $533 \mathrm{~N}(120 \mathrm{lbs})$ and hose pressure of $830 \mathrm{kPa},(120)$ psi (Williams and Prowell, 1999). The study composed of a $19 \mathrm{~mm}$ SuperPave mix, two aggregate types (sandstone and limestone), and four different asphalt binder types. Kandhal and Cooley (2002) studied several mixes of known rutting potential to better correlate rut susceptibility to mix types. A regression analysis was used conclude that both the cylindrical and beam specimens are acceptable means for determining the rut susceptibility. Moreover, evaluation of a standard rut depth was approached to establish a parameter whether a mix has a rutting potential. Shear and creep tests were performed 
to evaluate lab and field rutting to set a representative formula to calculate a standard rut depth. A rut depth of $8.0 \mathrm{~mm}$ was determined and was used to evaluate the rutting potential of mixes at higher performance grade temperature (Kandhal and Cooley, 2002).

Figure 2.6 Asphalt Pavement Analyzer

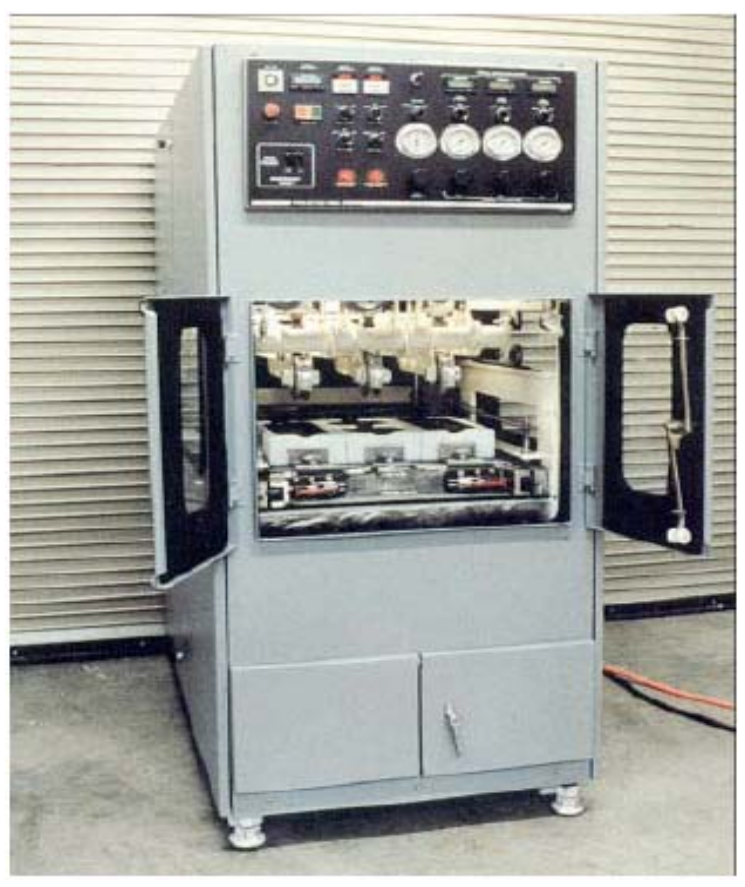

In 2002, Choubane, et al, used APA test results in conjunction with field measurements to establish values within the ranges of $7 \mathrm{~mm}$ to $9 \mathrm{~mm}$ to suggest the limiting criteria for the 8,000 repetitive load cycle for both beam and cylinder specimens. The test was data was only based on three mixes and 3 specimens per mix, therefore, adaptation of the results for performance testing were not necessary since different kinds of mix designs are used at different locations. Choubane, et al, (2002) also evaluated procedures for pass and fail which basically pertains to the comparison of rutting mixes with respect to which ruts more.

The rut depth measured with the APA cannot be directly correlated with field measured rut depths due to the non-mechanistic based measurement. Stress and strain conditions demonstrated by the APA cannot be defined mechanistically but can be correlated to field rut depths to predict rutting as studied by the Minnesota DOT (Skok, et al, 2002). The mission of the study was to establish a critical in-service rut depth 
criterion for field measurements in Minnesota by identifying projects throughout the state and correlating laboratory averages and variations in rut depths measured with the APA. A criteria value of $7.0 \mathrm{~mm}$ ( $0.28 \mathrm{in}$ ) was established and recommended for 8,000 pass cycles. Each wheel pass was equivalent to 130 ESAL's which represented 1,040,000 ESAL's for the 8,000 cycles. Testing parameters for the APA recommended by the Minnesota Department of Transportation can be found in Table 2.7.

The West Virginia University Asphalt Technology Laboratory Center has been using the APA for several years and has achieved satisfactory results. SuperPave mixes within the state of West Virginia has been evaluated with the APA, and a steady and reliable result has been determined with mixes that rutted in the lab with mixes that rutted in the field. No relationship was established between the APA rutting potential and the actual field performance (Zaniewski and Patino, 2005).

Table 2.7 APA Testing Parameters

\begin{tabular}{|l|l|}
\hline Parameter & Specification \\
\hline Test Temperature & $\begin{array}{l}\text { Upper Performance Grade of HMA Mixture being } \\
\text { Tested }\end{array}$ \\
\hline Environmental Condition & Dry \\
\hline Specimen Size, $\mathrm{mm}(\mathrm{in})$. & $150(6)$ diameter, $75(3)$ height \\
\hline Load, N (lb) & $445(100)$ \\
\hline Hose Pressure, $\mathrm{kPa}(\mathrm{psi})$ & $689(100)$ \\
\hline Wheel Speed, $\mathrm{m} / \mathrm{sec}$ & 0.61 \\
\hline Air Voids, $\%$ & $7 \pm 0.5$ \\
\hline $\begin{array}{l}\text { Number of Test Wheel Load } \\
\text { Cycles }\end{array}$ & 8000 \\
\hline Laboratory Compaction Device & SuperPave Gyratory Compactor \\
\hline Pretest Specimen Conditioning & 4 hours @ test Temperature \\
\hline Number of Seating Cycles & 50 \\
\hline
\end{tabular}

\subsection{2: Temperature Effect Model}

Temperature has an important effect in the rutting depth of APA samples. The $60^{\circ} \mathrm{F}$ testing temperature was used to remain consistent with previous tests conducted at West Virginia University Asphalt Technology Lab Center. The temperature effects 
model was developed by Shami, et al (1997) to compare the difference between samples with different testing temperatures (Zaniewski and Patino, 2005). If any two of the three variables are known, the other variable can be determined.

$$
\frac{\mathrm{R}}{\mathrm{R}_{0}}=\left(\frac{\mathrm{T}}{\mathrm{T}_{0}}\right)^{2.625}\left(\frac{\mathrm{R}}{\mathrm{R}_{0}}\right)^{0.276}
$$

Where,

$\mathrm{R}=$ Predicted rut depth.

$\mathrm{R}_{0}=$ Reference rut depth obtained from the APA test at the reference conditions $\mathrm{T}_{0}, \mathrm{~N}_{0}$.

$\mathrm{T}, \mathrm{N}=$ Temperature and load cycles the rut depth is sought.

$\mathrm{T}_{0}, \mathrm{~N}_{0}=$ Reference temperature and load cycles for $\mathrm{R}_{0}$.

Test results concluded that this model could be used to test samples at different temperatures and load cycles. This technique can be used to compare specimens tested at different test temperatures and parameters. Lesser load cycles can be used to expedite testing procedures (Zaniewski and Patino, 2005).

\subsection{3: Indirect Tensile Test}

The indirect tensile test (IDT) is a diametrical test use to evaluate the rutting potential of a mix (Roberts, et al, 2002). The IDT in most cases is also used to evaluate thermal cracking susceptibility and creep compliances of asphalt mixtures at low and immediate pavement temperatures. For low temperatures where thermal stresses are more significant, estimates from stiffness that are reasonable can be obtained from the indirect tensile test. Asphalt stiffness increases as temperature is reduced, which results in the asphalt concrete behaving as a linear elastic material. In 2002, The National Cooperative Highway Research Program (NCHRP) initiated numerous projects to evaluate a simple performance test for permanent deformation of asphalt mixtures. NCHRP Project 9-16 validated that the SGC compaction slope indicates a change in aggregate characteristics which was not a representative of stiffness and binder volume. Anderson, et al, (2003) studied this experiment with the use of IDT, volumetric 
properties, and SuperPave Gyratory Compactor properties to evaluate the rutting potential of a mix. The findings of the study concluded that the use of compaction slope in conjunction with the IDT strength can be used to provide an indicator of a rutting resistance of an asphalt mix and an increase in IDT strength could potentially lead to decreased rutting depth (Anderson, et al, 2003). However, the testing equipments used by Anderson to perform the experiment was expensive and not available for most the highway agencies, so it was not adaptable.

Christensen and Bonaquist (2004) suggest that the indirect tensile strength test performed at high temperatures is potentially a simple and accurate test for evaluating the rut resistance of asphalt concrete mixtures. The IDT strength test performed by Christensen and Bonaquist (2004) had a loading rate of $3.75 \mathrm{~mm} / \mathrm{min}$ using a standard Lottman breaking head of $150 \mathrm{~mm}$ diameter specimens with a test temperature of $33{ }^{\circ} \mathrm{C}$. Results from the study indicated a significant relationship between cohesion of mix and rutting. A current procedure uses the modified Lottman procedure (AASHTO T283) to evaluate the moisture susceptibility. This procedure is recommended because the testing equipment (Marshall Stabilometer) is equipped with a modified loading head to measure the strength of IDT specimens and readily available to state agencies. Other parameters influenced in testing hot mix asphalt are the test temperature and the load rate. The Marshall Stabilometer uses a load rate of $50 \mathrm{~mm} / \mathrm{min}$, where Anderson used a load rate of $3.75 \mathrm{~mm} / \mathrm{min}$. Moreover, further testing also indicated that using a load rate of 50 $\mathrm{mm} / \mathrm{min}$ at a test temperature of $10^{\circ} \mathrm{C}$ below the 7 -day average high pavement temperature provided similar results as tests conducted with a load rate $3.75 \mathrm{~mm} / \mathrm{min}$ at a test temperature of $33{ }^{\circ} \mathrm{C}$. Failure is more rapid under these conditions due to the larger loading rate and higher temperature and also the test can be completed in seconds, which makes it more efficient (Christensen and Bonaquist, 2004). The test is performed by loading a cylindrical specimen with a single or repeated compressive load which acts parallel to and along the vertical diametric plane (Figure 2.7a). The Loading configuration develops a relatively uniform tensile stress perpendicular to the direction of the applied load and along the vertical diametric plane, which ultimately causes the specimen to fail by splitting along the vertical diameter (Figure $2.7 \mathrm{~b}$ ). 
Figure 2.7 IDT Loading and failure mode

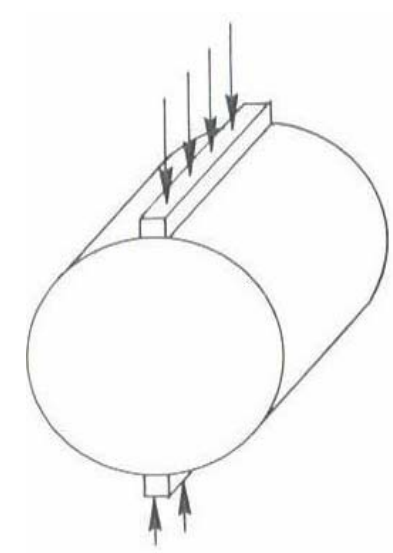

(a)

Indirect Tensile Test

During Loading

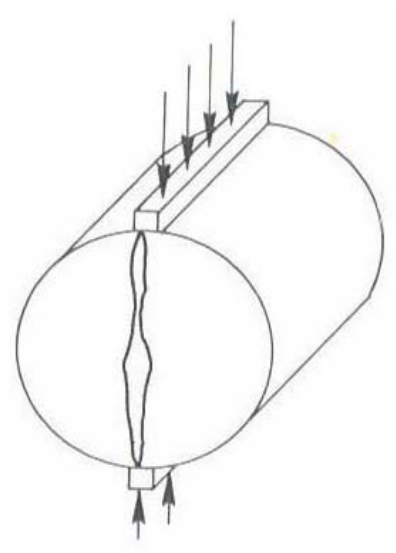

(b)

Indirect Tensile Test

at Failure

In 2004, Zaniewski and Srinivasan conducted a study with the IDT test at West Virginia University Asphalt Technology Laboratory and noticed a correlation between the IDT strength and the rut depth of samples tested in the APA. From the study, the IDT test supported and provided information on the cohesion of the mix with respect to stiffness of the asphalt binder, but does not evaluate other parameters such as the angle of internal friction of the aggregates (Zaniewski and Srinivasan, 2004). The Marshall Stabilometer was used at a loading rate of $50 \mathrm{~mm} / \mathrm{min}$ with a modified loading head and a test temperature of $60^{\circ} \mathrm{C}$. Nominal Maximum Aggregate Size (NMAS) was not a main effect of the tensile strength and that binder grade was the most important factor by using the analysis of variance (ANOVA) table (Zaniewski and Srinivasan, 2004).

The R squared value for IDT strength versus APA rut depth, and the standard error showed a significant correlation between rut depth and tensile strength in a way that as rut depth increased, IDT strength decreased (Zaniewski and Srinivasan, 2004). 


\subsection{SUMMARY OF LITERATURE REVIEW}

The WVDOH has been constructing HMA pavements with the SuperPave mix design method for several years and these mixes have performed well with regards to rutting (Zaniewski and Patino, 2005). Two base course mixes are currently used by the WVDOH, $19 \mathrm{~mm}$ and $37.5 \mathrm{~mm}$ NMAS designed with a 100 gyrations.

The original SuperPave $\mathrm{N}_{\text {design }}$ table was based on limited data. The consolidation of the $\mathrm{N}_{\text {design }}$ table was generated based on a laboratory study designed to evaluate the sensitivity of volumetric properties. A study conducted by Prowell and Brown, NCHRP Report 9-9(1) recommended lowering the compaction effort from 100 to 80 gyrations for $19 \mathrm{~mm}$ mixes and from 100 gyrations to 65 gyrations for $37.5 \mathrm{~mm}$ mixes. Results from the study showed that the compaction effort in the SuperPave $\mathrm{N}_{\text {design }}$ table were excessive and could be lowered up to 25 gyrations.

Lowering compactive effort should improve the quality and performance of a pavement with respect to cracking but this could lead to permanent deformation in the wheel path due to increased binder content. The literature indicates that there is a need to verify rutting potential with the recommended changes proposed by Prowell and Brown. 


\section{CHAPTER3: RESEARCH METHODOLOGY}

\subsection{INTRODUCTION}

This research evaluated what effect the NCHRP 9-9(1) (Prowell and Brown, 2007) would have on the rutting performance of typical $19 \mathrm{~mm}$ and $37.5 \mathrm{~mm}$ SuperPave mixes used by the WVDOH. Mix design and materials were donated by West Virginia Paving. The mix designs were verified at the West Virginia University Asphalt Technology Laboratory. Using the original aggregate blends, and the compaction efforts recommended by the NCHRP study, a new percent binder was established. Samples of the original and modified mixes were then prepared for testing with the Asphalt Pavement Analyzer and Indirect Tension Test. Finally, an Analysis of Variance, ANOVA, was performed to compare the factors in the experiment.

\subsection{DESIGNS}

The mixes used for this research were $19 \mathrm{~mm}$ and $37.5 \mathrm{~mm}$ base mixes. The binder used for all tests was a PG 70 - 22 supplied by Shelly Company, Kanauga, Ohio. The types of aggregates and proportions are shown in Table 3.1. Gradations and specific gravity data are presented in appendix A.

Table 3.1 Blend Properties for $19 \mathrm{~mm}$ and $37.5 \mathrm{~mm}$ Mixes

\begin{tabular}{|c|c|c|c|}
\hline \multicolumn{2}{|c|}{19 mm Mix } & \multicolumn{2}{c|}{37.5 mm Mix } \\
\hline $\begin{array}{c}\text { Aggregate } \\
\text { Type }\end{array}$ & $\begin{array}{c}\text { Percent of } \\
\text { Total } \\
\text { Aggregate }\end{array}$ & $\begin{array}{c}\text { Aggregate } \\
\text { Type }\end{array}$ & $\begin{array}{c}\text { Percent of } \\
\text { Total } \\
\text { Aggregate }\end{array}$ \\
\hline LS \# 67 & $30 \%$ & LS \#467 & $50 \%$ \\
\hline LS \#8 & $23 \%$ & LS \#67 & $11 \%$ \\
\hline LS SAND & $36 \%$ & SLAG SAND & $24 \%$ \\
\hline RAP & $11 \%$ & RAP & $15 \%$ \\
\hline FILLER & $0.0 \%$ & FILLER & $0.0 \%$ \\
\hline BLEND & $100 \%$ & BLEND & $100.0 \%$ \\
\hline
\end{tabular}




\subsection{AGGREGATE PREPARATION}

Material from each stockpile was sieved and the aggregates retained on each sieve were washed to remove fines. The sieve sizes used were $50 \mathrm{~mm}, 37.5 \mathrm{~mm}, 25 \mathrm{~mm}, 19 \mathrm{~mm}$, $12.5 \mathrm{~mm}, 9.5 \mathrm{~mm}, 4.75 \mathrm{~mm}, 2.36 \mathrm{~mm}, 1.18 \mathrm{~mm}, 600 \mu \mathrm{m}, 300 \mu \mathrm{m}$, and $75 \mu \mathrm{m}$. The aggregates were then dried and stored in bins. The fines washed off were discarded and bag house fines were used for the mineral filler. The aggregate from each stockpile and sieve were combined to produce the aggregate blend specified in the job mix formula.

The specific gravities of the aggregates were the specific gravities that were measured by the contractor. The calculations for the combined specific gravities of the blends can be seen in appendix A for the mixes.

\subsection{1: AGGREGATE BLENDS}

The mix design sheets used for this experiment were provided by West Virginia Paving and can be seen in Appendix A for both $19 \mathrm{~mm}$ mix and the $37.5 \mathrm{~mm}$ mix. A weigh-out table was generated for each mix design, which shows the mass of each aggregate size that should be used from each stockpile based on the gradations from the contractor. Weight-out tables are in appendix B.

The use of Reclaimed Asphalt Pavement (RAP) and slag made it difficult to produce the weigh-out tables. The RAP in the mix provided a portion of the binder used in the total mix, which had to be taken into consideration. The RAP binder was subtracted from the amount of virgin binder to be added tot the mix. In order for the proper amount of binder percentage to be obtained, the binder from the RAP had to be calculated. In the mix design analysis, 15 percent of RAP means that the RAP accounts for 15 percent of the stone in the mix.

The determination of the amount of binder in the RAP was achieved by calculating the amount of RAP stone to be used and finding the amount of binder the RAP contained. Based on ignitions tests performed in the lab, the percent of binder in the RAP was 5.9 percent. This was done by the contractor and verified in the WVU Asphalt Technology Lab (AASHTO T 308-99.) The NCAT Asphalt Content Tester (Model 
F85930, Series 945) was used for this test. The following equations were used to calculate the amount of binder in the RAP.

$$
\begin{aligned}
& \mathrm{P}_{\mathrm{s}}=100-\mathrm{P}_{\mathrm{b}} \\
& \mathrm{M}_{\mathrm{s}}=\mathrm{M}_{\mathrm{m}} * \mathrm{P}_{\mathrm{s}} \\
& \mathrm{M}_{\mathrm{sR}}=\mathrm{M}_{\mathrm{s}} * \mathrm{P}_{\mathrm{R}} \\
& \mathrm{M}_{\mathrm{R}}=\mathrm{M}_{\mathrm{sR}} /\left(1-\mathrm{P}_{\mathrm{bR}}\right) \\
& \mathrm{M}_{\mathrm{bR}}=\mathrm{M}_{\mathrm{R}} * \mathrm{P}_{\mathrm{bR}}
\end{aligned}
$$

Where,

$\mathrm{P}_{\mathrm{s}}=$ Percent stone in mix

$\mathrm{P}_{\mathrm{b}}=$ Percent binder in mix

$\mathrm{M}_{\mathrm{s}}=$ Mass stone in the mix

$\mathrm{M}_{\mathrm{m}}=$ Mass of mix

$\mathrm{M}_{\mathrm{sR}}=$ Mass of stone from RAP

$\mathrm{P}_{\mathrm{R}}=$ Percent RAP in the mix

$\mathrm{M}_{\mathrm{R}}=$ Mass of RAP in the mix

$\mathrm{P}_{\mathrm{bR}}=$ Percent binder in the RAP

$\mathrm{M}_{\mathrm{bR}}=$ Mass binder from RAP

The total amount of RAP that was weight out for each sample was $T_{R}$, which included binder and stone. The quartering method was used to select the RAP material used in each blend.

The amount of virgin binder to add to the mix was calculated using the following equations:

$$
\begin{aligned}
& \mathrm{M}_{\mathrm{b}}=\mathrm{M}_{\mathrm{m}} * \mathrm{P}_{\mathrm{b}} \\
& \mathrm{M}_{\mathrm{bV}}=\mathrm{M}_{\mathrm{b}}-\mathrm{M}_{\mathrm{bR}}
\end{aligned}
$$


Where,

$\mathrm{M}_{\mathrm{b}}=$ Mass of total binder

$\mathrm{M}_{\mathrm{bV}}=$ Mass of virgin binder

Another difficulty was the use of slag aggregates in the $37.5 \mathrm{~mm}$ mix. The absorption of slag is high, due to this property; the dry-back test method was used for the maximum theoretical specific gravity test (AASHTO T 209-99). The dry back procedure requires removing the sample from the water bath after taking the submerged weight and drying the sample on a No. 200 sieve to obtain the dry weight. This dry weight was used in the denominator of the theoretical maximum specific gravity equation.

\section{4: TESTING MIX DESIGNS}

The weighed-out aggregates, binder, mixing bucket and tools were placed and heated in an oven at the mixing temperature of $165^{\circ} \mathrm{C}$. When the materials were at the mixing temperature, the aggregates were poured in the mixing bucket and a desired amount of the heated binder at the same temperature was added. The aggregates and binder were mixed quickly and thoroughly in the bucket until uniform distribution of binder or complete coating of aggregates. The mix was then poured on a table and quartered to select the material for each sample. Two samples were weighed in a pan to create bulk specific gravity pills, $\mathrm{G}_{\mathrm{mb}}$, and one maximum theoretical specific gravity sample, $G_{m m}$. Sample weights obtained for bulk specific gravity pills $\left(G_{m b}\right)$ were between 4500 - 4700 grams in accordance to AASHTO T 312-03 and maximum theoretical specific gravity $\left(\mathrm{G}_{\mathrm{mm}}\right)$ was weighed in accordance with AASHTO T 209-99. The samples were cured in the oven at the compaction temperature of $154^{\circ} \mathrm{C}$ for $2 \mathrm{hrs} \pm 5$ mins, stirring after one hour. The samples were transferred into molds and compacted in the SuperPave Gyrator Compactor to the desired $\mathrm{N}_{\text {design }}$ number of gyrations. The SGC used in the lab was an AFGC125X model manufactured by Pine Instrument Company, Grove City, PA. The bulk specific gravity of the pills was determined in accordance with AASHTO T 166 and the theoretical maximum specific gravity was determined in 
accordance with AASHTO T 209. From these values the void content and other volumetric properties of the mixes could be calculated.

To verify that the mix design could be produced in the lab to attain the same parameters as the contractor, the mix was produced according to the mix design provided by West Virginia Paving. After the mix design was verified, the new design binder content was found for the lower gyration level. There were no attempts to alternate the blend of aggregates for the new design, only the percent of the virgin binder was optimized.

Four binder contents were selected to find the design binder content to use with the new mix design of 80 gyrations. Two bulk specific gravity pills and one maximum specific gravity sample was made for each binder content. The design binder content was the binder content that resulted in four percent air voids. The design binder content for the $19 \mathrm{~mm}$ mix with 80 gyrations was 5.9 percent. The design binder content for the 37.5 mm mix with 65 gyrations was 4.1 percent. The design binder content for the $19 \mathrm{~mm}$ mix increased by 0.5 percent and the $37.5 \mathrm{~mm}$ mix increased by 0.4 percent.

\section{5: PREPARING APA SAMPLES}

Asphalt Pavement Analyzer (APA) samples were constructed in the SuperPave Gyratory Compactor (SGC) to a specified height of $75 \mathrm{~mm}$ and air voids between the ranges of $7.0 \pm 0.5$. The mass of material per APA sample was based on the maximum specific gravity, $\mathrm{G}_{\mathrm{mm}}$, of the sample with considerations with the internal and external voids. The SGC was programmed to compact the sample to the specified height of 75 $\mathrm{mm}$ rather than compact to a certain number of gyrations. The mass of material needed to prepare the APA samples were calculated using the following equations (Zaniewski and Patino, 2005):

$$
\begin{aligned}
& \mathrm{V}_{\mathrm{mm}} \approx 0.93 * \mathrm{~V}_{\mathrm{c}} \\
& \mathrm{V}_{\mathrm{c}}=\pi * \mathrm{R}^{2} * \mathrm{H} \\
& \mathrm{M}_{\mathrm{m}}=\mathrm{V}_{\mathrm{mm}} / \mathrm{G}_{\mathrm{mm}}
\end{aligned}
$$


Where,

$\mathrm{V}_{\mathrm{mm}}=$ Volume of the mix

$\mathrm{V}_{\mathrm{c}}=$ Gross volume of the sample

$\mathrm{R}=$ Radius of the mold

$\mathrm{H}=$ Height of the sample

$\mathrm{M}_{\mathrm{m}}=$ Mass of the mix

$\mathrm{G}_{\mathrm{mm}}=$ Theoretical maximum specific gravity of the mix

Three samples were constructed using the original design binder content and six samples were constructed for the new design binder content. Samples were weighed out according to the mix design for each sample so each mix would make three APA samples. Samples were weighed out in groups of three, so one mix would produce three APA samples from the same mix design with the same binder content. The samples were prepared in a randomized fashion and were cooled for one week before they were tested in the APA machine.

\section{6: TESTING APA SAMPLES}

APA samples were allowed to cool and tested one week after they were compacted in the SuperPave Gyratory Compactor. The APA sample layout is shown in Figure 3.1. Six samples were randomly placed and tested in the mold positions for each run. Each run contained the two types of mixes $(19 \mathrm{~mm}$ and $37.5 \mathrm{~mm})$ with three specimens per mix. The distribution of the mixes and their specimens in each run can be seen in Table 3.3. The specimens were conditioned for four hours at a temperature of $60^{\circ}$ C. They were all tested at a temperature of $60^{\circ} \mathrm{C}$, a hose pressure of $100 \pm 5 \mathrm{psi}$, a wheel load pressure of $100 \pm 5 \mathrm{psi}$, and a cycle count of 8000 . The APA machine used in the lab was the Asphalt Pavement Analyzer II manufactured by Pavement Technology, Inc., serial number 97-005.

Rut depths measurements were taken with a digimatic depth gauge. Two measurements were taken, one at the front of the specimen and one at the back of the specimen before each run and after each run. Measurements were to the nearest $0.1 \mathrm{~mm}$. 
Figure 3.1 APA Specimen Layouts

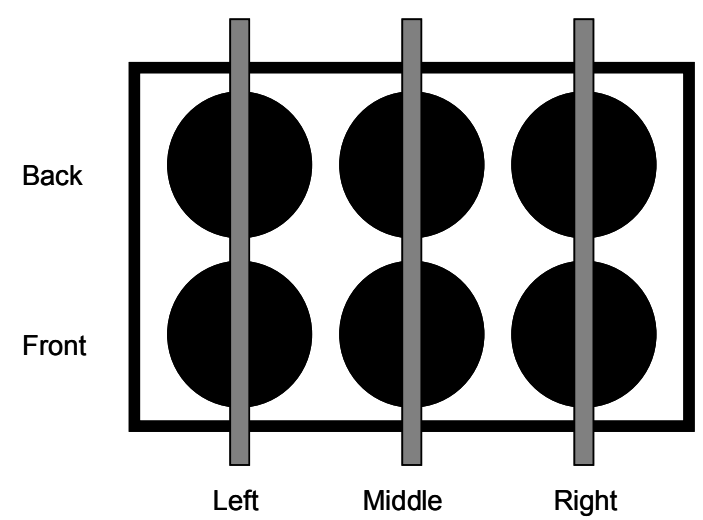

Table 3.2 Specimen Order and Location in APA

\begin{tabular}{|c|c|c|c|}
\hline $\begin{array}{l}\text { Run } \\
\text { Num. }\end{array}$ & $\begin{array}{l}\text { Specimen } \\
\text { Type }\end{array}$ & $\begin{array}{l}\text { Specimen } \\
\text { Label }\end{array}$ & $\begin{array}{l}\text { APA } \\
\text { Position }\end{array}$ \\
\hline \multirow[t]{6}{*}{1} & \multirow{3}{*}{$\begin{array}{l}19 \mathrm{~mm} \\
100 \text { Gyration }\end{array}$} & 10 & $\mathrm{RB}$ \\
\hline & & 11 & $\mathrm{MF}$ \\
\hline & & 12 & LB \\
\hline & \multirow{3}{*}{$\begin{array}{l}37.5 \mathrm{~mm} \\
80 \text { Gyration }\end{array}$} & 40 & $\mathrm{LF}$ \\
\hline & & 41 & MB \\
\hline & & 42 & $\mathrm{RF}$ \\
\hline \multirow[t]{6}{*}{2} & \multirow{3}{*}{$\begin{array}{l}19 \mathrm{~mm} \\
80 \text { Gyration }\end{array}$} & 20 & $\mathrm{LF}$ \\
\hline & & 21 & LB \\
\hline & & 22 & MB \\
\hline & \multirow{3}{*}{$\begin{array}{l}37.5 \mathrm{~mm} \\
80 \text { Gyration }\end{array}$} & 43 & $\mathrm{RB}$ \\
\hline & & 44 & MF \\
\hline & & 45 & RF \\
\hline \multirow[t]{6}{*}{3} & \multirow{3}{*}{$\begin{array}{l}19 \mathrm{~mm} \\
80 \text { Gyration }\end{array}$} & 23 & MB \\
\hline & & 24 & RF \\
\hline & & 25 & $\mathrm{RB}$ \\
\hline & \multirow{3}{*}{$\begin{array}{l}37.5 \mathrm{~mm} \\
100 \text { Gyration }\end{array}$} & 30 & LF \\
\hline & & 31 & LB \\
\hline & & 32 & $\mathrm{MF}$ \\
\hline
\end{tabular}


The rut depth was calculated by subtracting the initial measurement from the ending measurement. The rut depths from the front and back of the specimen were then averaged together.

\subsection{INDIRECT TENSILE STRENGTH TEST}

The IDT strength test was performed on the $\mathrm{G}_{\mathrm{mb}}$ samples originally compacted from each mix design to determine the air voids. The $\mathrm{G}_{\mathrm{mb}}$ samples were submerged in a water bath with a temperature of $140^{\circ} \mathrm{F}$ for an hour and 15 minutes and were tested in the Marshall Stabilometer with a modified loading rate of $50 \mathrm{~mm} / \mathrm{min}$. The load was applied parallel and along the vertical diametrical plane. The Marshall Stabilometer with a failure plane on a specimen is shown in Figure 3.2 (Zaniewski and Srinivasan, 2004). The force required for the samples to experience failure is plotted on a graph which is shown in Figure B.11 of Appendix B. From the graph, the ultimate force can be obtained which is used to determine the indirect tensile stress at failure by using the equation

$$
\sigma_{x}=\frac{2 P}{\pi d t}
$$

$\sigma_{\mathrm{x}}=$ Horizontal tensile stress at the center of the specimen, (psi)

$\mathrm{P}=$ Maximum load at failure, (lbs)

$\mathrm{d}=$ Diameter of sample, (inches)

$\mathrm{t}=$ Thickness of sample, (inches)

Figure 3.2 IDT Strength Test Setup with Marshall Stabilometer
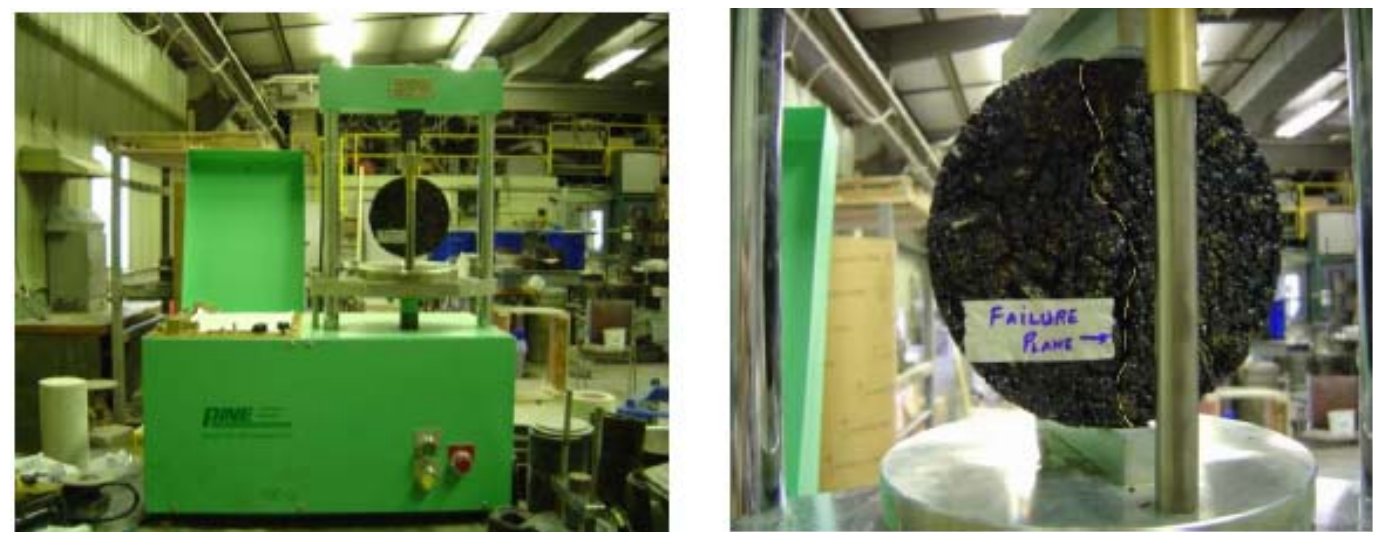

The strength of the mix was determined by averaging the indirect tensile stress for two samples designed with single binder content. 


\subsection{PARAFFIN COATED SAMPLES}

The paraffin coated samples were prepared to determine the bulk specific gravity $\left(\mathrm{G}_{\mathrm{mb}}\right)$ of $37.5 \mathrm{~mm}$ mixes. The proper measurement of $\mathrm{G}_{\mathrm{mb}}$ is very critical when using SuPerpave volumetrics. $\mathrm{G}_{\mathrm{mb}}$ establishes the basis for volumetric calculations used during the HMA mix design. Improper calculations and measurement of $\mathrm{G}_{\mathrm{mb}}$ could result in an air void target error, voids in the mineral aggregate error, etc. (Hall, et al, 2001).

Test was performed on the $37.5 \mathrm{~mm}$ bulk gravity specimens due to the aggregate structure and the orientation of the aggregates. With coarse-graded mixtures, the internal air voids can become interconnected which allows water to infiltrate into the sample rapidly during the saturation procedure. Figure 3.3 illustrates internal air voids of a coarse-graded mix compared with a fine-graded mix.

Figure 3.3 Interconnected air voids of Coarse and Fine Graded mixes

Coarse-Graded Mix

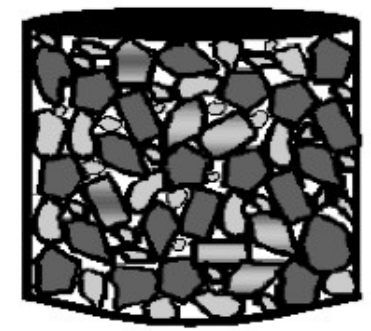

Fine-Graded Mix

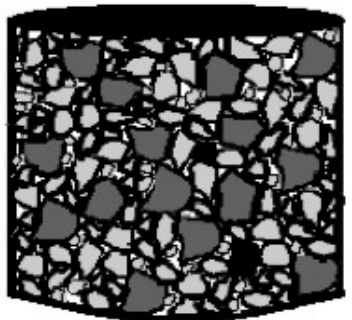

When using the AASHTO T-166 method to determine the $\mathrm{G}_{\mathrm{mb}}$, water tends to seep out quickly and this could result in false measurements. If the absorption of water by the specimen exceeds $2 \%$, paraffin wax should be used in accordance with AASHTO T 275-91 (2000). The $\mathrm{G}_{\mathrm{mb}}$ obtained from AASHTO T-16 and AASHTO T 275-91 methods are presented in Table 3.4.

Specimens to be tested were dried to constant mass and the weight was obtained. The specimens were then coated on all surfaces with melted paraffin sufficiently thick to seal all voids and the weight was recorded. After retaining the coated weight, the specimen was immersed in a water bath at $77 \pm 2^{\circ} \mathrm{F}$ and the submerged weight was determined. The bulk gravity $\left(\mathrm{G}_{\mathrm{mb}}\right)$ of the samples was calculated using the following equation: 
Table 3.3 AASHTO T-166 and AASHTO T 275-91 $\mathrm{G}_{\mathrm{mb}}$ for $37.5 \mathrm{~mm}$ mix

\begin{tabular}{|c|c|c|c|}
\hline \multirow{2}{*}{ Binder \% } & \multirow{2}{*}{$\begin{array}{c}\text { Sample } \\
\text { Number }\end{array}$} & \multicolumn{2}{|c|}{$\mathbf{G}_{\mathbf{m b}}$} \\
\cline { 3 - 4 } & & AASHTO T-166 & AASHTO T 275 - 91 \\
\hline \multirow{2}{*}{3.4} & 1 & 2.3893 & 2.3426 \\
\cline { 2 - 4 } & 2 & 2.3791 & 2.3673 \\
\hline \multirow{2}{*}{3.9} & 1 & 2.3924 & 2.3900 \\
\cline { 2 - 4 } & 2 & 2.3622 & 2.3550 \\
\hline \multirow{3}{*}{4.4} & 1 & 2.4271 & 2.4285 \\
\cline { 2 - 4 } & 2 & 2.4222 & 2.4156 \\
\hline \multirow{3}{*}{4.9} & 1 & 2.4419 & 2.4208 \\
\cline { 2 - 4 } & 2 & 2.4349 & 2.4234 \\
\hline
\end{tabular}

$$
G_{m b}=\frac{A}{D-E-\left[\frac{D-A}{F}\right]}
$$

Where

$\mathrm{A}=$ Mass of the dry specimen in air

$\mathrm{D}=$ Mass of the dry specimen plus paraffin coating in air

$\mathrm{E}=$ Mass of the dry specimen plus paraffin in water

$\mathrm{F}=$ Specific gravity of the paraffin at $77 \pm 2^{\circ} \mathrm{F}$ 


\section{CHAPTER 4: ANALYSIS AND RESULTS}

The results and analysis of the research are discussed and presented according to volumetric properties, APA testing results, and the results of the IDT strength test.

\subsection{VOLUMETRIC PROPERTIES}

Volumetric properties and criteria for West Virginia SuperPave mix design for 19 $\mathrm{mm}$ and $37.5 \mathrm{~mm}$ mixes can be seen in Table 4.1. The mixes were designed with the same aggregate blend gradations. The design binder content increased for the lower gyration mixes as expected. By lowering the compactive effort while maintaining the VTM at 4.0 resulted in an increased binder content of 0.5 percent for $19 \mathrm{~mm}$ mixes. Lowering the gyrations for $37.5 \mathrm{~mm}$ mixes resulted in an increased binder content of 0.4 percent. The VMA increased which met the criteria for minimum requirements and the VFA was in the acceptable range.

Table 4.1 Volumetric Properties and West Virginia Criteria

\begin{tabular}{|l|l|l|l|l|l|l|}
\hline NMAS & \multicolumn{2}{|l|}{$19 \mathrm{~mm}$} & $37.5 \mathrm{~mm}$ \\
\hline & Criteria & 100 Gyr. & 80 Gyr. & Criteria & 80 Gyr. & 65 Gyr. \\
\hline $\mathrm{Pb}, \%$ & - & 5.4 & 5.9 & - & 3.7 & 4.1 \\
\hline VTM, \% & 4.0 & 4.0 & 4.0 & 4.0 & 4.0 & 4.0 \\
\hline VMA, \% & 13.0 & 13.9 & 15.8 & 11.0 & 12.4 & 13.3 \\
\hline VFA, \% & $65-75$ & 71.0 & 72.0 & $65-75$ & 67 & 70.0 \\
\hline
\end{tabular}

\subsection{APA RESULTS}

The rut depth values for the Asphalt Pavement Analyzer test are shown in Table 4.2. This shows the three values compacted at the original mix design and six values for mixes compacted with the compaction levels recommended by Prowell and Brown (2007). For the $19 \mathrm{~mm}$ mix, the average rut depth with 100 gyrations was $5.7 \mathrm{~mm}$ and 
with 80 gyrations was $9.3 \mathrm{~mm}$. For the $37.5 \mathrm{~mm}$ mix, the average rut depth with 100 gyrations was $5.3 \mathrm{~mm}$ and with 65 gyrations was $7.1 \mathrm{~mm}$. For both mix designs, the mixes with higher asphalt content showed increased rutting potential.

Table 4.2 Rut depths (mm) for each specimen

\begin{tabular}{|c|c|c|c|c|}
\hline Replication & $\begin{array}{c}\mathbf{1 9} \mathbf{~} \mathbf{1 0 0} \\
\mathbf{1 0 0} \\
\text { Gyrations } \\
\text { (Original) }\end{array}$ & $\begin{array}{c}\mathbf{1 9} \mathbf{~} \mathbf{8 m} \\
\mathbf{8 0} \\
\text { Gyrations } \\
\text { (Revised) }\end{array}$ & $\begin{array}{c}\mathbf{3 7 . 5} \mathbf{~ m m} \\
\mathbf{8 0} \\
\text { Gyrations } \\
\text { (Original) }\end{array}$ & $\begin{array}{c}\mathbf{3 7 . 5} \mathbf{~ m m} \\
\mathbf{6 5} \\
\text { Gyrations } \\
\text { (Revised) }\end{array}$ \\
\hline 1 & 6.1 & 6.0 & 5.3 & 8.2 \\
\hline 2 & 4.3 & 8.0 & 6.5 & 5.4 \\
\hline 3 & 6.8 & 10.0 & 4.0 & 7.5 \\
\hline 4 & & 13.4 & & 5.0 \\
\hline 5 & & 12.6 & & 7.8 \\
\hline 6 & & 6.9 & & 8.8 \\
\hline Average & $\mathbf{5 . 7}$ & $\mathbf{9 . 5}$ & $\mathbf{5 . 3}$ & $\mathbf{7 . 1}$ \\
\hline
\end{tabular}

Research conducted by the Georgia Department of Transportation (GDOT) established a rut depth criterion of $5 \mathrm{~mm}$ to be good mixes (Collins, et al, 1995). Since the test was conducted at a temperature of $50^{\circ} \mathrm{C}$, the temperature effect model developed by Shami, et al (1997) was used to adjust the temperature to $60{ }^{\circ} \mathrm{C}$ to better correlate rut depth measured in the APA. This increased the limit from $5 \mathrm{~mm}$ to $8 \mathrm{~mm}$. The GDOT criteria had an important effect on WVDOH since the lab data indicated the SuperPave mixes constructed in the state meet the criteria and have good field performance (Zaniewski and Patino, 2005). 


\subsubsection{ANOVA for Position in APA}

Prior to investigating if the mix type or compaction effort factors were insignificant a check was performed. Previous work with the APA produced mixed results with respect to the issue of the effect of sample position in the APA. Patino (2005) found no effect; Hornbeck (2008) found samples in the right front and back, and the left front position had different means than the other positions. Patino's data set was much larger than Hornbeck's.

The effect of position on rut depth was evaluated with an Analysis of Variance. The $p$ value from the ANOVA indicates the probability of getting a mean difference between the groups as high. Low $p$ values indicate a low probability that a difference between groups occurred by chance. A p value of 0.05 was used in this research to identify when to reject the null hypothesis of equal means. All statistical analysis was performed using the Statistical Analysis Software (SAS).

Position was used as the factor with six levels. The three samples tested in each of the positions were treated as replicate samples, producing the data set shown in Table 4.3. The results of the ANOVA for sample position are shown in Table 4.4.

The ANOVA output is in Appendix B. The null hypothesis of equal means, at $\alpha=$ 0.05 , is rejected for the contrasts between the left and right channels, the middle and right channels, and for the combined left and middle versus the right channel. There is insufficient evidence to reject the null hypothesis for the contrast of front to back positions.

The rejection of the null hypothesis for several positions was investigated with the Duncan multiple range test. The result is shown in Figure 4.1. The positions are defined in Table 4.3. Figure 4.1 identifies that all positions other than position 3, middle front, "share a common mean." Given the limited size of the data set and the variability of the APA test the fact that not all positions shared a common mean can be accepted as an artifact of the experiment. However, in this case the position effect needs to be addressed to proceed with the investigation with the primary experimental factors: mix type and compaction effort. 
Table 4.3 Sample Position in APA

\begin{tabular}{|c|c|c|c|c|c|c|}
\hline $\begin{array}{l}\text { Factor } \\
\text { level }\end{array}$ & Replicati & & 1 & 2 & 3 & Average \\
\hline \multirow{3}{*}{1} & \multicolumn{2}{|c|}{ Mix type } & 37.5 & 19 & 37.5 & \\
\hline & \multicolumn{2}{|c|}{ Compaction } & Revised & Revised & Original & \\
\hline & Position & LF & 8.2 & 8.0 & 5.3 & 7.17 \\
\hline \multirow{3}{*}{2} & \multicolumn{2}{|c|}{ Mix type } & 19 & 19 & 37.5 & \\
\hline & \multicolumn{2}{|c|}{ Compaction } & Original & Revised & Original & \\
\hline & Position & LB & 6.1 & 6.0 & 6.5 & 6.20 \\
\hline \multirow{3}{*}{3} & \multicolumn{2}{|c|}{ Mix type } & 19 & 37.5 & 37.5 & \\
\hline & \multicolumn{2}{|c|}{ Compaction } & Original & Revised & Original & \\
\hline & Position & MF & 4.3 & 5.0 & 4.0 & 4.43 \\
\hline \multirow{3}{*}{4} & \multicolumn{2}{|c|}{ Mix type } & 37.5 & 19 & 19 & \\
\hline & \multicolumn{2}{|c|}{ Compaction } & Revised & Revised & Revised & \\
\hline & Position & MB & 5.4 & 10.0 & 6.9 & 7.43 \\
\hline \multirow{3}{*}{5} & \multicolumn{2}{|c|}{ Mix type } & 37.5 & 37.5 & 19 & \\
\hline & \multicolumn{2}{|c|}{ Compaction } & Revised & Revised & Revised & \\
\hline & Position & $\mathbf{R F}$ & 7.5 & 8.8 & 12.6 & 9.63 \\
\hline \multirow{3}{*}{6} & \multicolumn{2}{|c|}{ Mix type } & 19 & 37.5 & 19 & \\
\hline & \multicolumn{2}{|c|}{ Compaction } & Original & Revised & Revised & \\
\hline & Position & RB & 6.8 & 7.8 & 13.4 & 9.33 \\
\hline
\end{tabular}

Table 4.4 ANOVA Results for Sample Position in APA

\begin{tabular}{|c|c|c|c|c|}
\hline $\begin{array}{c}\text { Source of } \\
\text { Variance }\end{array}$ & $\begin{array}{c}\text { Sum of } \\
\text { Squares }\end{array}$ & $\begin{array}{c}\text { Degrees of } \\
\text { Freedom }\end{array}$ & $\begin{array}{c}\text { Mean } \\
\text { Square }\end{array}$ & P-value \\
\hline \hline Treatments & 57.0 & 5 & 11.4 & 0.0961 \\
\hline \hline $\mathrm{F}=\mathrm{B}$ & 1.5 & 1 & 1.5 & 0.5818 \\
\hline $\mathrm{LF}=\mathrm{LB}$ & 1.4 & 1 & 1.4 & 0.5946 \\
\hline $\mathrm{L}=\mathrm{M}$ & 1.7 & 1 & 1.7 & 0.5597 \\
\hline $\mathrm{L}=\mathrm{R}$ & 23.5 & 1 & 23.5 & 0.0448 \\
\hline $\mathrm{M}=\mathrm{R}$ & 37.8 & 1 & 37.8 & 0.0149 \\
\hline $\mathrm{L}+\mathrm{M}=\mathrm{R}$ & 40.3 & 1 & 40.3 & 0.0125 \\
\hline Error & 56.3 & 12 & 5.0 & 0.1502 \\
\hline Total & 113.0 & 17 & & \\
\hline
\end{tabular}


Figure 4.1 Duncan Multiple Range Test for APA Positions

RUT DEPTH VERSUS LOCATION IN APA

13,2009

15:05 Friday, November

The GLM Procedure

Duncan's Multiple Range Test for DEPTH

NOTE: This test controls the Type I comparisonwise error rate, not the experimentwise error rate.

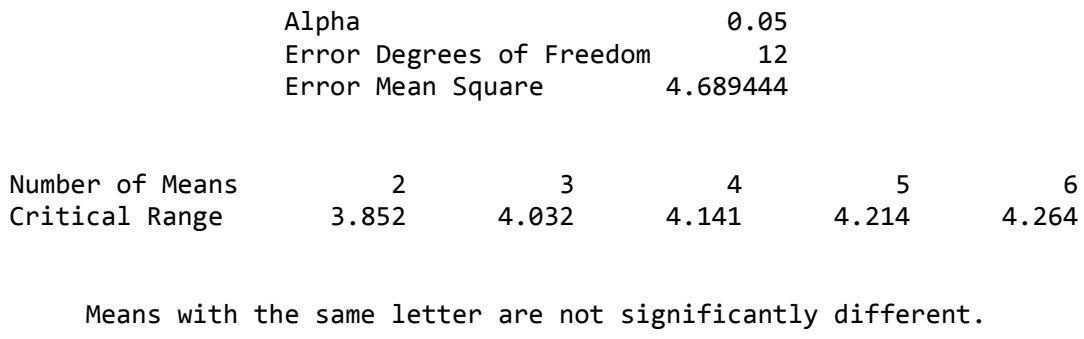

Duncan Grouping

Mean N POSITION

$9.633 \quad 3 \quad 5$

$9.333 \quad 3 \quad 6$

$\begin{array}{lll}7.433 & 3 & 4\end{array}$

$\begin{array}{lll}7.167 & 3 & 1\end{array}$

$6.200 \quad 3 \quad 2$

$4.433 \quad 3 \quad 3$ 
The data were reorganized into the format shown in Table 4.2.3. The samples which were tested in position 3 were:

$19 \mathrm{~mm}$, original

37.5 , original

37.5 , revised

There was no assignable cause identified to support elimination of these data, so subsequent analyses were performed using both the original data set and a modified data set. The modification to the data set was to replace the observations from the middle front position with the average from the replicates prepared with the same mix type and compaction effort. The modified data set is shown in Table 4.5.

Table 4.5 Modified Data Set for Position in APA

\begin{tabular}{|c|c|c|c|c|c|c|}
\hline $\begin{array}{l}\text { Factor } \\
\text { level }\end{array}$ & \multicolumn{2}{|c|}{ Replication } & 1 & 2 & 3 & Average \\
\hline \multirow{3}{*}{1} & \multicolumn{2}{|c|}{ Mix type } & 37.5 & 19 & 37.5 & \\
\hline & \multicolumn{2}{|c|}{ Compaction } & Revised & Revised & Original & \\
\hline & Position & $\mathbf{L F}$ & 8.2 & 8.0 & 5.3 & 7.17 \\
\hline \multirow{3}{*}{2} & \multicolumn{2}{|c|}{ Mix type } & 19 & 19 & 37.5 & \\
\hline & \multicolumn{2}{|c|}{ Compaction } & Original & Revised & Original & \\
\hline & Position & LB & 6.1 & 6.0 & 6.5 & 6.20 \\
\hline \multirow{3}{*}{3} & \multicolumn{2}{|c|}{ Mix type } & 19 & 37.5 & 37.5 & \\
\hline & \multicolumn{2}{|c|}{ Compaction } & Original & Revised & Original & \\
\hline & Position & MF & 4.36 .4 & 5.05 .9 & 4.08 .3 & 4.436 .86 \\
\hline \multirow{3}{*}{4} & \multicolumn{2}{|c|}{ Mix type } & 37.5 & 19 & 19 & \\
\hline & \multicolumn{2}{|c|}{ Compaction } & Revised & Revised & Revised & \\
\hline & Position & MB & 5.4 & 10.0 & 6.9 & 7.43 \\
\hline \multirow{3}{*}{5} & \multicolumn{2}{|c|}{ Mix type } & 37.5 & 37.5 & 19 & \\
\hline & \multicolumn{2}{|c|}{ Compaction } & Revised & Revised & Revised & \\
\hline & Position & RF & 7.5 & 8.8 & 12.6 & 9.63 \\
\hline \multirow{3}{*}{6} & \multicolumn{2}{|c|}{ Mix type } & 19 & 37.5 & 19 & \\
\hline & \multicolumn{2}{|c|}{ Compaction } & Original & Revised & Revised & \\
\hline & Position & RB & 6.8 & 7.8 & 13.4 & 9.33 \\
\hline
\end{tabular}


The ANOVA to test for position was run with the modified data set with the results shown in Table 4.6. The null hypothesis of equal means was rejected for the contrast of the left versus right channels. However, the Duncan multiple range test, Figure 4.2, suggest common means for all positions.

Table 4.6 ANOVA for test Position with modified data set

\begin{tabular}{|c|c|c|c|c|}
\hline $\begin{array}{c}\text { Source of } \\
\text { Variance }\end{array}$ & $\begin{array}{c}\text { Sum of } \\
\text { Squares }\end{array}$ & $\begin{array}{c}\text { Degrees of } \\
\text { Freedom }\end{array}$ & $\begin{array}{c}\text { Mean } \\
\text { Square }\end{array}$ & P-value \\
\hline \hline Treatments & 29.0 & 5 & 5.8 & 0.3737 \\
\hline \hline F = B & 0.2 & 1 & 0.2 & 0.8270 \\
\hline LF = LB & 1.4 & 1 & 1.4 & 0.6030 \\
\hline L = M & 0.6 & 1 & 0.6 & 0.7217 \\
\hline L = R & 23.5 & 1 & 23.5 & 0.0492 \\
\hline $\mathrm{M}=\mathrm{R}$ & 16.3 & 1 & 16.3 & 0.0932 \\
\hline $\mathrm{L}+\mathrm{M}=\mathrm{R}$ & 26.3 & 1 & 26.3 & 0.0391 \\
\hline Error & 58.9 & 12 & 4.9 & \\
\hline Total & 17 & 87.9 & & \\
\hline
\end{tabular}


Figure 4.2 Modified Duncan Multiple Range Test for APA Positions RUT DEPTH VERSUS LOCATION IN APA MODIFIED MF

November 13, 2009

$$
15: 41 \text { Friday }
$$

The GLM Procedure

Duncan's Multiple Range Test for DEPTH

NOTE: This test controls the Type I comparisonwise error rate, not the experimentwise error rate.

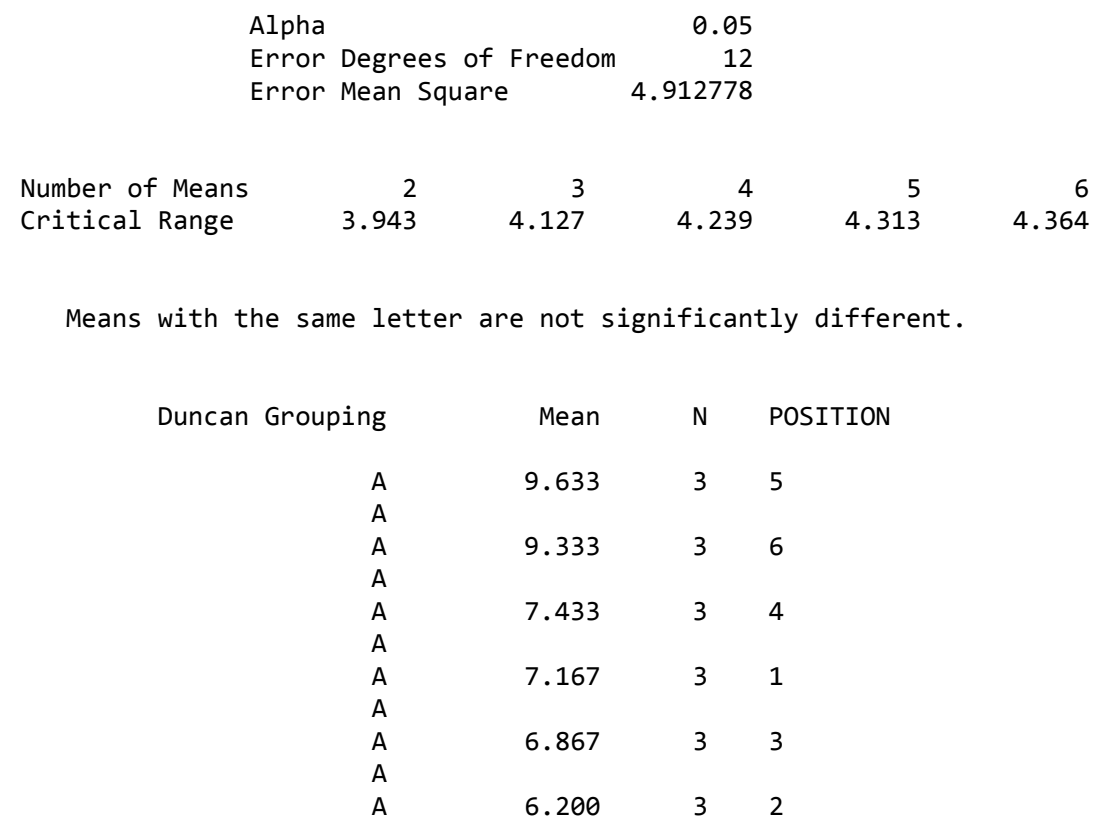

\subsubsection{ANOVA for Experimental Factors}

The laboratory test on rutting was evaluated with the analysis of variance (ANOVA) method using the General Linear Model (GLM) with two factors being the mix design type (19 $\mathrm{mm}$ and $37.5 \mathrm{~mm})$ and the compaction effort (100 and 80 gyrations for $19 \mathrm{~mm}$ mix and 100 and 65 gyrations for $37.5 \mathrm{~mm} \mathrm{mix}$ ). The factor levels are presented in Table 4.7. The ANOVA table for the original data set is shown in Table 4.8. The null hypothesis was that the original and redesigned mixes have the equal mean rutting potential. 
Table 4.7 Factor Levels for Rut Depth Analysis

\begin{tabular}{|l|c|c|}
\hline \multicolumn{1}{|c|}{ Mix Type } & \multicolumn{2}{|c|}{ Gyrations } \\
\hline \hline & $100=$ M1 & $80=\mathbf{M} 2$ \\
\hline $\mathbf{1 9} \mathbf{~ m m}$ & $100=$ M3 & $65=\mathbf{M} 4$ \\
\hline
\end{tabular}

The $\mathrm{p}$ value in the analysis for the means between M1 and M2 was 0.0273 which is less than 0.05 , meaning the null hypothesis can be rejected for the $19 \mathrm{~mm}$ mixes, with 100 and 80 gyrations. The $\mathrm{p}$ value for the means for $37.5 \mathrm{~mm}$ mixes, $\mathrm{M} 3=\mathrm{M} 4$ was 0.2442 . Since this value is larger than 0.05 , it indicated that there is insufficient evidence to reject the null hypothesis. The equal means for all factor levels was 0.1937 meaning there is no difference between means for the factors.

Table 4.8 ANOVA for Experimental Factors, original data set

\begin{tabular}{|c|c|c|c|c|}
\hline $\begin{array}{c}\text { Source of } \\
\text { Variance }\end{array}$ & $\begin{array}{c}\text { Sum of } \\
\text { Squares }\end{array}$ & $\begin{array}{c}\text { Degrees of } \\
\text { Freedom }\end{array}$ & $\begin{array}{c}\text { Mean } \\
\text { Square }\end{array}$ & P-value \\
\hline \hline Treatments & 48.4 & 3 & 16.1 & 0.0445 \\
\hline $\mathrm{M} 1=\mathrm{M} 2$ & 28.1 & 1 & 28.1 & 0.0273 \\
\hline $\mathrm{M} 3=\mathrm{M} 4$ & 6.8 & 1 & 6.8 & 0.2442 \\
\hline $\mathrm{M} 1+\mathrm{M} 2=\mathrm{M} 3+\mathrm{M} 4$ & 8.0 & 1 & 8.0 & 0.2091 \\
\hline Error & 64.8 & 14 & 64.8 & \\
\hline Total & 113.3 & 17 & & \\
\hline
\end{tabular}

The contrast between the mixes produced a p value of 0.2091 with the conclusion that there is insufficient information to reject the null hypothesis of equal means. The failure to reject the null hypothesis for the mix type comparison was unexpected as the conventional wisdom is increasing aggregate size should reduce rutting potential. Examining the means in Table 4.2 shows the mean rutting potential for the $19 \mathrm{~mm}$ 
revised mix is much larger than the other means. None of the samples for the $19 \mathrm{~mm}$ revised mix, were tested in the middle front position.

The ANOVA was rerun with the modified data set producing Table 4.9. With the modified data from Table 4.5, the contrast for the mix type produced a $\mathrm{p}$ value of 0.2532 resulting in a conclusion that there is insufficient information to reject the null hypothesis. This indicates that even with the modified data set, there are no significant differences between the middle front position and the other positions.

Table 4.9 ANOVA for Experimental Factors with modified data set

\begin{tabular}{|c|c|c|c|c|}
\hline $\begin{array}{c}\text { Source of } \\
\text { Variance }\end{array}$ & $\begin{array}{c}\text { Sum of } \\
\text { Squares }\end{array}$ & $\begin{array}{c}\text { Degrees of } \\
\text { Freedom }\end{array}$ & $\begin{array}{c}\text { Mean } \\
\text { Square }\end{array}$ & P-value \\
\hline \hline Treatments & 33.5 & 3 & 11.1 & 0.0738 \\
\hline $\mathrm{M} 1=\mathrm{M} 2$ & 18.6 & 1 & 18.6 & 0.0462 \\
\hline $\mathrm{M} 3=\mathrm{M} 4$ & 6.2 & 1 & 6.2 & 0.2259 \\
\hline $\mathrm{M} 1+\mathrm{M} 2=\mathrm{M} 3+\mathrm{M} 4$ & 5.2 & 1 & 5.2 & 0.2532 \\
\hline Error & 54.4 & 14 & 3.8 & \\
\hline Total & 87.9 & 17 & & \\
\hline
\end{tabular}

\subsection{INDIRECT TENSILE TEST (IDT) RESULTS}

The IDT test was performed on the bulk specific gravity mix $\left(\mathrm{G}_{\mathrm{mb}}\right)$ specimens that were used to determine the air voids of the mixes. The IDT test results are shown in Table 4.10. Strength versus binder results were graphed and a polynomial regression model was fit to determine IDT versus binder content for mixes designed using the lowered compaction effort recommended by NCHRP 9-9(1) (Prowell and Brown, 2007). Figure 4.3 and 4.4 shows the graph of IDT strength versus binder percent for $19 \mathrm{~mm}$ and $37.5 \mathrm{~mm}$ mixes. 
Table 4.10 IDT Strength Test

\begin{tabular}{|c|c|c|c|c|c|c|c|}
\hline $\begin{array}{l}\text { Percent } \\
\text { Binder }\end{array}$ & Mix Type & Label & Gyrations & $\begin{array}{l}\text { Strength } \\
\text { (Ibs) }\end{array}$ & Average & Thickness & $\begin{array}{c}\text { Tensile } \\
\text { stress }(\sigma x) \\
\text { psi }\end{array}$ \\
\hline \multirow{2}{*}{5.9} & $19 \mathrm{~mm}$ & B1 & 80 & 500 & \multirow{2}{*}{560} & \multirow{2}{*}{$\begin{array}{l}4.45 \\
4.39 \\
\end{array}$} & 12.12 \\
\hline & $19 \mathrm{~mm}$ & B2 & 80 & 620 & & & 15.24 \\
\hline \multirow{2}{*}{6.4} & $19 \mathrm{~mm}$ & B3 & 80 & 670 & \multirow{2}{*}{679} & 4.33 & 16.70 \\
\hline & $19 \mathrm{~mm}$ & B4 & 80 & 688 & & 4.40 & 16.87 \\
\hline \multirow{2}{*}{5.4} & $19 \mathrm{~mm}$ & B5 & 80 & 618 & \multirow{2}{*}{616.5} & 4.45 & 14.98 \\
\hline & $19 \mathrm{~mm}$ & $\mathrm{~B} 6$ & 80 & 615 & & 4.49 & 14.78 \\
\hline \multirow{2}{*}{6.9} & $19 \mathrm{~mm}$ & B7 & 80 & 650 & \multirow{2}{*}{677.5} & 4.29 & 16.35 \\
\hline & $19 \mathrm{~mm}$ & B8 & 80 & 705 & & 4.28 & 17.77 \\
\hline \multirow{2}{*}{5.4} & $19 \mathrm{~mm}$ & $A 5^{*}$ & 100 & 550 & \multirow{2}{*}{550} & 4.41 & 13.46 \\
\hline & $19 \mathrm{~mm}$ & $\mathrm{~A} 6^{*}$ & 100 & 550 & & 4.43 & 13.40 \\
\hline \multirow{2}{*}{4.4} & $37.5 \mathrm{~mm}$ & $\mathrm{~A} 1$ & 65 & 780 & \multirow{2}{*}{827.5} & 4.34 & 19.39 \\
\hline & $37.5 \mathrm{~mm}$ & A2 & 65 & 875 & & 4.30 & 21.96 \\
\hline \multirow{2}{*}{3.9} & $37.5 \mathrm{~mm}$ & A3 & 65 & 695 & \multirow{2}{*}{545.5} & 4.46 & 16.81 \\
\hline & $37.5 \mathrm{~mm}$ & A4 & 65 & 396 & & 4.58 & 9.33 \\
\hline \multirow{2}{*}{3.4} & $37.5 \mathrm{~mm}$ & A5 & 65 & 495 & \multirow{2}{*}{610} & 4.46 & 11.98 \\
\hline & $37.5 \mathrm{~mm}$ & A6 & 65 & 725 & & 4.45 & 17.58 \\
\hline \multirow{2}{*}{4.9} & $37.5 \mathrm{~mm}$ & A7 & 65 & 790 & \multirow{2}{*}{727.5} & 4.34 & 19.64 \\
\hline & $37.5 \mathrm{~mm}$ & A8 & 65 & 665 & & 4.29 & 16.73 \\
\hline \multirow{2}{*}{3.7} & $37.5 \mathrm{~mm}$ & $\mathrm{~A} 3^{*}$ & 80 & 810 & \multirow{2}{*}{977.5} & 4.30 & 20.33 \\
\hline & $37.5 \mathrm{~mm}$ & $\mathrm{~A} 4^{*}$ & 80 & 1145 & & 4.28 & 28.87 \\
\hline
\end{tabular}

The IDT strength for the $19 \mathrm{~mm}$ mixes can be determined directly from Table 4.10 or Figure 4.3. The two specimens generated from the original $19 \mathrm{~mm}$ mix design with 100 gyrations were averaged to represent the IDT strength, thus resulting in strength of 13.4 psi. The IDT strength for $19 \mathrm{~mm}$ mixes with 80 gyrations was 13.7 psi. This value was used for IDT strength due to the fact that the $19 \mathrm{~mm}$ mixes constructed with 80 gyrations resulted in a design binder content of 5.9 percent at 4 percent air voids.

The IDT strength for $37.5 \mathrm{~mm}$ mixes constructed with 100 gyrations could also be determined directly from Table 4.10 or Figure 4.4. The two specimens generated from the 
mix design were averaged to represent the IDT strength of 24.6 psi. For 37.5 mixes with a compactive effort of 80 gyrations, the strength can be determined by using the design binder content (4.1 percent) from Figure 4.4.

Figure 4.3 IDT Strength vs Binder Percent for $19 \mathrm{~mm}$ Mixes

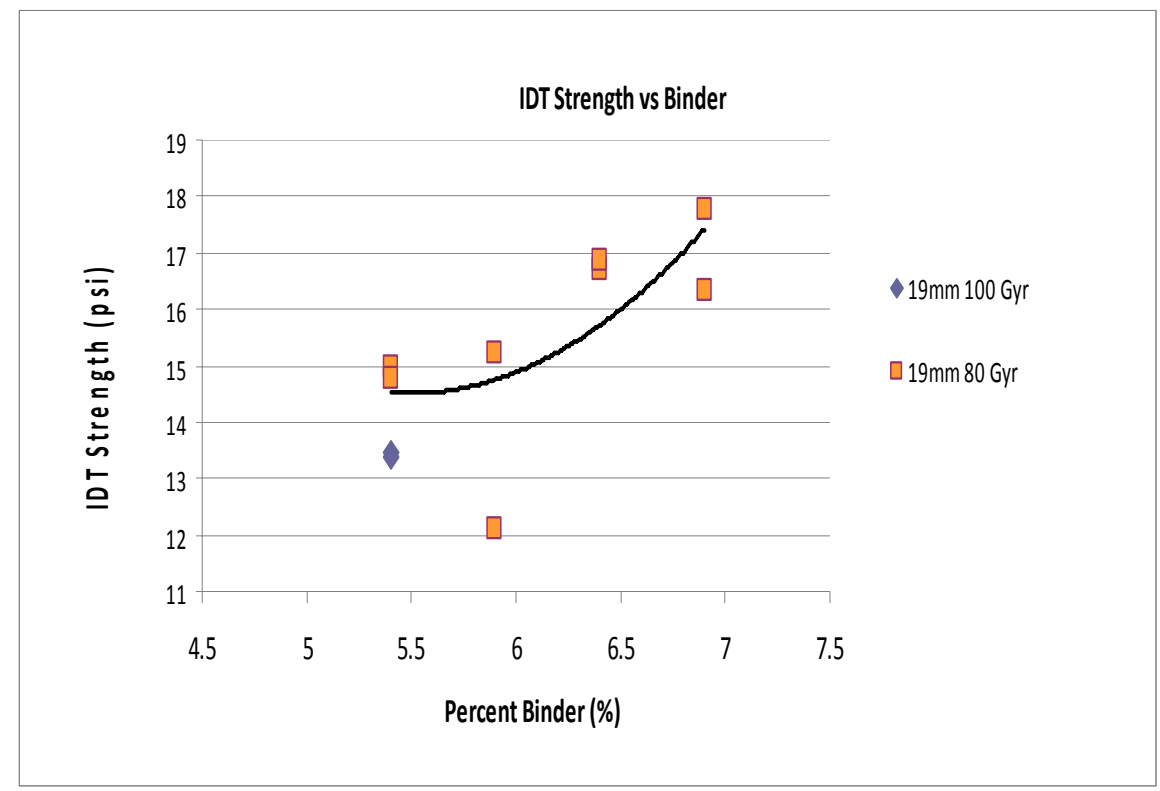

Figure 4.4 IDT Strength vs Binder Percent for $37.5 \mathrm{~mm}$ Mixes

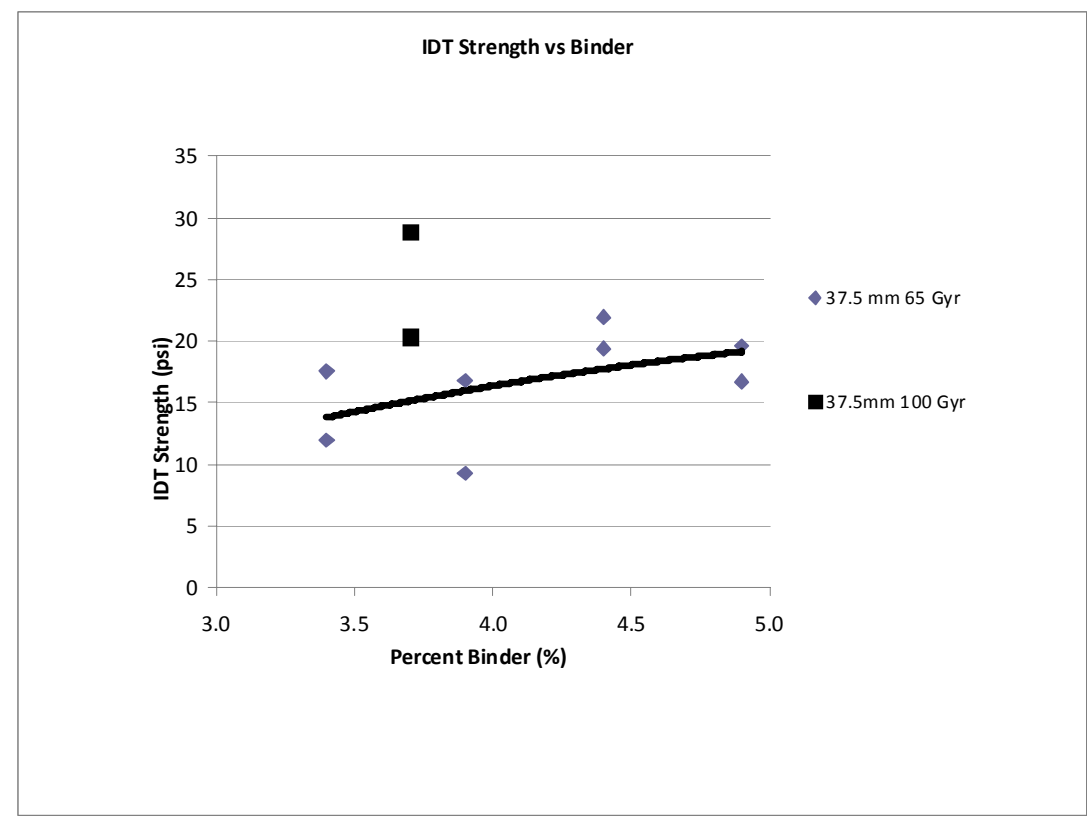


IDT strengths for $19 \mathrm{~mm}$ and $37.5 \mathrm{~mm}$ NMAS and the corresponding binder content is presented in Table 4.11 .

Table 4.11 IDT Strength for Design Binder Contents

\begin{tabular}{|c|c|c|c|}
\hline NMAS & Gyrations & Binder Content (\%) & IDT Strength (psi) \\
\hline \hline \multirow{2}{*}{$\mathbf{1 9} \mathbf{~ m m}$} & 100 & 5.4 & 13.4 \\
\cline { 2 - 4 } & 80 & 5.9 & 13.7 \\
\hline \multirow{2}{*}{$\mathbf{3 7 . 5} \mathbf{~ m m}$} & 80 & 3.7 & 24.6 \\
\cline { 2 - 4 } & 65 & 4.1 & 16.8 \\
\hline
\end{tabular}

For the $19 \mathrm{~mm}$ mixes, the indirect tensile strength increased as the compaction level decreased with respect to an increase in binder content. This could be a result of cohesion and adhesion of the aggregates due to an increase in binder content with respect to stiffness. IDT strength for $37.5 \mathrm{~mm}$ mixes decreased significantly when the binder content was increased and the compaction effort decreased. This is a direct result of the larger aggregates being directly on top of each other during compaction in the SGC.

\subsubsection{Comparing IDT with APA}

The IDT test results and the APA rut depths were graphed to determine if the strength of the mixes increased or decreased with respect to rutting potential. Figure 4.5 and Figure 4.6 shows the IDT strength and APA rut depth for $19 \mathrm{~mm}$ mix and $37.5 \mathrm{~mm}$ mixes, respectively. For $19 \mathrm{~mm}$ mixes, IDT strength increases as rutting potential increases and for the 37.5 mixes, the IDT strength decreases as the rutting potential increases. 
Figure 4.5 IDT Strength vs APA Rut Depth for $19 \mathrm{~mm}$ Mix

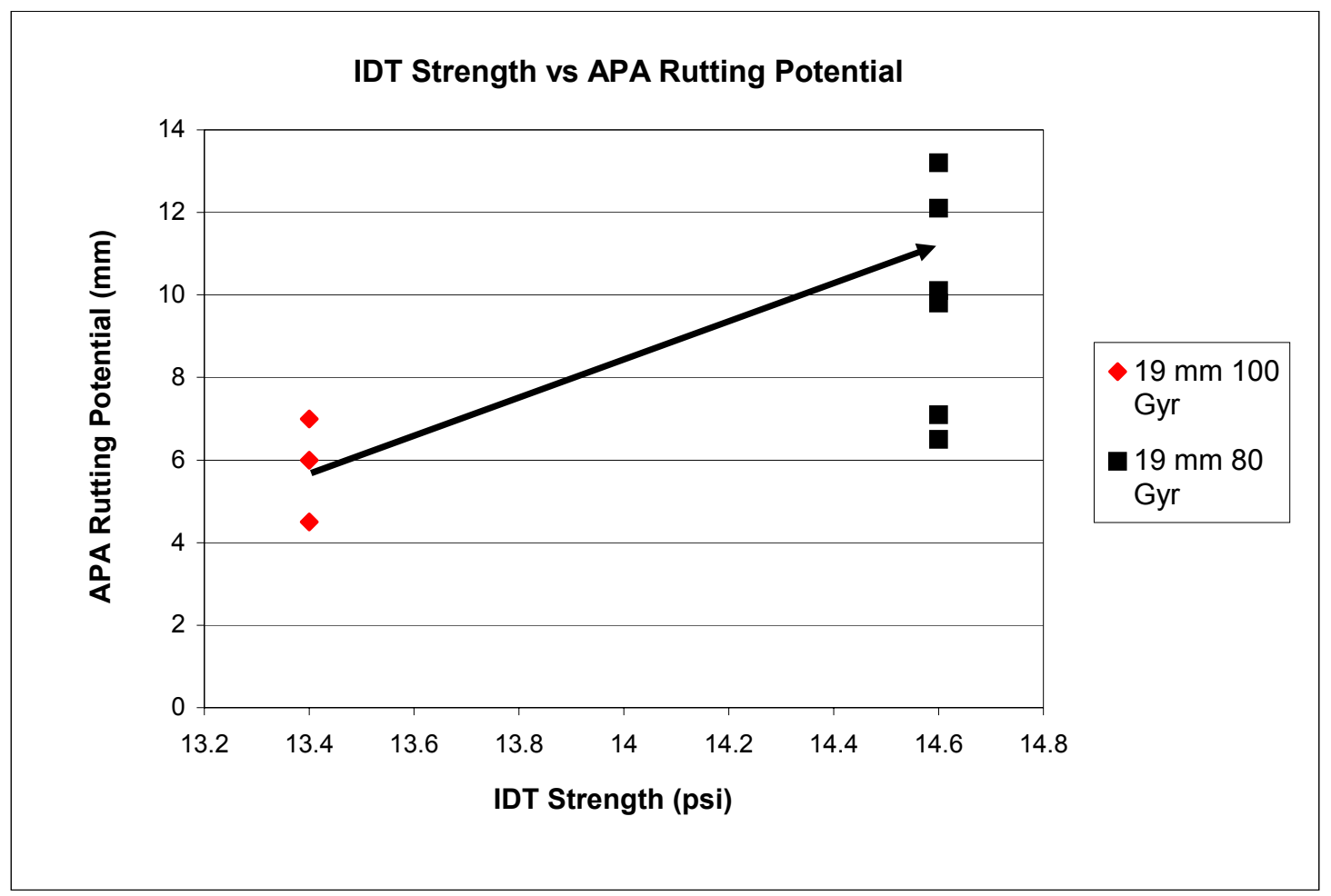

Figure 4.6 IDT Strength vs APA Rut Depth for $37.5 \mathrm{~mm}$ Mix

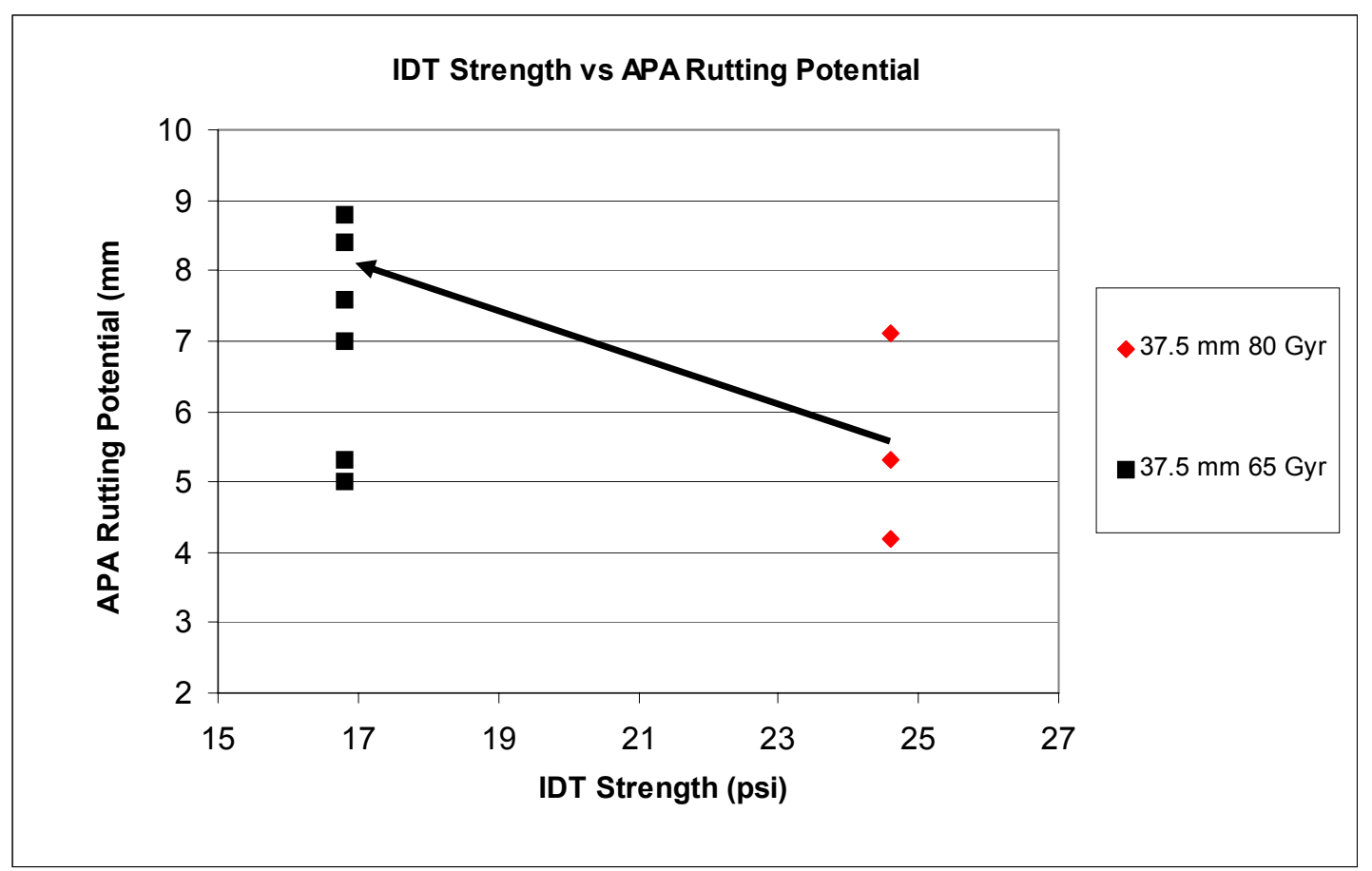




\section{CHAPTER 5: CONCLUSIONS AND RECOMMENDATIONS}

\subsection{CONCLUSIONS}

This research was performed to evaluate the affect lowering compaction effort, as recommended by the NCHRP 9-9(1) (Prowell and Brown, 2007), would have on SuperPave base course mixes used by the West Virginia Department of Highways (WVDOH). The two base course mixes currently used by the WVDOH are $19 \mathrm{~mm}$ NMAS with a design binder content of 5.4 percent and $37.5 \mathrm{~mm}$ NMAS with a design binder content of 3.7 percent. These mixes are designed with a PG 70-22 binder for a traffic load of 3 to 30 million ESALs. Both mixes were originally designed using a compaction effort of 100 gyrations under the current WVDOH practices.

The compaction effort was decreased from a 100 to 80 gyrations for the $19 \mathrm{~mm}$ mix and the $37.5 \mathrm{~mm}$ mix, was decreased from 100 to 65 gyrations as recommended by Prowell and Brown, (2007) and new design binder content was determined. The new design binder content increased for the lower gyration mixes as expected. The $19 \mathrm{~mm}$ mix resulted in an increased binder content of 0.5 percent and the $37.5 \mathrm{~mm}$ mix increased in a binder content of 0.4 percent. The original and new design binder contents were used to produce APA samples to evaluate the influence of increasing binder content on rutting potential. The Statistical Analysis Software was used along with a 95 percent confidence level to test the null hypothesis of equal means across the mix types and binder contents. The ANOVA test indicates that the means for the high and low gyrations for the $19 \mathrm{~mm}$ mix resulted in a p-value of 0.0273 which concludes that null hypothesis can be rejected for the $19 \mathrm{~mm}$ mixes. The means for the high and low gyrations for the $37.5 \mathrm{~mm}$ mixes resulted in a p-value of 0.2442 which concludes that

there was insufficient evidence to reject the null hypothesis. Based on the findings from the ANOVA table, $19 \mathrm{~mm}$ mixes constructed with a lower compaction effort are not rut susceptible and 37.5 mixes constructed with a lower compaction effort had insufficient evidence to reject that it is rut susceptible.

The Indirect Tensile strength was also evaluated using the $\mathrm{G}_{\mathrm{mb}}$ samples. With increased binder content, the $19 \mathrm{~mm}$ mixes demonstrated that, IDT strength increases as 
rutting potential increases and for the 37.5 mixes, the IDT strength decreases as the rutting potential increases.

\subsection{RECOMMENDATIONS}

Determining the appropriate design binder content for asphalt concrete is crucial to long term pavement performance. The history of SuperPave mixes in WV has demonstrated the mixes are rut resistant. There has not been a long term evaluation of SuperPave performance. Given the generally good performance of SuperPave mixes, any change to the mix design methodology must be made with care.

The evaluation of the two mix types used in this study did demonstrate that selecting the design binder content from samples prepared with the same aggregate blend is increased when the compaction effort is reduced. This is in accordance with the recommendations of Prowell and Brown, (2007).

However, the data set used in this research was limited to allow interpolation of the results to the general population of asphalt concrete mixes used in the state. The mixes evaluated contained both slag and recycled asphalt pavement. Mix designs with these materials may or may not be representative of mixes prepared with 100 percent crushed limestone.

Only three samples per APA and two samples per IDT observation were used in this research. In light of the inherent variability of mix preparation and testing with these devices, research should be performed to evaluate the required complete size needed to produce more robust results.

The rutting potential of the mixes was evaluated. The statistical analysis indicate the $19 \mathrm{~mm}$ base with higher binder content has more rutting potential than the samples prepared using the current methodology. The null hypothesis of equal means was not rejected for the 37.5 mixes. However, since there are base mixes rutting potential may not be a critical issue. Modern pavement design methods, such as the Mechanistic Empirical Pavement Design System, demonstrate rutting is primarily a concern with SuperPave mixes. Base mixes are designed for fatigue resistance and the increasing asphalt content and film thickness should be beneficial to fatigue performance. However, 
evaluation of fatigue behavior is outside the current capabilities of the West Virginia University Asphalt Technology Laboratory. 


\section{REFERENCES}

American Association of State Highway and Transportation Officials 2004(a): Standard Specifications for Testing Materials and Methods for Sampling and Testing. $24^{\text {th }}$ Edition, AASHTO, Washington, D.C., 2004.

Anderson, R. M., R. D. W. Christensen, R. Bonaquist: Estimating the Rutting Potential of Asphalt Mixtures using SuperPave Gyratory Compaction Properties and Indirect Tensile Strength. Journal of the Association of Asphalt Paving Technologists, Vol. 72, 2003 pg 1-26.

Brown, D: SuperPave Enters the Modern Era. Better Roads, vol. 75, Number 9. 2005. pg 30-36.

Brown, E. R., and S. A. Cross. A National Study of Rutting in Hot Mix Asphalt (HMA) Pavements: Proc., Association of Asphalt Paving Technologists, Vol. 61, 1992.

Brown, E. R., and M. S. Buchanan, NCHRP Research Results Digest 237: Superpave Gyratory Compaction Guidelines, Transportation Research Board, National Research Council, 1999

Brown, E.R, P.S. Kandhal, and J. Zhang: Performance Testing of HMA. NCAT Report01-05A, Auburn, Alabama. Nov, 2001.

Brown, E. R., and R. D. Mallick: An Initial Evaluation of Ndesign SuperPave Gyratory Compactor. Journal of the Association of Asphalt Paving Technologists (AAPT), Minneapolis, MN, Volume 67, 1998

Choubane, G., G. E. Page, and J. A. Musselman: Suitability of Asphalt Pavement Analyzer for Predicting Pavement Rutting. Transportation Research Record, Issue 1723, 2002, pg. 107-115.

Christensen, D. W., R. Bonaquist, D. A. Anderson, S: Gokhale. Indirect Tensile Strength as a Simple Performance Test. Transportation Research Circular E-C068: New Simple Performance Tests for Asphalt Mixes. Transportation Research Board, September, 2004. pg 44-57.

Collins, R., D. Watson, and B. Campbell: Development and Use of the Georgia Loaded Wheel Tester. In Transportation Research Record 1492, TRB, National Research Council, Washington, D.C., July 1995, pp. 202-207

Cominsky, R. J., Huber, G. A., Kennedy, T. W., M Anderson: The SuperPave Mix Design Manual for New Consrtuction and Overlays. Strategic Highway Research Program. SHRP-A-407, National Research Council, 1994.

Cominsky, R., R. B. Leahy, and E. T. Harrigan: Level One Mix Design: Materials Selection, Compaction, and Conditioning, SHRP-A-408, Strategic Highway Research Program, National Research Council, 1994.

Coree, B. J. and K. VanDerHors: SuperPave Compaction. Transportation Conference Procedings. 1998. pg 264-267 
Harmelink, D., and T. Aschenbrener: In-Place Voids Monitoring of Hot Mix Asphalt Pavements, Report No. CDOT-DTD-R-2002-11, Colorado Department of Transportation, 2002.

Hall, K. D., F. T. Griffith, and S. T. Williams: Examination of Operator Variability for Selected Methods for Measuring Bulk Specific Gravity of Hot-Mix Asphalt Concrete. Transportation Research Record, 2001.

Harman, T.P., J. D'Angelo, and J.R. Bukowski: Evaluation of SuperPave Gyratory Compactor in the Field Management of Asphalt Mixes: Four Simulation Studies. Transportation Reasearch Record. Flexible Pavement Construction, 1995.

Hornbeck, N. C. Effect of Compaction Effort on SuperPave Surface Course Materials: M.S.C.E, West Virgina University, 2008.

Kandhal, P.S. and R.B. Mallick: Potential of Asphalt Pavement Analyzer (APA) to Predict Rutting of Hot Mix Asphalt. Proceedings, 1999 International Conference on Accelerated Pavement Testing, Reno, Nevada, October 18-20, 1999.

Kandhal, P. S., and L. A. Cooley: Evaluation of Permanent Deformation of Asphalt Mixtures using Loaded Wheel Tester. National Center for Asphalt Technology. Report 02-08. October, 2002.

Kuennen, T: Does Superpave have a local future? Better Roads, July 2003

Lai, J. S: Evaluation of Rutting Characteristics of Asphalt Mixes Using Loaded WheelTester. Project No. 8609, Georgia Department of Transportation, Dec. 1986

Mohammad, L. N: Performance Test for Hot Mix Asphalt (HMA) including Fundamental and Empirical Procedures. ASTM Special Technical Publication, n 1469, 2006

Prowell, B. D., E. R. Brown, and M. Huner: Evaluation of the Internal Angle of Gyration of SuperPave Gyratory Compactors in Alabama. National Center for Asphalt Technology Report 03-04, 2003.

Prowell, B. D. and E. R. Brown: SuperPave Mix Design: Verifying Gyration Levels in the $N_{\text {Design }}$ Table. National Center for Asphalt Technology, Auburn, AL. Transportation Research Board. 2007.

Roads \& Bridges: A SuperPave Primer. www.roadsbridges.com. Accessed November 1, 2009. http://www.roadsbridges.com/A-Superpave-Primer-article277

Roberts, F. L., P. S. Kandhal, and E. R. Brown: Hot Mix Asphalt Materials, Mixture Design, and Construction. National Center for Asphalt Technology, $2^{\text {nd }}$ edition, 1996.

Roberts, F. L., Mohammad, L. N., Wang, L. B: History of Hot Mix Asphalt Design in the United States. $150^{\text {th }}$ Anniversary paper, American Society of Civil Engineers, Journal of Materials in Civil Engineering. Vol. 14, No. 4 August 2002.

Shami, H. I., J. S. Lai, J. A. D'Angelo, and T. P. Harman: Development of Time-Effect Model for Predicting Rutting of Asphalt Mixtures Using the Georgia Loaded Wheel Tester. Transportation Research Record 1590, Transportation Research Board, National Research Council, Washington, D. C., 1997, PP 17 -22. 
Skok, E. L., A. Turk, and E. Johnson: Asphalt Pavement Analyzer Evaluation. Minnesota Department of Transportation, St. Paul, MN, September, 2002.

Williams, C. R., and Prowell, B. D: Comparison of laboratory wheel-tracking test results with WesTrack performance. Transportation Research Record, n 1681, p 121-128, 1999.

Zaniewski, J. P. and G. E. Patino: Evaluation of SuperPave Mixtures in West Virginia using the Asphalt Pavement Analyzer. Reports to the West Virginia Department of Highways, April, 2005. 


\section{APPENDIX A}

Table A.1 Gradation and $\mathrm{G}_{\mathrm{sb}}$ for $19 \mathrm{~mm}$ Mix

\section{Asphalt Specific Gravity \\ Gb 1.036}

\begin{tabular}{|c|c|c|c|c|c|c|c|c|c|c|c|c|c|}
\hline \multicolumn{6}{|c|}{ Agqreqate Gradations } & \multicolumn{8}{|c|}{$\begin{array}{l}\text { Design Aggregate Structure } 1 \\
\text { Percent of Aggregates }\end{array}$} \\
\hline & & & & & & & No. 1 & No. 2 & No. 3 & No. 4 & No. & $5 \mid$ No. 6 & Combined \\
\hline & Size & L/S \#6 & L/S \#8 & L/S Sand & RAP & Spec & $30 \%$ & $23 \%$ & $36 \%$ & $11.0 \%$ & $0 \%$ & $0.0 \%$ & \\
\hline 25 & 25 & 100 & 100 & 100 & 100 & & 30 & 23 & 36 & 11 & 0 & 0 & 100 \\
\hline 19 & 19 & 95 & 100 & 100 & 98.8 & & 28.5 & 23 & 36 & 10.87 & 0 & 0 & 98 \\
\hline 12.5 & 12.5 & 41 & 100 & 100 & 90 & 100 & 12.3 & 23 & 36 & 9.9 & 0 & 0 & 81 \\
\hline $3 / 8$ & 9.5 & 29 & 76 & 100 & 80 & $90-100$ & 8.7 & 17.5 & 36 & 8.8 & 0 & 0 & 71 \\
\hline 4 & 4.75 & 9 & 22 & 92 & 64 & 90 max & 2.7 & 5.06 & 33.1 & 7.04 & 0 & 0 & 48 \\
\hline 8 & 2.36 & 3.8 & 5 & 61 & 44.2 & $32-67$ & 1.14 & 1.15 & 22 & 4.862 & 0 & 0 & 29 \\
\hline 16 & 1.18 & 2.9 & 2.8 & 28 & 25 & & 0.87 & 0.64 & 10.1 & 2.75 & 0 & 0 & 14 \\
\hline 30 & 600 & 2.6 & 2.1 & 18 & 22 & & 0.78 & 0.48 & 6.48 & 2.42 & 0 & 0 & 10 \\
\hline 50 & 300 & 2.4 & 1.9 & 14 & 14.8 & & $\mid 0.72$ & 0.44 & 5.04 & 1.628 & 0 & 0 & 8 \\
\hline 200 & 75 & 2.2 & \begin{tabular}{|l|l}
1.7 \\
\end{tabular} & 8.8 & 9.5 & $2-10$ & 0.66 & 0.39 & 3.17 & 1.045 & 0 & 0 & 5.3 \\
\hline & Gsb & 2.613 & 2.647 & 2.580 & 2.723 & & & & & & & Gsb & 2.623 \\
\hline & Gsa & 2.713 & 2.729 & 2.735 & 2.723 & & & & & & & Gsa & 2.727 \\
\hline
\end{tabular}

Table A.2 Gradation and $\mathrm{G}_{\mathrm{sb}}$ for $37.5 \mathrm{~mm}$ Mix

\section{Asphalt Specific Gravity \\ $\mathrm{Gb} \quad 1.036$}

\begin{tabular}{|c|c|c|c|c|c|c|c|c|c|c|c|c|c|}
\hline \multicolumn{6}{|c|}{ Aggregate Gradations } & \multicolumn{8}{|c|}{$\begin{array}{l}\text { Design Aggregate Structure } 1 \\
\text { Percent of Aggregates }\end{array}$} \\
\hline & & & & & & & No. 1 & No. 2 & No. 3 & No. 4 & No. & 5 No. 6 & Combined \\
\hline & Size & L/S \#46 & L/S \#6 & Slag Sa & RAP & Spec & $50 \%$ & $11 \%$ & $24.0 \%$ & $15.0 \%$ & $0 \%$ & $0.0 \%$ & \\
\hline 50 & 50 & 100 & 100 & 100 & 100 & & 50 & 11 & 24 & 15 & 0 & 0 & 100 \\
\hline 37.5 & 37.5 & 96.1 & 100 & 100 & 100 & & 48.05 & 11 & 24 & 15 & 0 & 0 & 98 \\
\hline 25 & 25 & 55.5 & 100 & 100 & 100 & & 27.75 & 11 & 24 & 15 & 0 & 0 & 78 \\
\hline 19 & 19 & 34.7 & 97.1 & 100 & 98.8 & & 17.35 & 10.7 & 24 & 14.82 & 0 & 0 & 67 \\
\hline 12.5 & 12.5 & 9.8 & 70.6 & 100 & 97.6 & 100 & 4.9 & 7.77 & 24 & 14.64 & 0 & 0 & 51 \\
\hline $3 / 8$ & 9.5 & 3.1 & 51.5 & 100 & 93.8 & $90-100$ & 0 & 5.67 & 24 & 14.07 & 0 & 0 & 45 \\
\hline 4 & 4.75 & 2.2 & 16.8 & 94.5 & 66.1 & $90 \mathrm{ma}$ & 1.1 & 1.85 & 22.68 & 9.915 & 0 & 0 & 36 \\
\hline 8 & 2.36 & 2.2 & 6 & 70.5 & 44.2 & $32-67$ & 1.1 & 0.66 & 16.92 & 6.63 & 0 & 0 & 25 \\
\hline 16 & 1.18 & 2.1 & 4.5 & 49.2 & 33.2 & & 1.05 & 0.5 & 11.81 & 4.98 & 0 & 0 & 18 \\
\hline 30 & 600 & 1.8 & 4.1 & 32.2 & 26 & & 0.9 & 0.45 & 7.728 & 3.9 & 0 & 0 & 13 \\
\hline 50 & 300 & 1.7 & 4 & 19.4 & 14.8 & & 0.85 & 0.44 & 4.656 & 2.22 & 0 & 0 & 8 \\
\hline 200 & 75 & 1.4 & 3.6 & 6.1 & 6.9 & $2-10$ & 0.7 & 0.4 & 1.464 & 1.035 & 0 & 0 & 3.6 \\
\hline & Gsb & 2.639 & 2.632 & 2.779 & 2.723 & & & & & & & Gsb & 2.683 \\
\hline & Gsa & 2.725 & 2.729 & 2.888 & 2.723 & & & & & & & Gsa & 2.763 \\
\hline
\end{tabular}


Table A.3 Specific Gravity for $19 \mathrm{~mm}$ and $37.5 \mathrm{~mm}$ Blends

\begin{tabular}{|c|c|c|c|c|c|}
\hline \multicolumn{2}{|c|}{19 mm Mix } & \multicolumn{3}{c|}{$\mathbf{3 7 . 5}$ mm Mix } \\
\hline \hline $\begin{array}{c}\text { Aggregate } \\
\text { Type }\end{array}$ & $\begin{array}{c}\text { Bulk Specific } \\
\text { Gravity }\end{array}$ & $\begin{array}{c}\text { Apparent } \\
\text { Specific } \\
\text { Gravity }\end{array}$ & $\begin{array}{c}\text { Aggregate } \\
\text { Type }\end{array}$ & $\begin{array}{c}\text { Bulk Specific } \\
\text { Gravity }\end{array}$ & $\begin{array}{c}\text { Apparent } \\
\text { Specific } \\
\text { Gravity }\end{array}$ \\
\hline LS \#67 & 2.613 & 2.713 & LS \#467 & 2.639 & 2.725 \\
\hline LS \#8 & 2.647 & 2.729 & LS \#67 & 2.632 & 2.729 \\
\hline LS SAND & 2.58 & 2.735 & SLAG & 2.779 & 2.888 \\
\hline RAP & 2.723 & 2.723 & RAND & 2.723 & 2.723 \\
\hline Filler & 2.628 & 2.628 & Filler & 2.628 & 2.628 \\
\hline Blend & 2.620 & 2.726 & Blend & 2.683 & 2.783 \\
\hline
\end{tabular}

Table A.4 Volumetric Parameters for $19 \mathrm{~mm}$ and $37.5 \mathrm{~mm}$ Verification Mix

\begin{tabular}{|c|c|c|}
\hline Parameter & 19 mm Mix & 37.5 mm Mix \\
\hline \hline VTM & 5.3 & 11.8 \\
\hline VMA & 14.8 & 67.1 \\
\hline VFA & 64.0 & 87.4 \\
\hline \%G $_{\mathrm{mm}, \text { Nini }}$ & 84.2 & 2.708 \\
\hline $\mathrm{G}_{\mathrm{se}}$ & 2.663 & 0.4 \\
\hline $\mathrm{P}_{\mathrm{ba}}$ & 0.6 & 3.358 \\
\hline $\mathrm{P}_{\mathrm{be}}$ & 4.834 & 1.1 \\
\hline $\mathrm{D} / \mathrm{B}$ & 1.3 & \\
\hline
\end{tabular}


Table A.5 Optimum Binder Content for 19 mm 80 Gyrations Mix

\begin{tabular}{|c|r|r|r|r|}
\hline \multirow{2}{*}{ Parameter } & \multicolumn{5}{|c|}{ Binder Percent (\%) } \\
\cline { 2 - 5 } & $\mathbf{5 . 4}$ & $\mathbf{5 . 9}$ & $\mathbf{6 . 4}$ & $\mathbf{6 . 9}$ \\
\hline \hline VTM & 5.9 & 4.0 & 3.1 & 0.1 \\
\hline VMA & 16.2 & 15.8 & 15.7 & 15.1 \\
\hline VFA & 63.4 & 75.0 & 80.4 & 99.4 \\
\hline$\% \mathrm{G}_{\mathrm{mm}, \text { Nini }}$ & 84.250 & 85.964 & 86.847 & 89.245 \\
\hline $\mathrm{G}_{\mathrm{se}}$ & 2.7 & 2.7 & 2.7 & 2.7 \\
\hline $\mathrm{P}_{\mathrm{ba}}$ & 0.85 & 0.71 & 0.93 & 0.42 \\
\hline $\mathrm{P}_{\mathrm{be}}$ & 4.596 & 5.232 & 5.530 & 6.509 \\
\hline $\mathrm{D} / \mathrm{B}$ & 1.1 & 1 & 1 & 0.8 \\
\hline
\end{tabular}

Table A.6 Optimum Binder Content for 37.5 mm 65 Gyrations Mix

\begin{tabular}{|c|c|c|c|c|}
\hline \multirow{2}{*}{ Parameter } & \multicolumn{4}{|c|}{ Binder Percent (\%) } \\
\cline { 2 - 5 } & $\mathbf{3 . 4}$ & $\mathbf{3 . 9}$ & $\mathbf{4 . 4}$ & $\mathbf{4 . 9}$ \\
\hline \hline VTM & 6.2 & 5.1 & 3.0 & 1.5 \\
\hline VMA & 14.2 & 13.1 & 13.6 & 13.6 \\
\hline VFA & 56.3 & 60.5 & 78.2 & 88.9 \\
\hline$\% G_{m m, N i n i}$ & 86.9 & 87.6 & 89.3 & 90.7 \\
\hline $\mathrm{G}_{\mathrm{se}}$ & 2.678 & 2.658 & 2.672 & 2.666 \\
\hline $\mathrm{P}_{\mathrm{ba}}$ & -0.1 & -0.4 & -0.2 & -0.2 \\
\hline $\mathrm{P}_{\mathrm{be}}$ & 3.468 & 4.256 & 4.553 & 5.128 \\
\hline $\mathrm{D} / \mathrm{B}$ & 1.0 & 0.8 & 0.8 & 0.7 \\
\hline
\end{tabular}


Figure A.1 VTM vs Binder Percent for 19 mm 80 Gyrations Mix

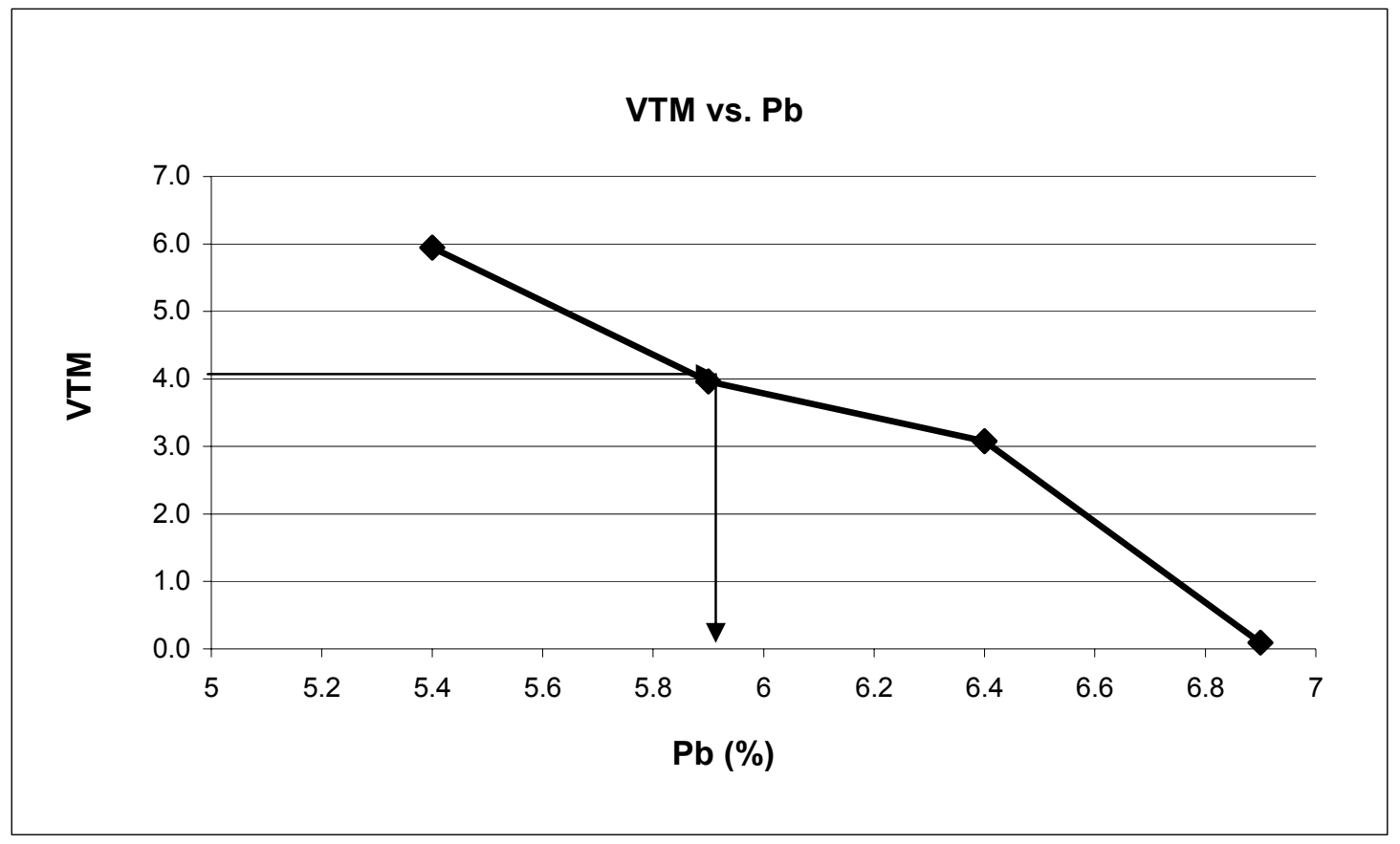

Figure A.2 VMA vs Percent Binder for 19 mm 80 Gyrations Mix

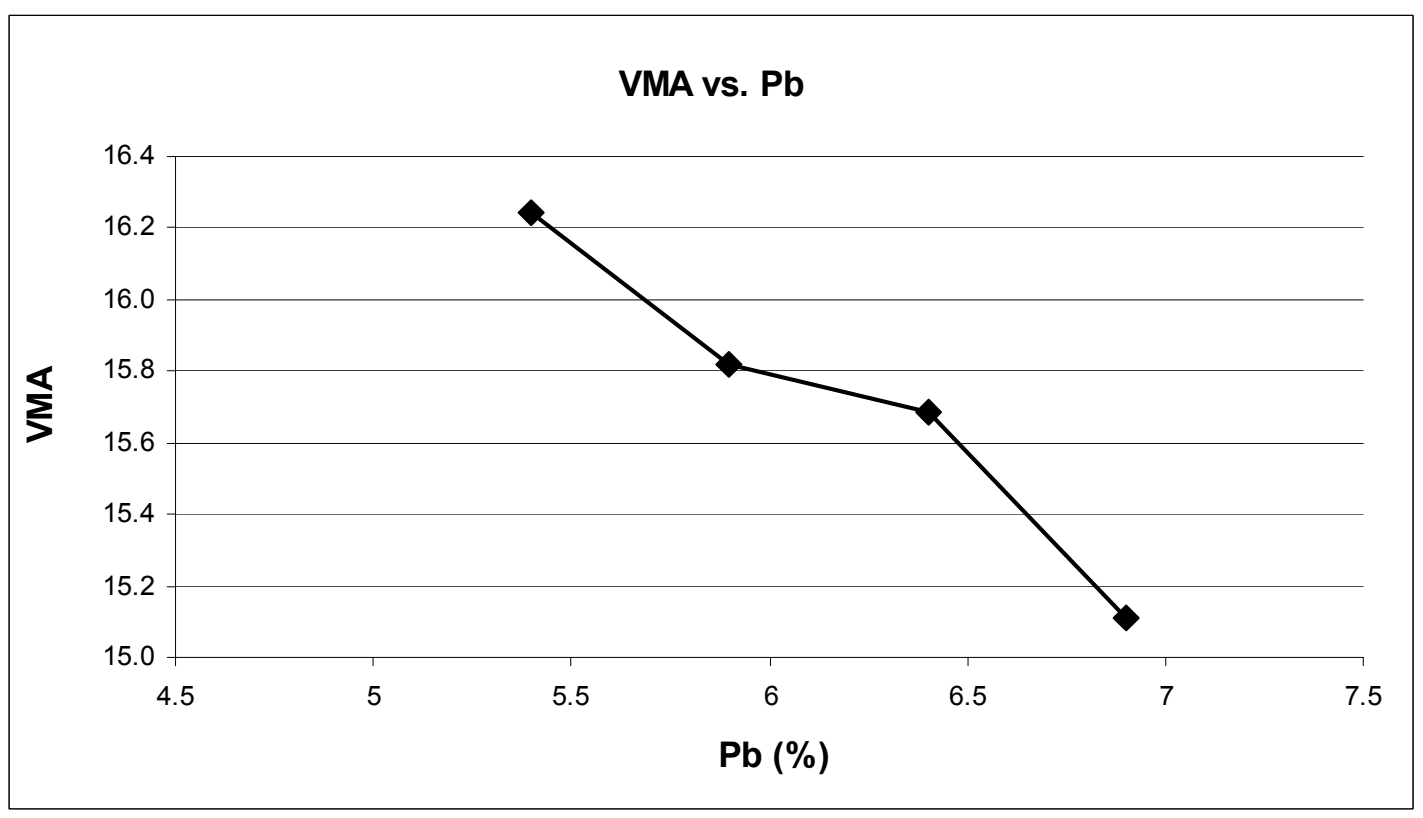


Figure A.3 VFA vs Percent Binder for 19 mm 80 Gyrations Mix

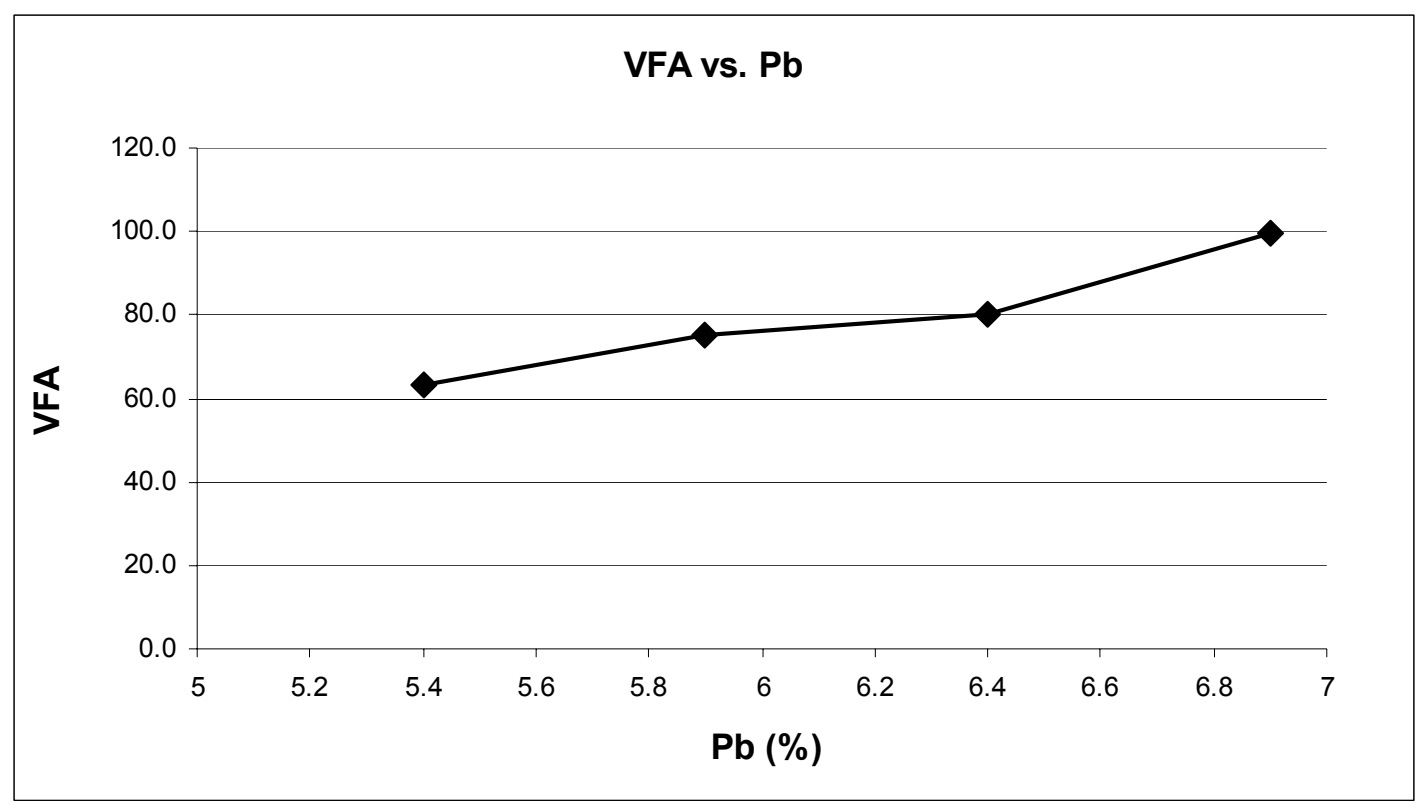

Figure A.4 D/B vs Percent Binder for 19 mm 80 Gyrations Mix

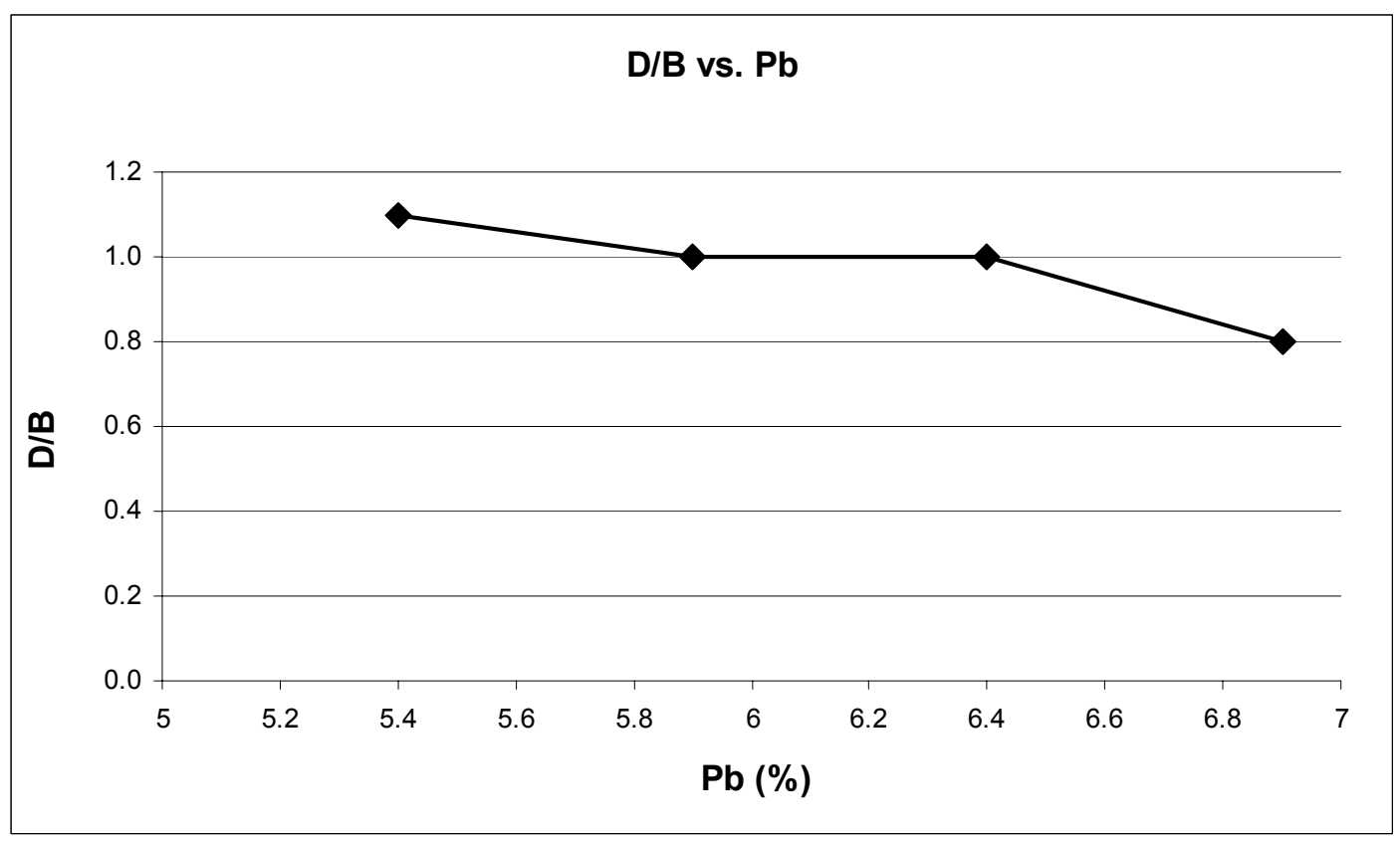


Figure A.5 \% $\mathrm{G}_{\mathrm{mm}}$ vs Percent Binder for $19 \mathrm{~mm} 80$ Gyrations Mix

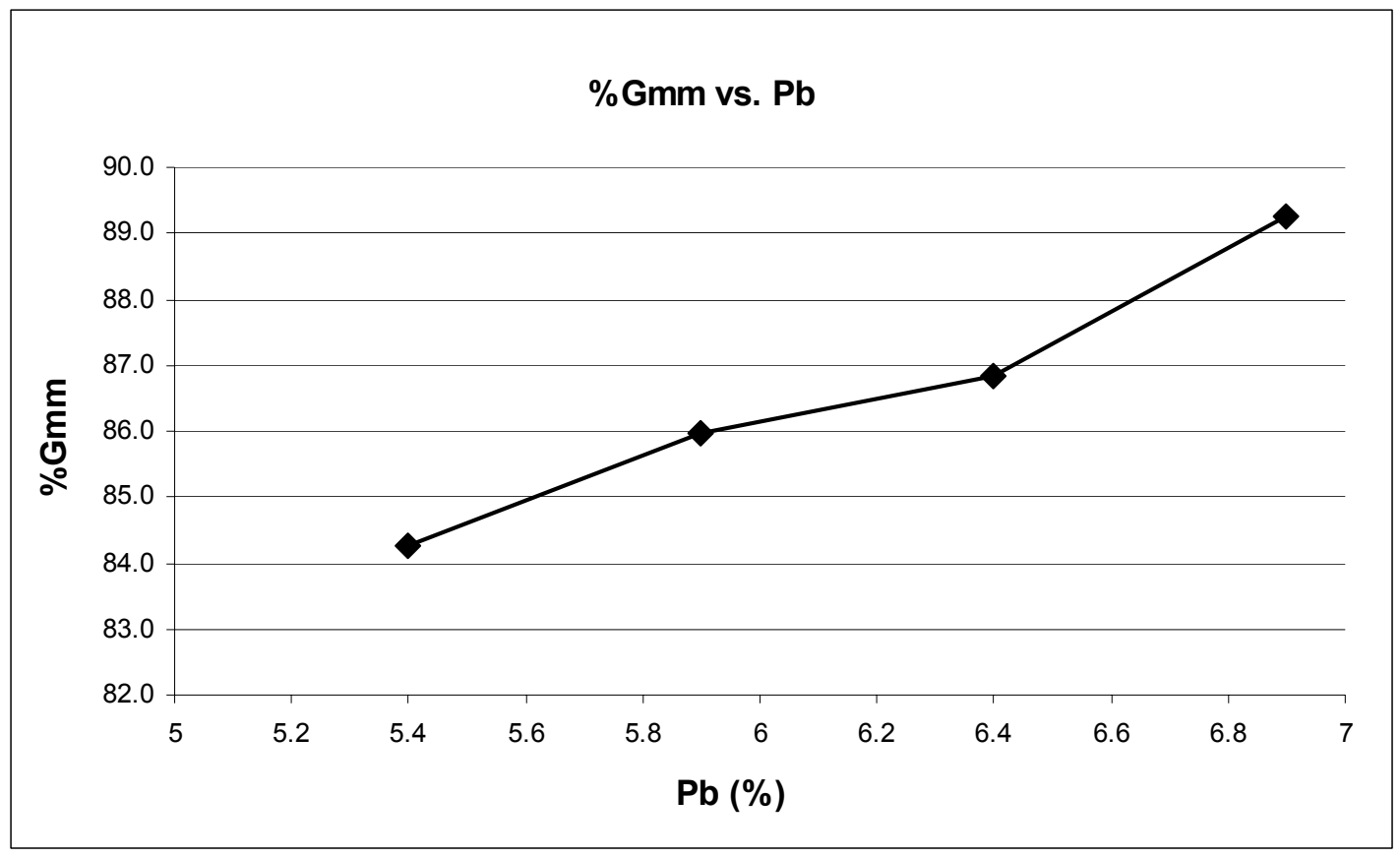

Figure A.6 VTM vs Binder Percent for 37.5 mm 65 Gyrations Mix

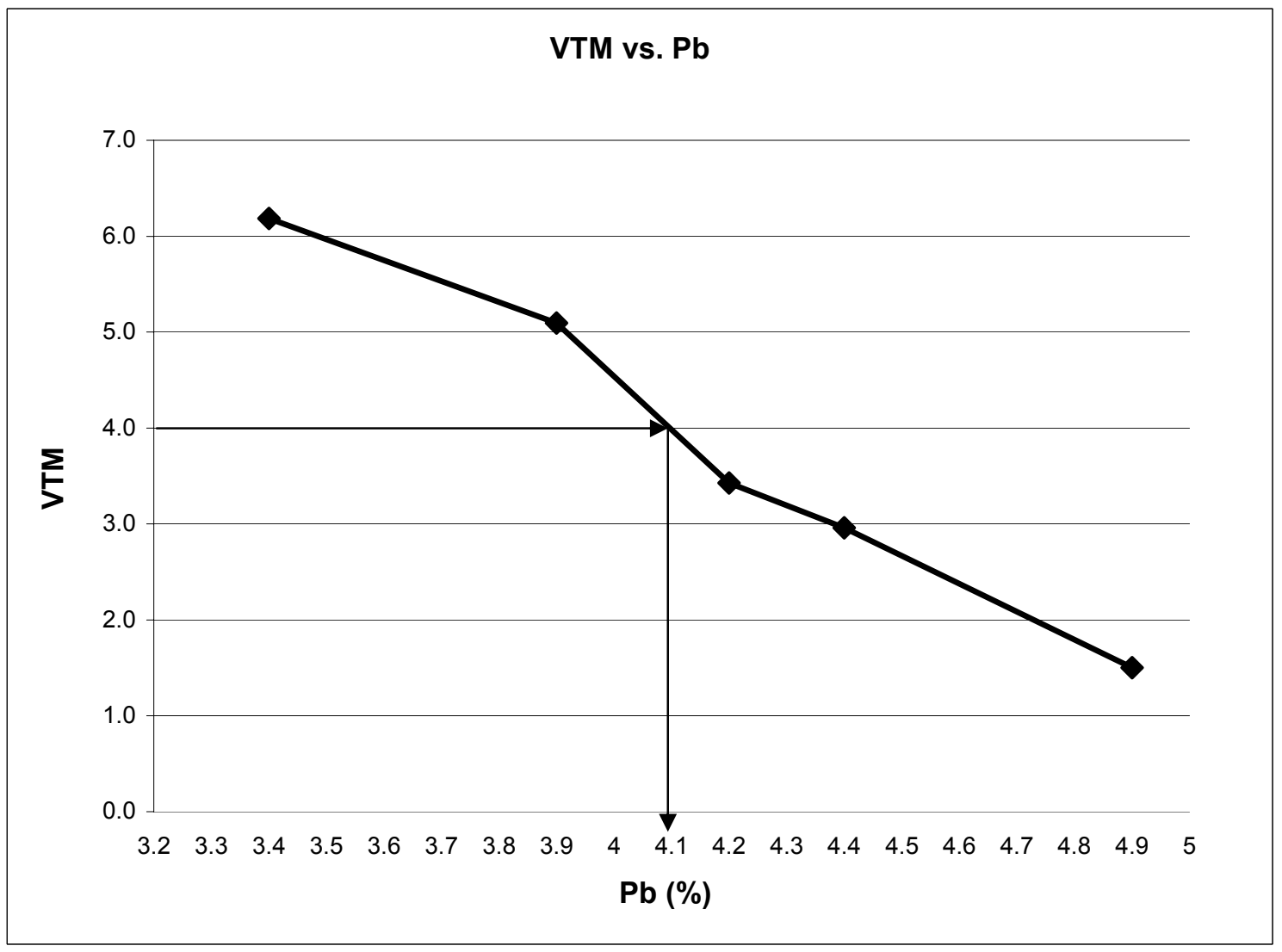


Figure A.7 VMA vs Percent Binder for 37.5 mm 65 Gyrations Mix

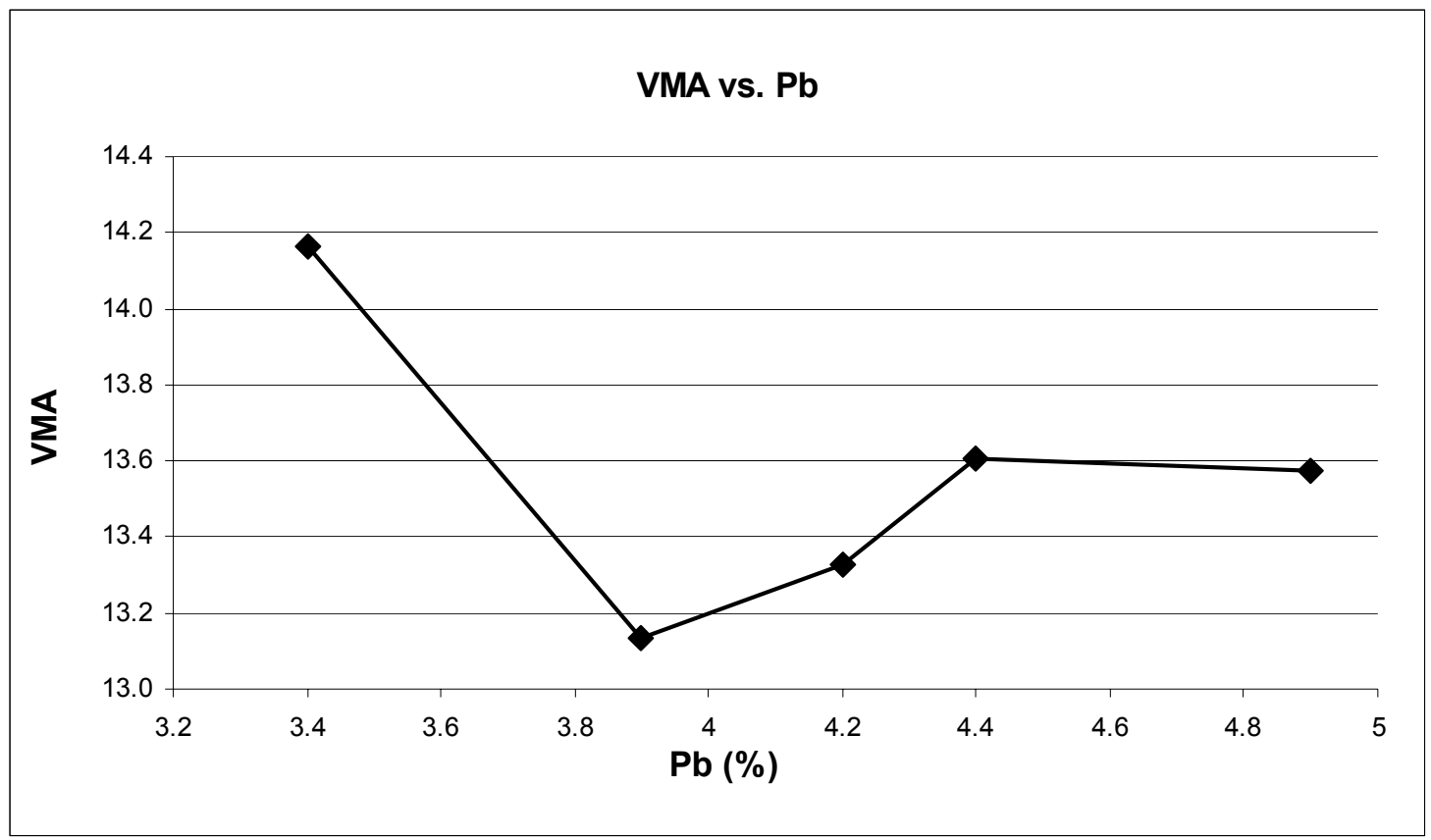

Figure A.8 VFA vs Percent Binder for $37.5 \mathrm{~mm} 65$ Gyrations Mix

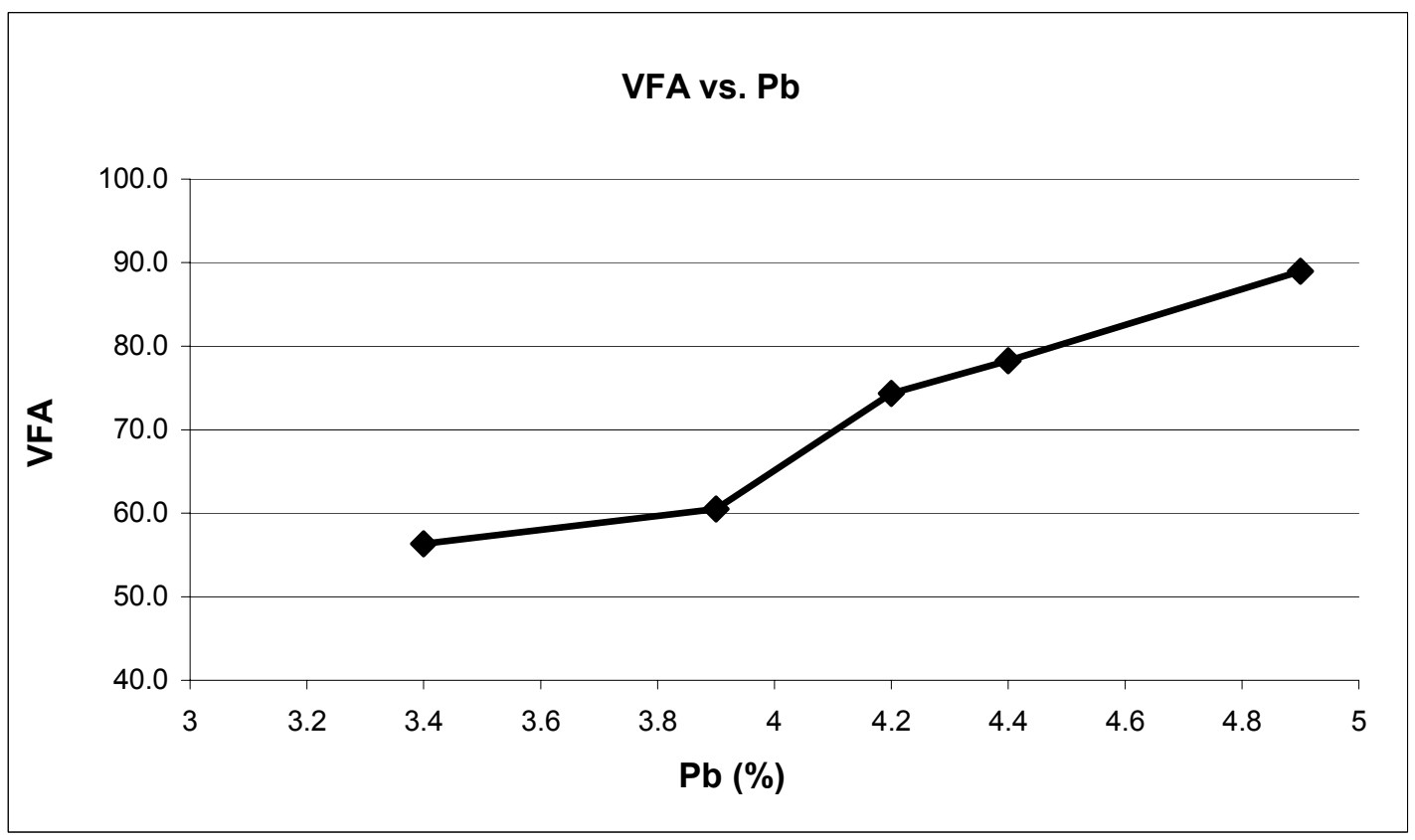


Figure A.9 D/B vs Percent Binder for 37.5 mm 65 Gyrations Mix

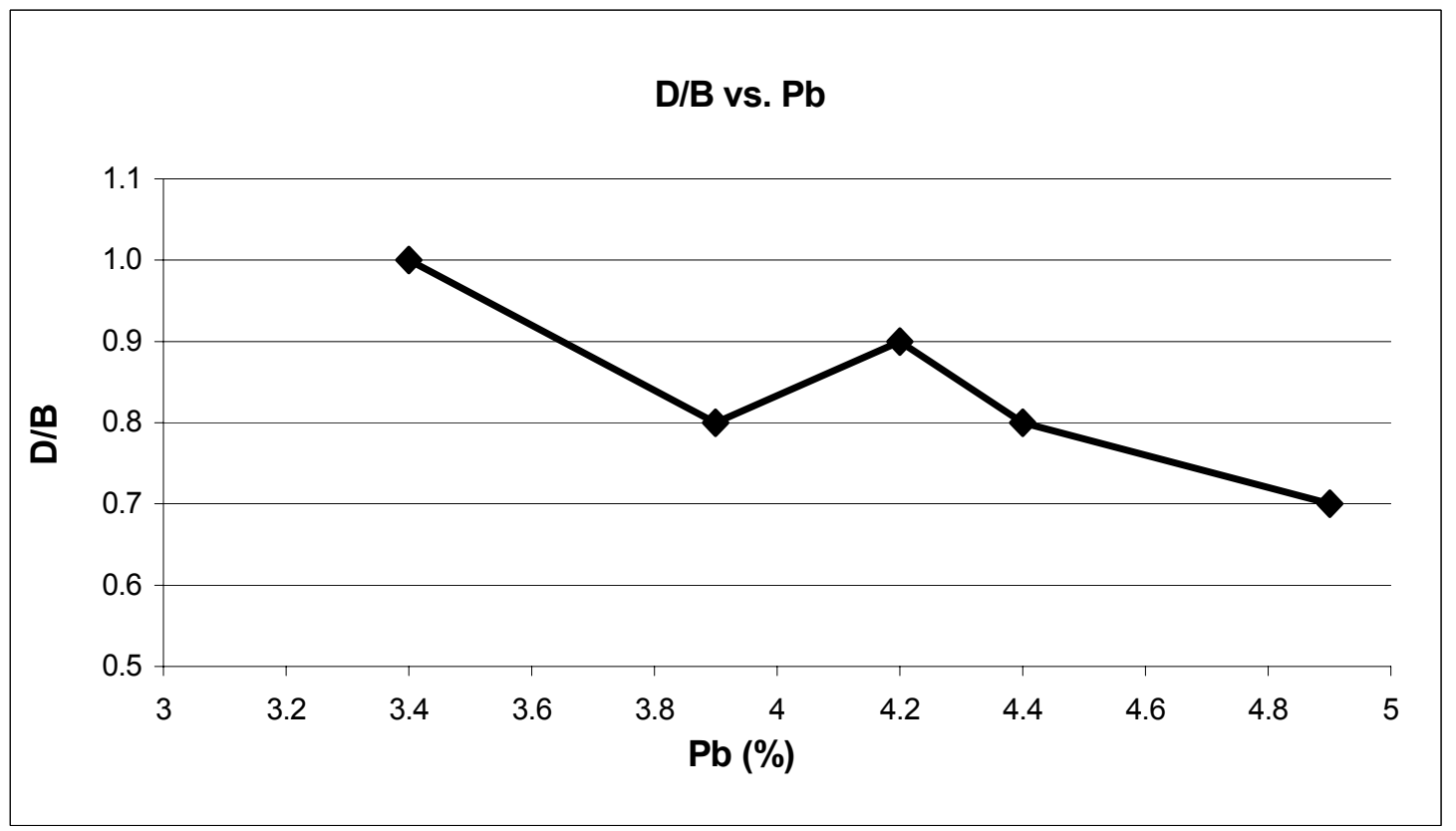

Figure A.10 $\% \mathrm{G}_{\mathrm{mm}}$ vs Percent Binder for $37.5 \mathrm{~mm} 65$ Gyrations Mix

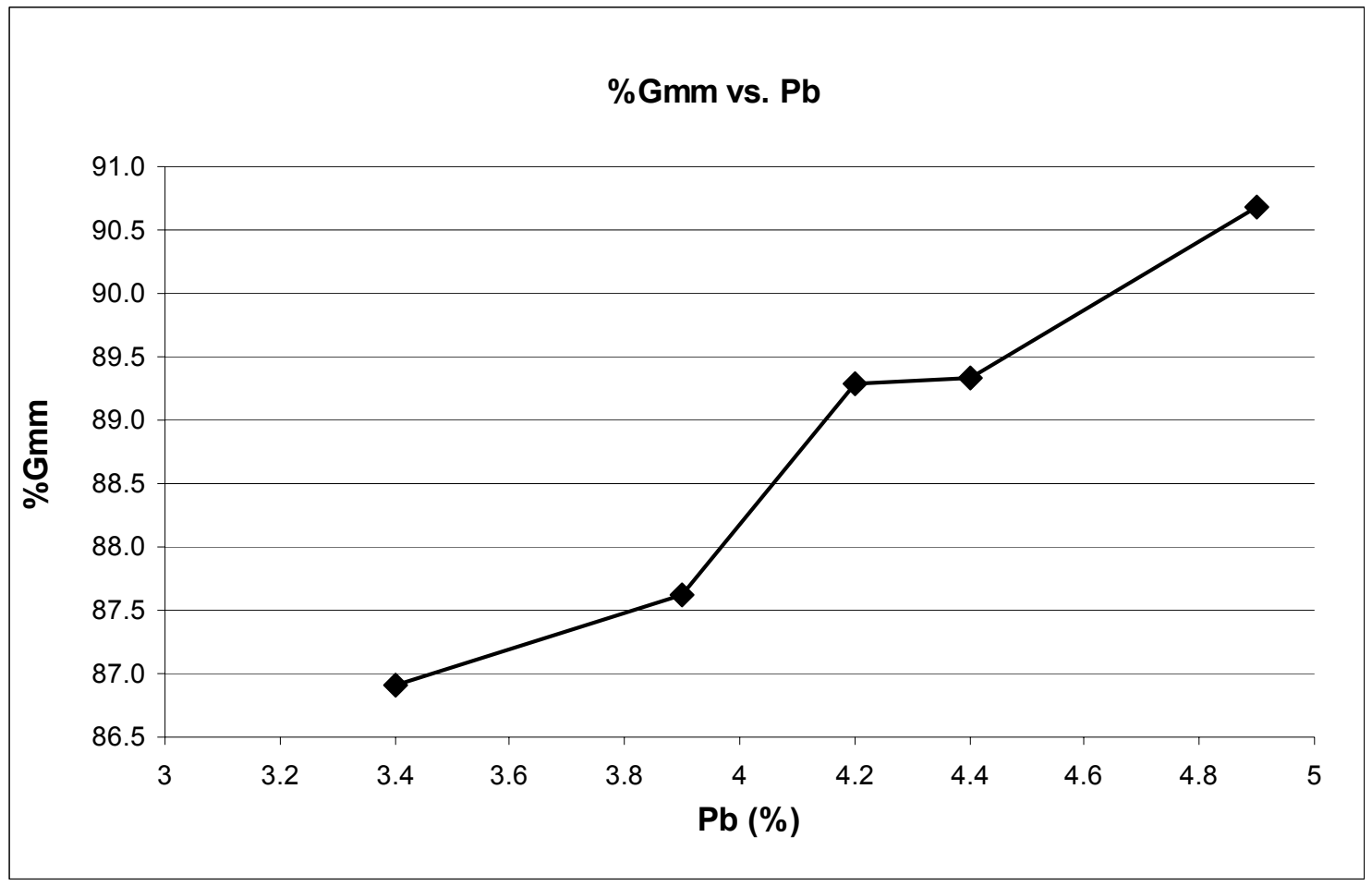




\section{APPENDIX B}

Figure B.1 Data for SAS Program evaluating Rutting Potential

\section{APA BASE COARSE RUT DEPTHS}

22:14 Sunday, November 15, 2009

$\begin{array}{cccc}\text { OBS } & \text { SAMPLE FACTOR DER } \\ 1 & 1 & 1 & 6.1 \\ 2 & 2 & 1 & 4.3 \\ 3 & 3 & 1 & 6.8 \\ 4 & 4 & 2 & 6.0 \\ 5 & 5 & 2 & 8.0 \\ 6 & 6 & 2 & 10.0 \\ 7 & 7 & 2 & 13.4 \\ 8 & 8 & 2 & 12.6 \\ 9 & 9 & 2 & 6.9 \\ 10 & 10 & 3 & 5.3 \\ 11 & 11 & 3 & 6.5 \\ 12 & 12 & 3 & 4.0 \\ 13 & 13 & 4 & 8.2 \\ 14 & 14 & 4 & 5.4 \\ 15 & 15 & 4 & 7.5 \\ 16 & 16 & 4 & 5.0 \\ 17 & 17 & 4 & 7.8 \\ 18 & 4 & 8.8\end{array}$


Figure B.2 Factor Levels for SAS Program Evaluating Rutting Potential

\section{APA BASE COARSE RUT DEPTHS}

22:14 Sunday, November 15, 2009

The GLM Procedure
Class Level Information
Class Levels Values
SIZE $\quad 4 \quad 1234$
Number of Observations Read
Number of Observations Used


Figure B.3 ANOVA Results for Base Course Rutting Potential

APA BASE COARSE RUT DEPTHS

22:14Sunday, November 15, 2009

The GLM Procedure

Dependent Variable: DEPTH

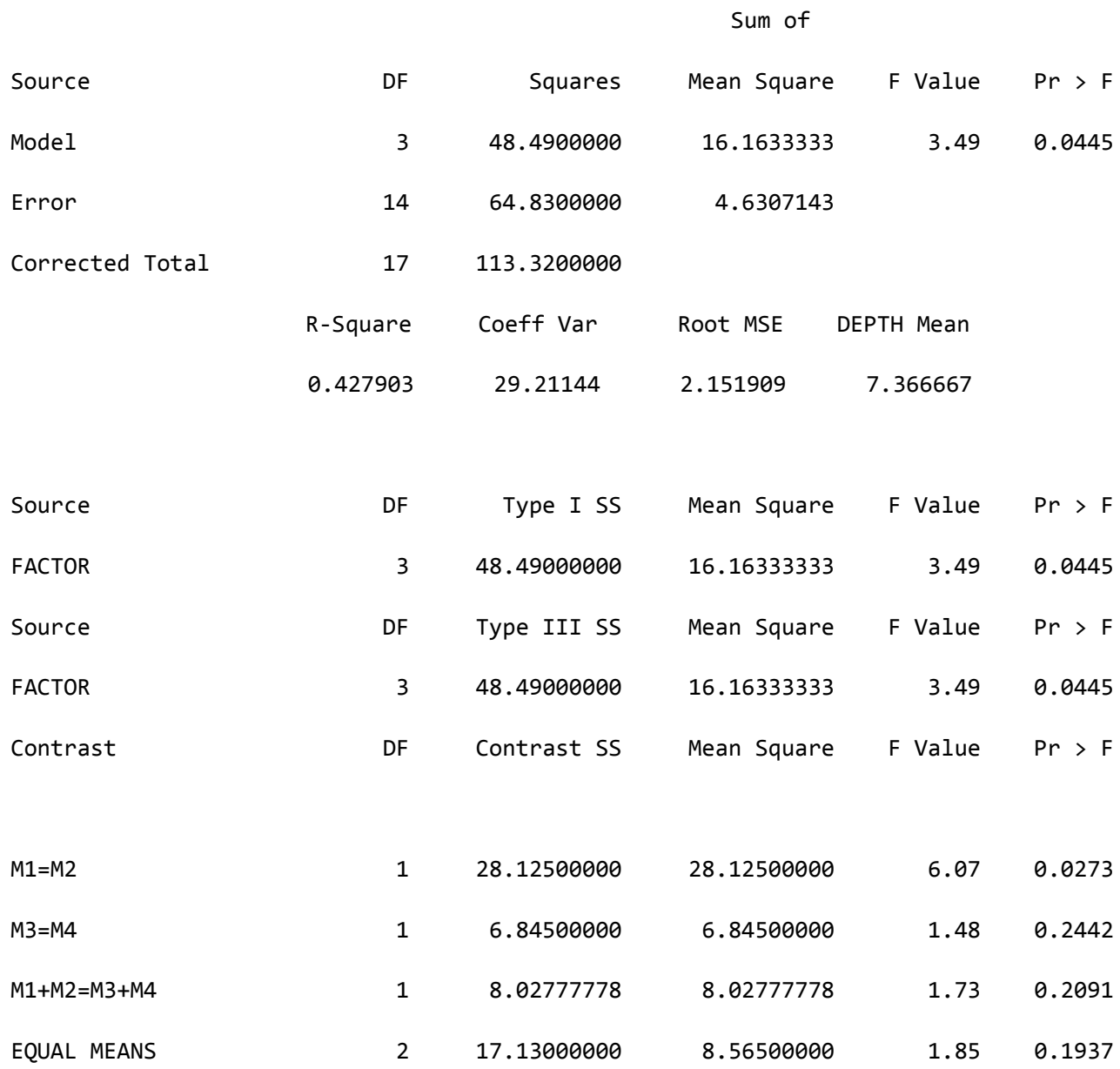

Parameter

Estimate Error

$t$ Value $\operatorname{Pr}>|t|$

H0: $M 1=M 2$

$-3.75000000$

1.52162977

$-2.46$

0.0273

$H 0: M 3=M 4$

$-1.85000000$

1.52162977

$-1.22$

0.2442

$H 0: M 1+M 2=M 3+M 4$

2.83333333

2.15190945

1.32

0.2091 
Figure B.4 Duncan Multiple Range Test for Rutting Potential

APA BASE COARSE RUT DEPTHS

22:14 Sunday, November 15, 2009

The GLM Procedure

Duncan's Multiple Range Test for DEPTH

NOTE: This test controls the Type I comparisonwise error rate, not the experimentwise error rate.

$\begin{array}{lr}\text { Alpha } & 0.05 \\ \text { Error Degrees of Freedom } & 14 \\ \text { Error Mean Square } & 4.630714 \\ \text { Harmonic Mean of Cell Sizes } & 4 \\ \text { NOTE: Cell sizes are not equal. }\end{array}$

Number of Means

2

3

4

Critical Range

3.264

3.420

3.516

Means with the same letter are not significantly different.

Duncan Grouping Mean N FACTOR

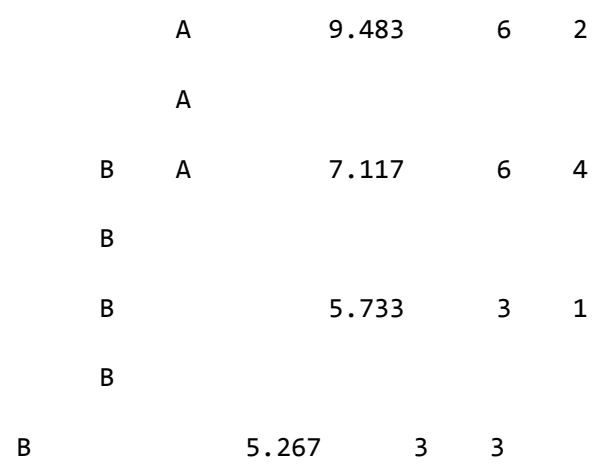


Figure B.5 Data for SAS Program evaluating Rutting Potential vs APA Position

RUT DEPTH VERSUS LOCATION IN APA

15:05 Friday, November 13, 2009

\begin{tabular}{cccr} 
OBS & \multicolumn{4}{c}{ SAMPLE POSITION } \\
1 & 1 & 1 & 8.2 \\
2 & 2 & 1 & 8.0 \\
3 & 3 & 1 & 5.3 \\
4 & 4 & 2 & 6.1 \\
5 & 5 & 2 & 6.0 \\
6 & 6 & 2 & 6.5 \\
7 & 7 & 3 & 4.3 \\
8 & 8 & 3 & 5.0 \\
9 & 9 & 3 & 4.0 \\
10 & 10 & 4 & 5.4 \\
11 & 11 & 4 & 10.0 \\
12 & 12 & 4 & 6.9 \\
13 & 13 & 5 & 7.5 \\
14 & 14 & 5 & 8.8 \\
16 & 15 & 5 & 12.6 \\
16 & 16 & 6 & 6.8 \\
& 17 & 6 & 7.8 \\
13 & 6 & 13.4
\end{tabular}


Figure B.6 Factor Levels for SAS Program evaluating Rutting Potential vs APA Position

RUT DEPTH VERSUS LOCATION IN APA

15:05 Friday, November 13, 2009

The GLM Procedure

Class Level Information

Class Levels Values

POSITION $\quad 6 \quad 123456$

Number of Observations Read 18

Number of Observations Used 18 
Figure B.7 ANOVA Results for Rutting Potential vs APA Position

RUT DEPTH VERSUS LOCATION IN APA

15:05 Friday, November 13, 2009

The GLM Procedure

Dependent Variable: DEPTH

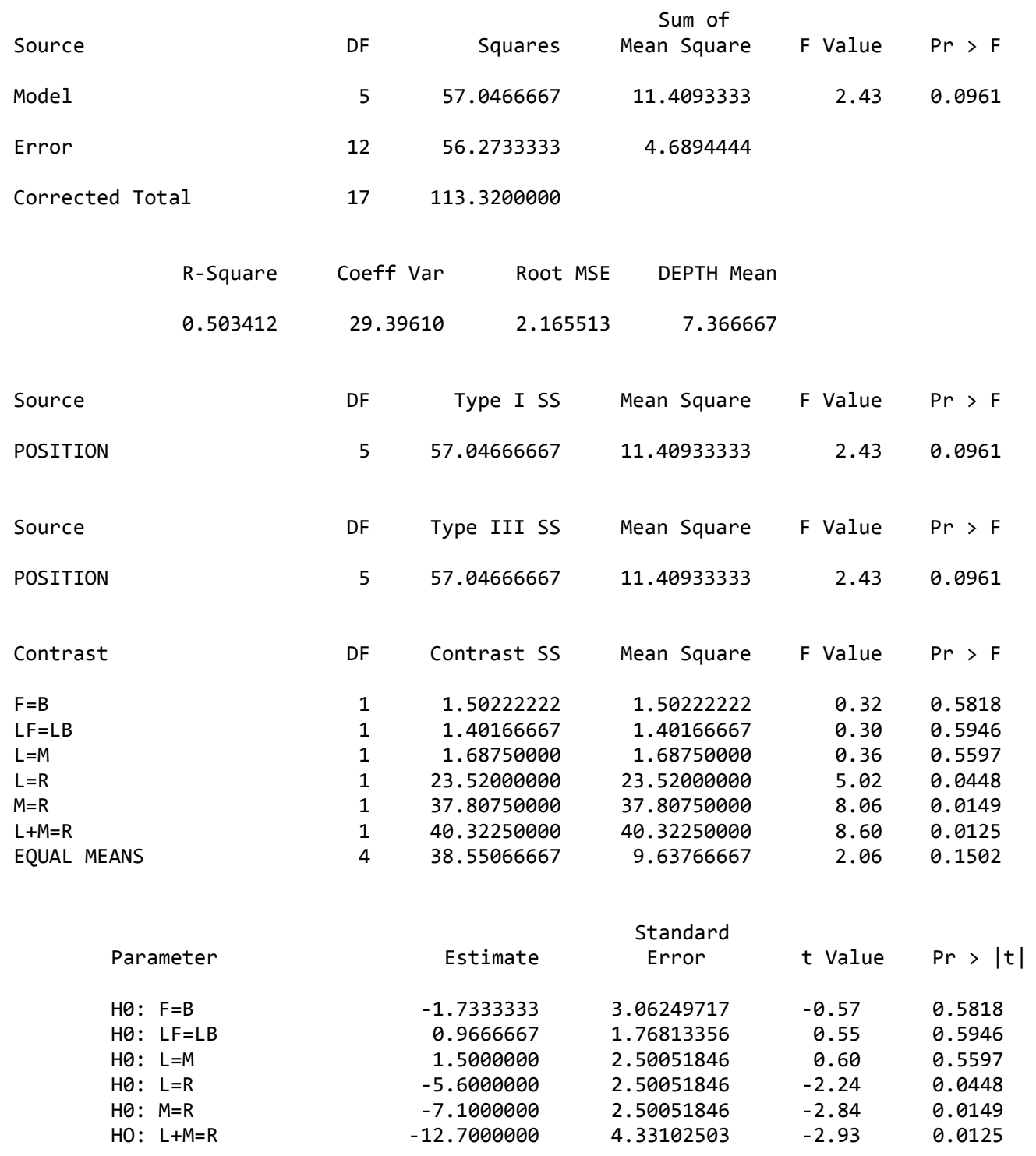


Figure B.8 ANOVA Results for Base Course Rutting Potential (Modified Data)

APA BASE COARSE RUT DEPTHS

22:44 Monday, November 16, 2009

The GLM Procedure

Dependent Variable: DEPTH

\begin{tabular}{|c|c|c|c|c|c|}
\hline Source & DF & Squares & $\begin{array}{c}\text { Sum of } \\
\text { Mean Square }\end{array}$ & F Value & $\mathrm{Pr}>\mathrm{F}$ \\
\hline Model & 3 & 33.52777778 & 11.17592593 & 2.87 & 0.0738 \\
\hline Error & 14 & 54.44833333 & 3.88916667 & & \\
\hline \multirow[t]{3}{*}{ Corrected Total } & 17 & 87.97611111 & & & \\
\hline & \multicolumn{2}{|l|}{ R-Square } & Root MSE & \multicolumn{2}{|l|}{ DEPTH Mean } \\
\hline & 0.381101 & 25.37366 & 1.972097 & \multicolumn{2}{|c|}{7.772222} \\
\hline Source & DF & Type I SS & Mean Square & F Value & $\mathrm{Pr}>\mathrm{F}$ \\
\hline FACTOR & 3 & 33.52777778 & 11.17592593 & 2.87 & 0.0738 \\
\hline Source & DF & Type III SS & Mean Square & F Value & $\mathrm{Pr}>\mathrm{F}$ \\
\hline FACTOR & 3 & 33.52777778 & 11.17592593 & 2.87 & 0.0738 \\
\hline Contrast & DF & Contrast SS & Mean Square & F Value & $\mathrm{Pr}>\mathrm{F}$ \\
\hline$M 1=M 2$ & 1 & 18.60500000 & 18.60500000 & 4.78 & 0.0462 \\
\hline M3=M4 & 1 & 6.24222222 & 6.24222222 & 1.61 & 0.2259 \\
\hline \multirow{2}{*}{$\begin{array}{l}M 1+M 2=M 3+M 4 \\
\text { EOUAL MEANS }\end{array}$} & 1 & 5.52250000 & 5.52250000 & 1.42 & 0.2532 \\
\hline & 2 & 10.32750000 & 5.16375000 & 1.33 & 0.2965 \\
\hline Parameter & & Estimate & $\begin{array}{l}\text { Standard } \\
\text { Error }\end{array}$ & t Value & $\operatorname{Pr}>|t|$ \\
\hline H0: M1=M2 & & 3.05000000 & 1.39448318 & -2.19 & 0.0462 \\
\hline HO: M3=M4 & & 1.76666667 & 1.39448318 & -1.27 & 0.2259 \\
\hline $\mathrm{H} 0: \quad M 1+M 2=M 3+M 4$ & & 2.35000000 & 1.97209702 & & \\
\hline
\end{tabular}


Figure B.9 Duncan Multiple Range Test for Rutting Potential (Modified Data)

APA BASE COARSE RUT DEPTHS

22:44 Monday, November 16, 2009

The GLM Procedure

Duncan's Multiple Range Test for DEPTH

NOTE: This test controls the Type I comparisonwise error rate, not the experimentwise error rate.

$\begin{array}{lr}\text { Alpha } & 0.05 \\ \text { Error Degrees of Freedom } & 14 \\ \text { Error Mean Square } & 3.889167 \\ \text { Harmonic Mean of Cell Sizes } & 4 \\ & \\ \text { NOTE: Cell sizes are not equal. }\end{array}$

Number of Means

Critical Range

2.991

3.134

3.222

Means with the same letter are not significantly different.

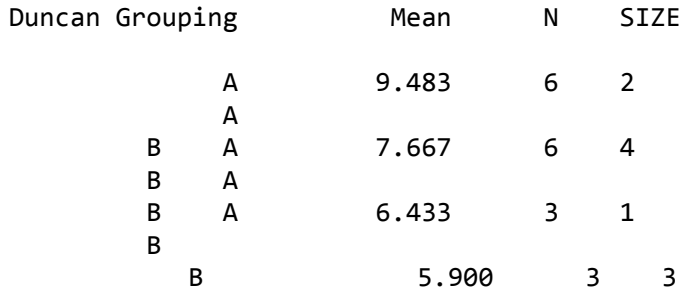


Figure B.10 ANOVA Test for Rutting Potential vs APA Position (Modified Data)

RUT DEPTH VERSUS LOCATION IN APA MODIFIED MIDDLE FRONT

15:41 Friday, November 13, 2009

The GLM Procedure

Dependent Variable: DEPTH

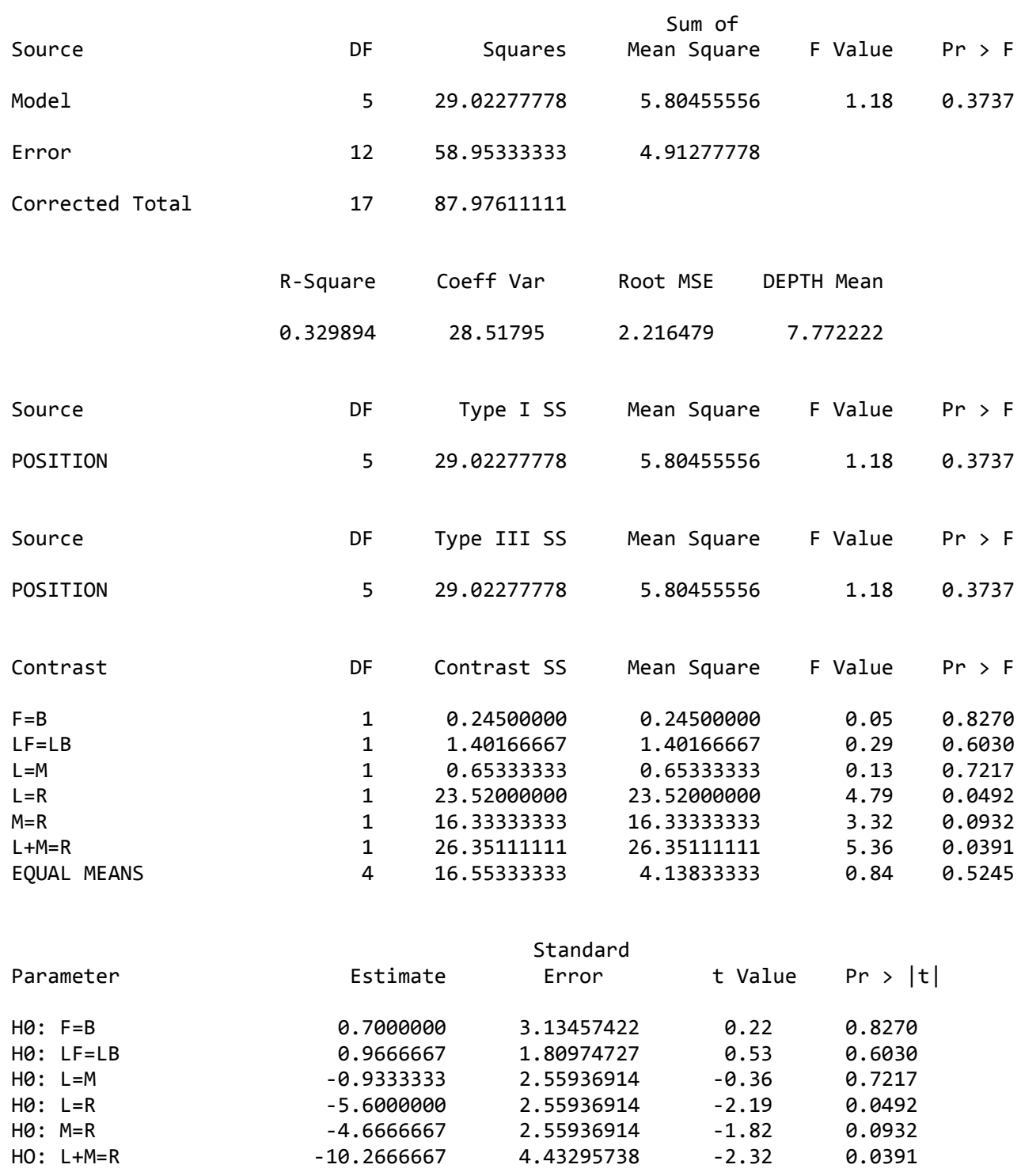

Figure B.12 Duncan Multiple Range Test for Rutting Potential (Modified Data)

RUT DEPTH VERSUS LOCATION IN APA MODIFIED MIDDLE FRONT 
Duncan's Multiple Range Test for DEPTH

NOTE: This test controls the Type I comparisonwise error rate, not the experimentwise error rate.

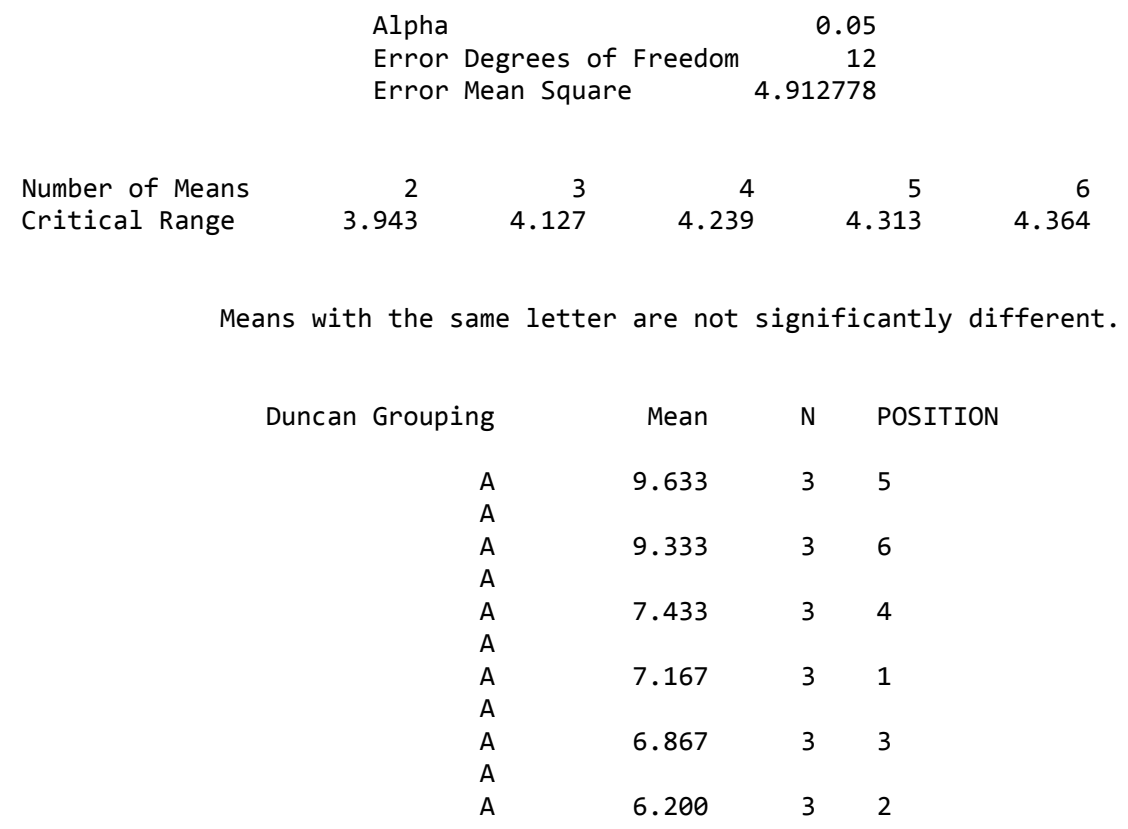


Table B.1 Weight-out Table for $19 \mathrm{~mm}$ Mix with RAP

\begin{tabular}{|c|c|c|c|c|c|c|c|c|c|c|c|c|c|c|}
\hline & \multicolumn{3}{|c|}{ Mix Weighout Table } & \multirow[t]{2}{*}{$19 \mathrm{~mm}$} & & & \multirow[b]{2}{*}{ P_b Total } & \multirow[b]{2}{*}{$5.4 \%$} & & \multirow[b]{2}{*}{$10,406.0$} & \multirow[b]{2}{*}{ P_s } & 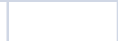 & \multirow[t]{2}{*}{ 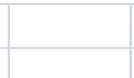 } & \\
\hline & & & & & & & & & & & & & & \\
\hline & \multicolumn{2}{|c|}{2 Bulk } & \multicolumn{2}{|c|}{$1 \mathrm{Gmm}$} & & & & & & & & & & \\
\hline & \multirow{2}{*}{\multicolumn{2}{|c|}{$\begin{array}{l}4,500.0 \mathrm{~g} \\
\text { Percent Stone P_s }\end{array}$}} & $2,000.0$ & \multirow{2}{*}{ g } & \multicolumn{2}{|c|}{ Total Sample Weight } & & $11,000.0$ & $\mathrm{~g}$ & \multicolumn{2}{|c|}{ Wgt. Virgin Matrl. } & $9,783.5$ & g & \\
\hline & & & $94.6 \%$ & & $\%$ Virgin $\mathrm{B}$ & inder & & $4.7 \%$ & & & & & & \\
\hline & \multicolumn{2}{|c|}{ Weight of Stone W_S } & $10,406.0$ & \multirow[t]{2}{*}{$g$} & \multicolumn{2}{|c|}{ Weight of Binder W_b } & & 522.1 & $\mathrm{~g}$ & $\%$ RAP & $11.1 \%$ & & P_b RAP & $5.9 \%$ \\
\hline & & & & & & & & & & Weight RAP & 1216.5 & g & $W_{-} b$ in RAP & 71.77 \\
\hline & Stockpile & L/S \#67 & $g$ & Stockpile & L/S \#8 & $g$ & Stockpile & L/S Sand & $g$ & & & & W_s in RAP & $1,144.70$ \\
\hline Sieve Size & $\%$ Passing & $\%$ Retaine & Weight & $\%$ Passing & $\%$ Retaine & Weight & $\%$ Passing & $\%$ Retaine & Weight & & & & & \\
\hline 25 & 100 & 0 & 0.0 & 100 & 0 & 0.0 & 100 & 0 & 0.0 & & Weight Bin & nder & 593.90 & \\
\hline 19 & 95 & 5 & 156.1 & 100 & 0 & 0.0 & 100 & 0 & 0.0 & & Weight Sto & & $10,406.10$ & \\
\hline 12.5 & 41 & 54 & 1685.8 & 100 & 0 & 0.0 & 100 & 0 & 0.0 & & & & $11,000.00$ & \\
\hline 9.5 & 29 & 12 & 374.6 & 76 & 24 & 574.4 & 100 & 0 & 0.0 & & & & & \\
\hline 4.75 & 9 & 20 & 624.4 & 22 & 54 & 1292.4 & 92 & 8 & 299.7 & & & & & \\
\hline 2.36 & 3.8 & 5.2 & 162.3 & 5 & 17 & 406.9 & 61 & 31 & 1161.3 & & & & & \\
\hline 0.06 & 2.6 & 0.1 & 3.1 & 2.1 & 0.7 & 16.8 & 18 & 10 & 374.6 & & & & & \\
\hline 0.03 & 2.4 & 0.2 & 6.2 & 1.9 & 0.2 & 4.8 & 14 & 4 & 149.8 & & & & & \\
\hline 0.075 & 2.2 & 0.2 & 6.2 & 1.7 & 0.2 & 4.8 & 8.8 & 5.2 & 194.8 & & & & & \\
\hline \multirow[t]{19}{*}{ Pan } & & 2.2 & 68.7 & & 1.7 & 40.7 & & 8.8 & 329.7 & & & & & \\
\hline & & 95 & 3121.7 & & 100 & 2393.5 & & 100 & 3746.1 & & & & & \\
\hline & & & & & & & & & & & & & & \\
\hline & & & & & & & & & & $100.0 \%$ & & & & \\
\hline & & & & Stockpile & RAP & $g$ & & & & 9261.4 & $=V s$ & 10406.1 & $=\mathrm{Ts}$ & \\
\hline & & & & Blend & $11.0 \%$ & 1144.7 & & & & $100 \%$ & & & & \\
\hline & & & Sieve Size & $\%$ Passing & $\%$ Retaine & Weight & & & & & Sieve Size & $\%$ Passing & Target & \\
\hline & & & 25 & 100 & 0 & 0.0 & & & & & 25 & 100 & 100 & \\
\hline & & & 19 & 98.8 & 1.2 & 13.7 & & & & & 19 & 98 & 98 & \\
\hline & & & 12.5 & 90 & 8.8 & 100.7 & & & & & 12.5 & 81 & 81 & \\
\hline & & & 9.5 & 80 & 10 & 114.5 & & & & & 9.5 & 71 & 71 & \\
\hline & & & 4.75 & 64 & 16 & 183.2 & & & & & 4.75 & 48 & 48 & \\
\hline & & & 1.18 & 25 & 19.2 & 219.8 & & & & & 1.18 & 14 & 14 & \\
\hline & & & 0.06 & 22 & 3 & 34.3 & & & & & 0.06 & 10 & 10 & \\
\hline & & & 0.03 & 14.8 & 7.2 & 82.4 & & & & & 0.03 & 8 & 8 & \\
\hline & & & 0.075 & 9.5 & 5.3 & 60.7 & & & & & 0.075 & 5.3 & 5.3 & \\
\hline & & & Pan & & 9.5 & 108.7 & & & & & Pan & & & \\
\hline & & & & & 98.8 & 1144.7 & 10406.0 & & & & & & & \\
\hline & & & & & 9261.3 & 9261.3 & & & & & & & & \\
\hline
\end{tabular}


Table B.2 Weight-out Table for $37.5 \mathrm{~mm}$ Mix with RAP

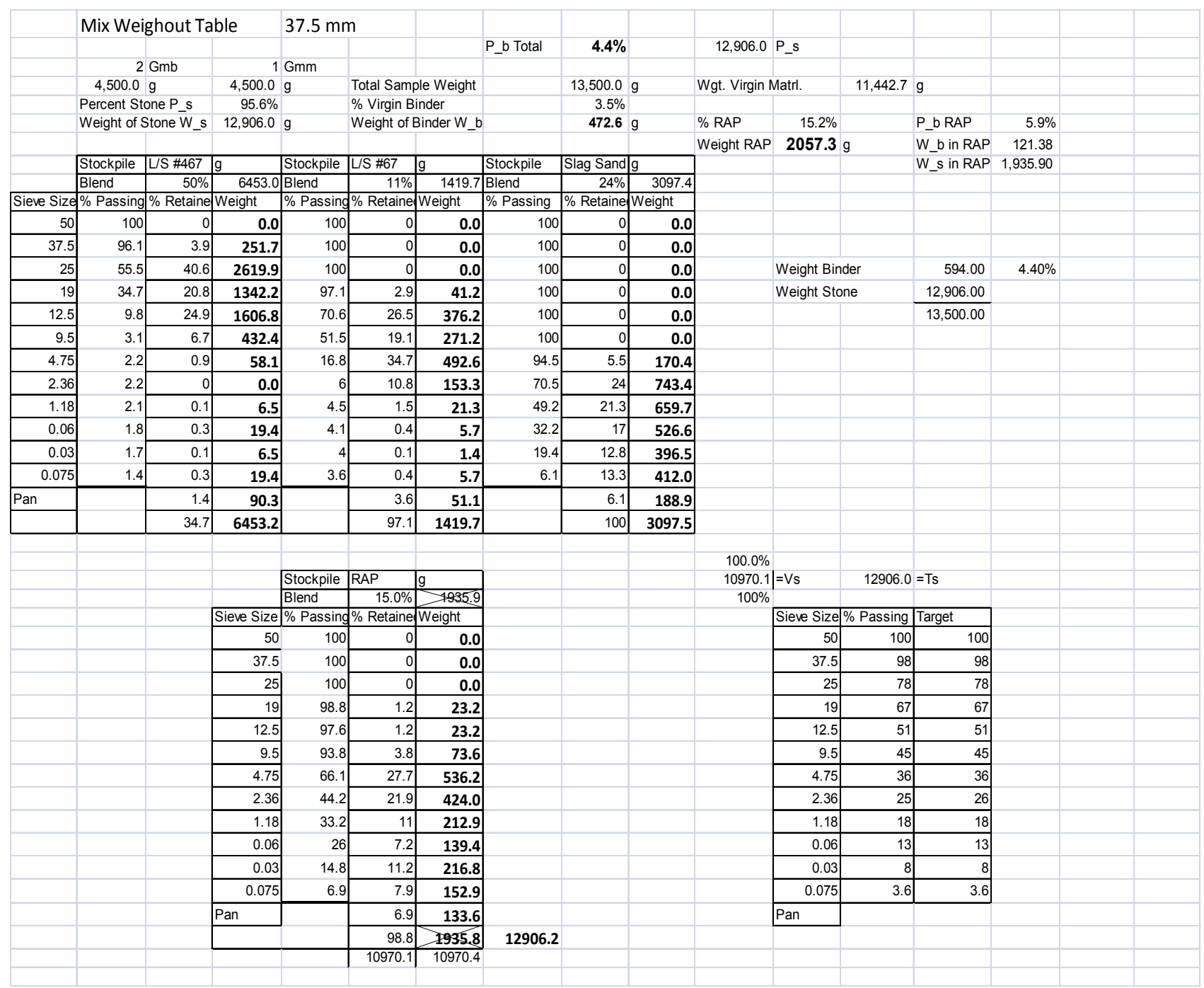


Figure B.11 IDT Test Plot

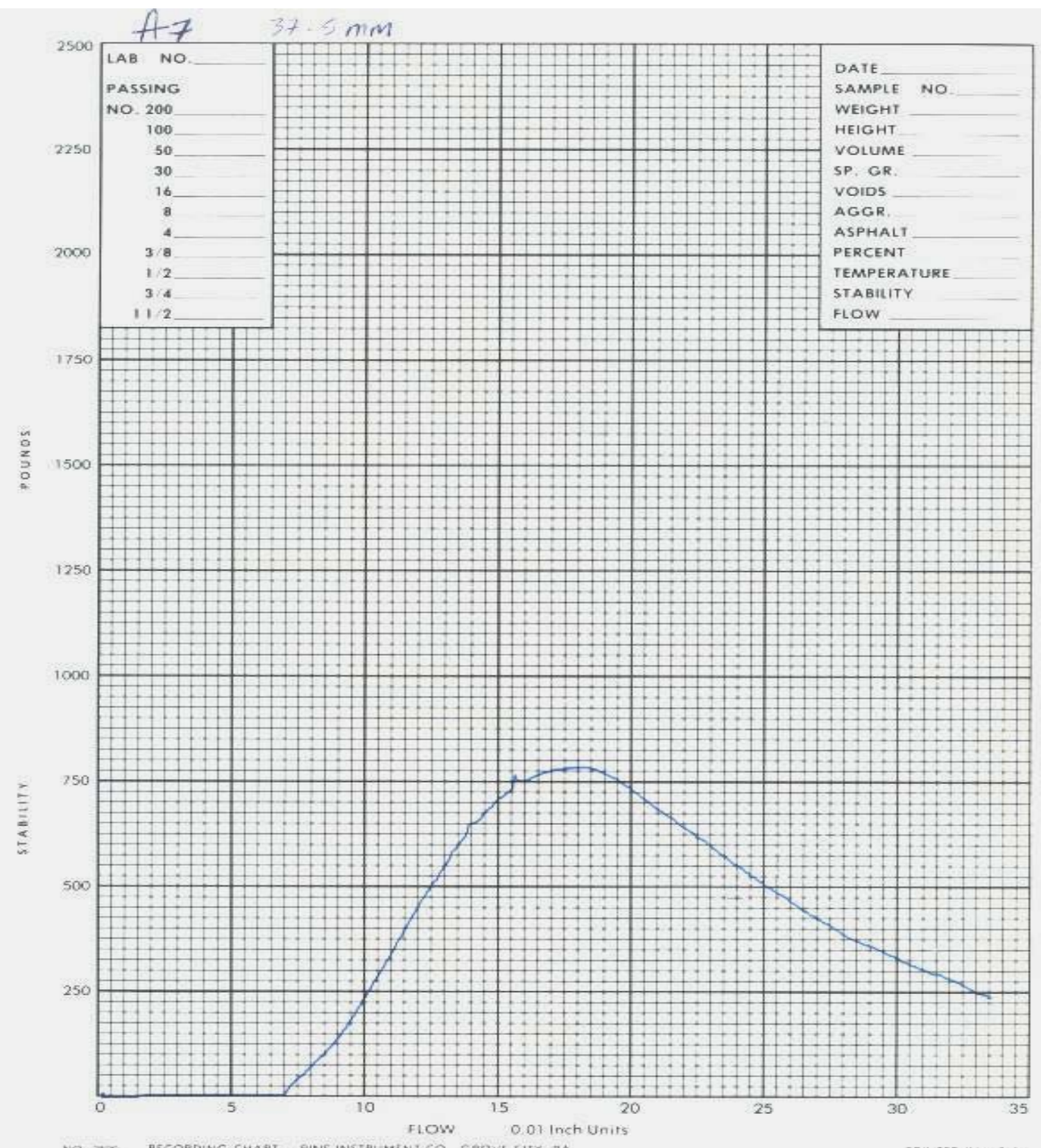

NO $\mathrm{XWO}$ RECORDING CHART PINE INSTRUNENTCO GROVE CITY PA

PRITUTF IN US: SA 
Figure B.12 IDT Strength vs Percent Binder for 19 mm Mix with Regression

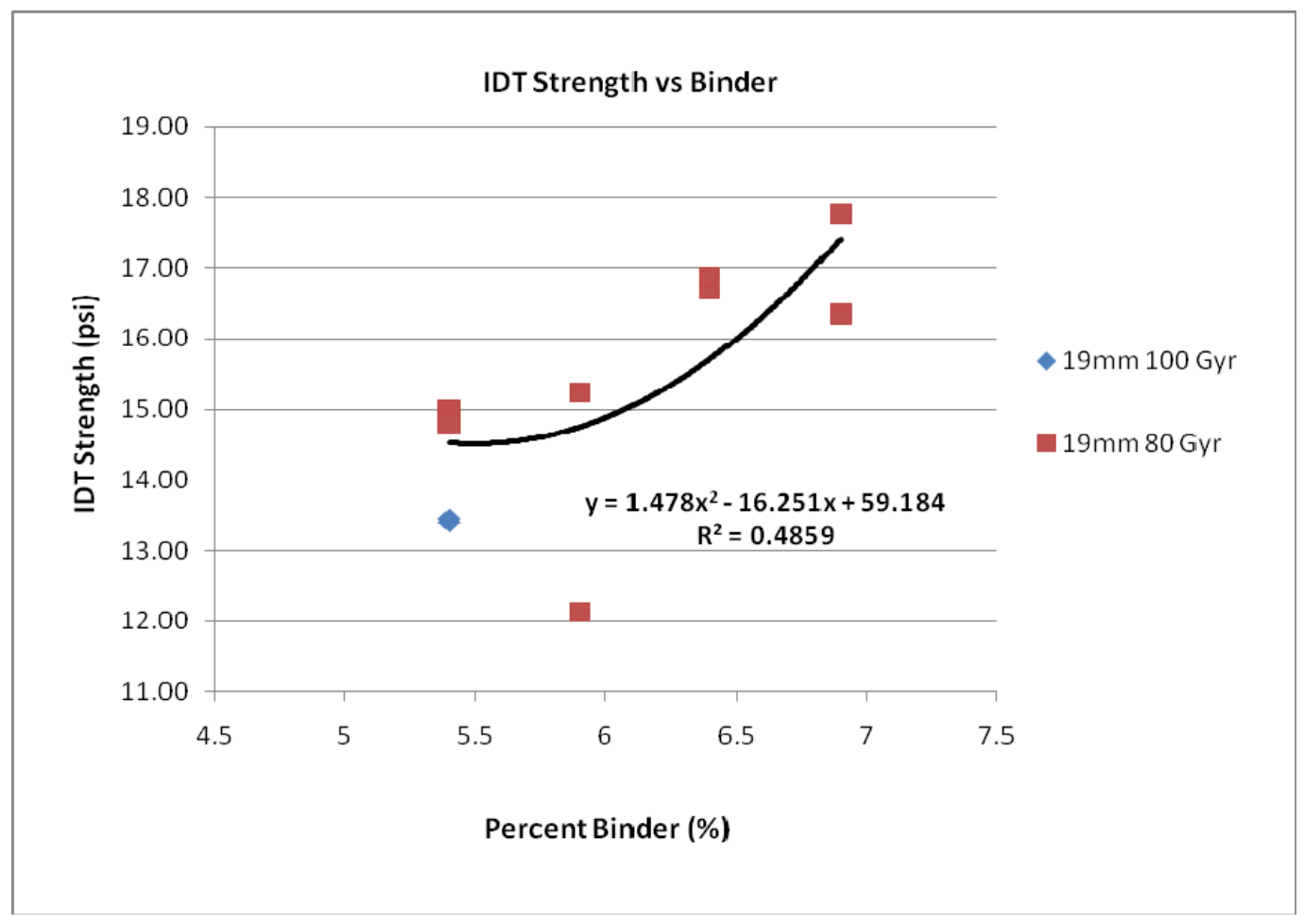

Figure B.13 IDT Strength vs Percent Binder for 37.5 mm Mix with Regression

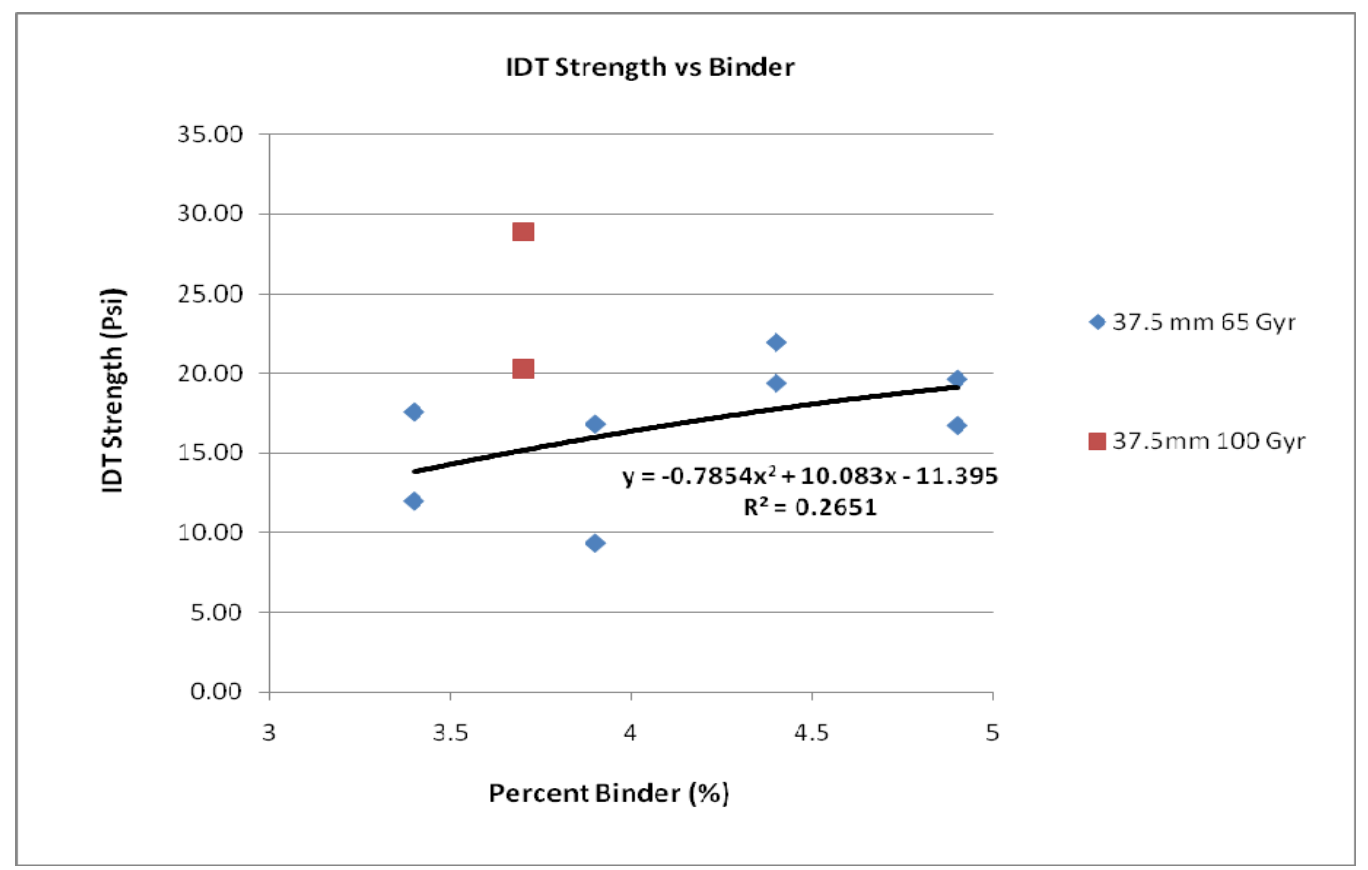


Figure B.14 APA Data Recording Sheet for Initial Readings

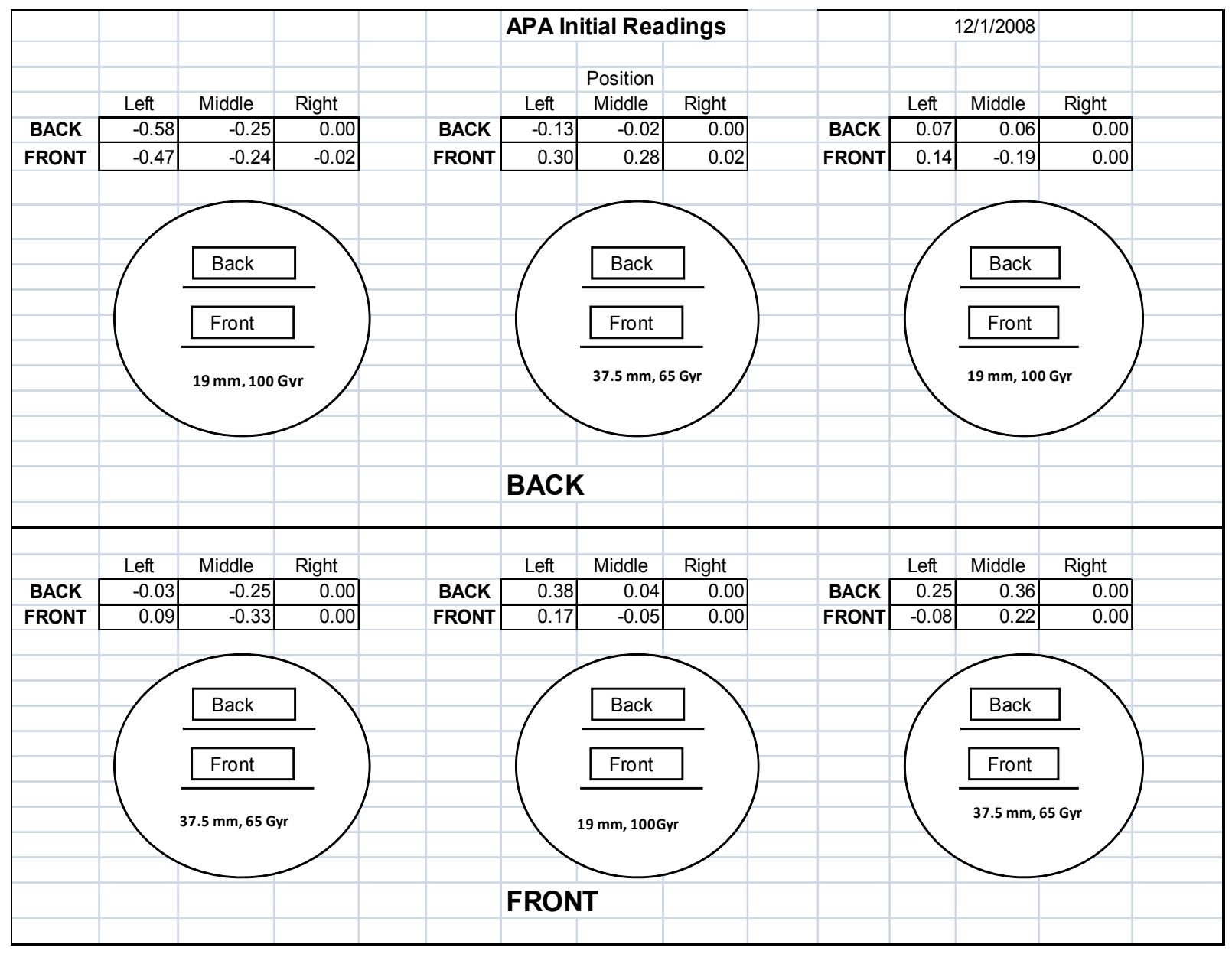


Figure B.15 APA Data Recording Sheet for Final Readings

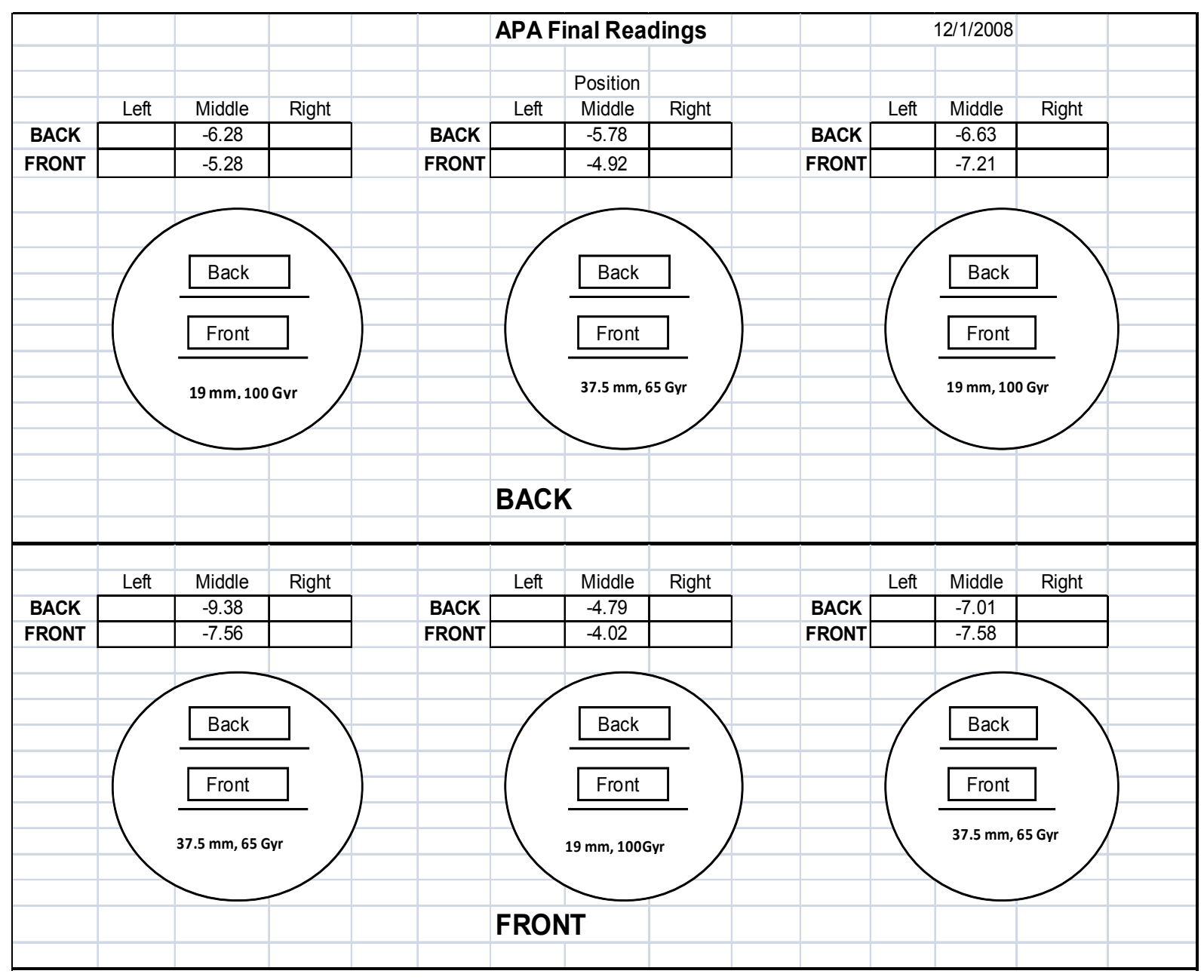

